\title{
The fathers' role in child nutrition in Ethiopia
}

Citation for published version (APA):

Bilal, S. (2015). The fathers' role in child nutrition in Ethiopia. [Doctoral Thesis, Maastricht University]. Datawyse / Universitaire Pers Maastricht. https://doi.org/10.26481/dis.20151014sb

Document status and date:

Published: 01/01/2015

DOI:

10.26481/dis.20151014sb

Document Version:

Publisher's PDF, also known as Version of record

\section{Please check the document version of this publication:}

- A submitted manuscript is the version of the article upon submission and before peer-review. There can be important differences between the submitted version and the official published version of record.

People interested in the research are advised to contact the author for the final version of the publication, or visit the DOI to the publisher's website.

- The final author version and the galley proof are versions of the publication after peer review.

- The final published version features the final layout of the paper including the volume, issue and page numbers.

Link to publication

\footnotetext{
General rights rights.

- You may freely distribute the URL identifying the publication in the public portal. please follow below link for the End User Agreement:

www.umlib.nl/taverne-license

Take down policy

If you believe that this document breaches copyright please contact us at:

repository@maastrichtuniversity.nl

providing details and we will investigate your claim.
}

Copyright and moral rights for the publications made accessible in the public portal are retained by the authors and/or other copyright owners and it is a condition of accessing publications that users recognise and abide by the legal requirements associated with these

- Users may download and print one copy of any publication from the public portal for the purpose of private study or research.

- You may not further distribute the material or use it for any profit-making activity or commercial gain

If the publication is distributed under the terms of Article $25 \mathrm{fa}$ of the Dutch Copyright Act, indicated by the "Taverne" license above, 
The fathers' role in child nutrition in Ethiopia

Selamawit Mengesha Bilal 
@Selamawit Mengesha Bilal

No part of this book may be reproduced or transmitted in any form or by any means, without prior permission in writing by the author, or when appropriate, by the publishers of the publications.

Layout: Tiny Wouters

Cover: Cover designed by Selamawit M.Bilal.

Picture: Ethiopian child playing with his father.

Production: Datawyse | Universitaire Pers Maastricht

ISBN: 9789461594822 


\section{The fathers' role in child nutrition in Ethiopia}

\section{Dissertation}

to obtain the degree of Doctor at Maastricht University, on the authority of the Rector Magnificus, Prof.dr.L.L.G. Soete in accordance with the decision of Board of Deans, and the degree of Doctor at the University of Alcala, on the authority of the Rector Magnificus,

Prof.dr. Femando Galvan, to be defended in public on Wednesday, 14 October 2015 at 14:00 hours. 


\section{Promoter}

Prof. dr. G.J. Dinant

\section{Co-promoter}

Dr. M.G. Spigt

Dr. R. Blanco: University of Alcalá, Madrid, Spain.

\section{Assessment Committee}

Prof. dr. T. Van der Weijden (Chairman)

Prof. dr.H.W. van den Bome, Maastricht University

Prof. dr. W.L.J.M. Deville, University of Amsterdam

Prof. dr. F.J.M. Feron, Maastricht University

Dr. Araya Abrha Medhaniye, Mekelle University, Ethiopia

Dr. P. de la Villa Polo, Alcala University, Spain

These studies were funded by a PhD Scholarship from the Spanish International Agency for Development Aid (AECID, Spain). Expenses associated with the preparation phase and defence of the thesis were covered by CAPHRI, School for Public Health and Primary Care of Maastricht University, Peter Debyeplein 1, 6229 HA Maastricht, the Netherlands. 


\section{Contents}

Abbreviations

Chapter 1 General introduction

Chapter 2 Practices and challenges of growth monitoring and

promotion in Ethiopia: a qualitative study

J Health Popul Nutr 2014;32:441-451

Chapter 3 The influence of father's child feeding knowledge and practices on children's dietary diversity: a study in urban and rural districts of Northern Ethiopia, 2013 Matern Child Nutr 2014 Dec; doi:10.1111/mcn.1215

Chapter 4 The view of fathers on their role in young child care and child feeding: a qualitative study among Ethiopian fathers Submitted

Chapter 5 How to improve fathers' involvement in young child feeding? A qualitative study in Ethiopia

Submitted

Chapter $6 \quad$ General discussion

Summary 89

Summary in Amharic

Summary in Tigrigna

Summary in Spanish

Valorisation

Aknowledgement

Biography 


\section{Abbreviations}

$\begin{array}{ll}\text { CBN } & \text { Community Based Nutrition } \\ \text { CI } & \text { Confidence Interval } \\ \text { EDHS } & \text { Ethiopian Demographic and Health Survey } \\ \text { ENA } & \text { Essential Nutrition Action } \\ \text { EOS } & \text { Enhanced Outreach Strategy } \\ \text { FGD } & \text { Focus Group Discussion } \\ \text { GDP } & \text { Gross Domestic Product } \\ \text { GMP } & \text { Growth Monitoring and Promotion } \\ \text { HDA } & \text { Health Development Army } \\ \text { HEP } & \text { Health Extension Program } \\ \text { HEW } & \text { Health Extension Worker } \\ \text { HSDP } & \text { Health Sector Development Plan } \\ \text { IYCF } & \text { Infant and Young Child Feeding } \\ \text { MCH } & \text { Maternal and Child Health } \\ \text { MDD } & \text { Minimum Dietary Diversity } \\ \text { MDG } & \text { Millennium Development Goal } \\ \text { MUAC } & \text { Mid-Upper Arm-Circumference } \\ \text { OR } & \text { Odds Ratio } \\ \text { TSF } & \text { Targeted Supplementary Food } \\ \text { UNICEF } & \text { United Nations Children's Fund } \\ \text { VCHW } & \text { Voluntary Community Health Worker } \\ \text { WHO } & \text { World Health Organisation }\end{array}$




\section{Chapter 1}

General introduction 
Chapter 1 


\section{Child feeding practice in a global context}

Child feeding practice is a universal topic in respect to over- and under-nutrition ${ }^{2-5}$, particularly significant in developing countries where under-nutrition is the underlying cause of more than $50 \%$ of child deaths ${ }^{1}$. Proper child feeding is crucial for optimal growth, health and development of children, especially in the age of 0-2 years. However, this period is often marked by micronutrient deficiencies that interfere with optimal growth, resulting in frequent childhood illnesses ${ }^{2,6-9}$.

Interventions have been implemented to combat child malnutrition through addressing different socioeconomic and cultural factors, and improving child feeding practices. However, gradual changes that have been observed in child nutritional status still call for attention ${ }^{1,10}$. Interventions were often implemented through mothers as the primary caregivers, while a child's full development probably depends on the complex care that they receive from both the mother and father ${ }^{10,11}$. Considering the greater amount of attention given to mothers in different child health intervention programs, it seems that the fathers' role is usually considered insignificant ${ }^{12-14}$.

The role of fathers in child health has recently begun to appear on the agenda of organisations of the developed world; in aims to solve chronic child health problems including childhood obesity ${ }^{12,15-17}$. However, in developing countries, despite fathers overruling role in incoming generation and decision making for the family, they have been largely neglected in agendas for improvements to child health. The fathers' role in the child's life also remains insignificant in the perspectives of health workers' and policy makers', and their involvement is invisible in child health policies and child health care programs $^{18,19}$.

\section{Family life in Ethiopia}

A typical Ethiopian family consists of the father, mother, children and extended family members. Families are usually large and family bands are strong. The father is the authority figure, and men and women have clear roles, defined by their gender. Rural families tend to have more gender-specific roles than urban families ${ }^{20}$.

Traditionally, looking after the children is the mothers' responsibility. Mothers feed their children, change their clothes, bathe, play and put them to sleep. They are also responsible for the domestic activities around the house such as cooking, cleaning, fetching water and shopping from the market. Fathers are responsible for raising money and ensure there is food from the garden for the family. They also maintain contact with family members outside of the home.

Mothers are usually considered to be subordinate to their husbands, and are expected to work at home while fathers work in the field or have a job elsewhere. During our studies we observed that mothers were often present in households that we visited. 
Most of them carried their baby on their back or side, while cleaning the house or cooking a meal. Fathers were often not at home, and it was usually not possible to meet them unannounced.

If both parents work outside, they depend on maids and extended family members to look after the children. It is common in the community where I reside, that families have at least one extended family member and often a maid to look after the children or to help mothers with a variety of household activities. The traditional view is that fathers neither cook nor do shopping, because housework is considered a woman's job. This is the rule in many areas of the country.

Although many people continue to follow these traditional roles in Ethiopia, it can be seen -particularly in urban areas - that women are beginning to take a major role in employment, while men are becoming more involved in child care and household life ${ }^{20}$. This transition is especially visible in young couples. Married couples at the age of 20s and 30s have less hard-and-fast rules to define their role based on gender, although they are still influenced by traditional beliefs and practices unknowingly. Therefore, the equal sharing of child care and domestic responsibilities seems something that one cannot easily find in an Ethiopian family.

\section{Improving child health and nutrition}

The government of Ethiopia has formulated and implemented a number of policies and strategies to improve the health of its citizens, and is giving priority to mothers and children $^{21}$. The most far reaching plan is the 20-year Health Sector Development Plan (HSDP), introduced in 1997. One of the innovative initiatives undertaken under this plan is the Health Extension Workers (HEW) program. HEWs are female health workers trained to improve skills and behaviours within the household and at the health post.

HEWs extend their reach through a recently established Health Development Army (HDA), which usually consists of volunteer women. HDA refers to an organised movement of the community through participatory learning and action meetings. Organising a functional HDA requires the establishment of health development teams that comprise of up to 30 households residing in the same neighbourhood. The team is further divided into smaller groups of six members, referred to as 'one-to-five networks'.

Despite major progress that has been made to improve the health status of the population in the last two decades, the population's health remains relatively poor and the major health problems in the country still include largely preventable communicable diseases and nutritional disorders ${ }^{22}$. Children remain a very vulnerable group and the high rate of child deaths confirms this fact: infant mortality rate is $59 / 1,000$ live births and under-five mortality rate is $88 / 1,000$ live births ${ }^{23}$. These deaths are usually due to pneumonia, diarrhoea, malaria, neonatal problems and malnutrition. 
Malnutrition is an underlying cause in more than $50 \%$ of child deaths ${ }^{21}$. Over the past two decades, the Ethiopian government has been working to combat this problem that has troubled Ethiopian history since the $1980 \mathrm{~s}^{24,25}$. The Millennium Development Goal (MDG) of eradicating extreme hunger and poverty was implemented in $2000^{26}$. Since then, improving child nutrition has been one of the priorities of the Ethiopian health plan; with a goal to reduce the under-five mortality rate to $68 / 1,000$ live births and the infant mortality rate to 31/1,000 live births by 2015 .

The health sector has increased its efforts to enhance good nutritional practices through health education, treatment of extremely malnourished children and provision of micronutrients to most vulnerable mothers and children. In addition, the Health Extension Program (HEP) has included nutrition as one of the health packages. Furthermore, a national nutrition strategy has been developed and implemented by the government of Ethiopia to improve the nutritional status of mothers and children through the following programs: Enhanced Outreach Strategy (EOS) with Targeted Supplementary Food (TSF) and Transitioning of EOS into HEP, Health Facility Nutrition Services, Community Based Nutrition (CBN), Growth Monitoring and Promotion (GMP) and Micronutrient Interventions and Essential Nutrition Actions (ENA)/Integrated Infant and Young Feeding (IYCF ) Counseling services have been implemented as an essential element to improve the growth of children ${ }^{27,28}$. The core indicators of IYCF include breast feeding practice (early initiation of breastfeeding, exclusive breastfeeding under 6 months, continued breastfeeding until 1 year), introduction of solid, semi-solid or soft foods, minimum dietary diversity, minimum meal frequency, minimum acceptable diet and consumption of iron-rich or iron-fortified foods.

According to the 2011 children nutrition indicators, significant progress has been made to reduce hunger and malnutrition in Ethiopia following the adoption of MDGs in 2000. For example, the number of stunted children (under the age of five) declined from $57.8 \%$ in $2000-01$ to $44.4 \%$ in $2010-11$, the number of underweight children declined from $41 \%$ to $28.7 \%$ during the same period ${ }^{29}$. However, these figures are still very high, including when compared to other developing countries.

\section{The father's role in child feeding practice in Ethiopia}

Child feeding practice in Ethiopia is very poor, and the 2011 national infant and young child feeding indicators confirmed that only $4 \%$ of breastfed children met the minimum acceptable diet, which is the consumption food from four or more groups at least 2 or 3 times (depending on age) per day ${ }^{23}$. This implies that there is significant difficulty in reaching this standard with the existing interventions that are often targeted through mothers $^{30}$.

Many factors in relation to the mothers' child feeding practices have been investigated, such as socioeconomic status, culture, family, community, beliefs, tradition and 
religion $^{11,31-33}$. To our knowledge, there is minimal scientific literature on fathers' involvement in child feeding. However their role in their family - other than income generation, farming and dealing with family contacts outside the home - is very limited. Studies to date most often address fathers' socio-economic status in relation to children's lives ${ }^{12,14,17}$, but they are superficial and insufficient evidence for understanding fathers' impact on children feeding and planning of future interventions.

\section{Purpose and outline of the thesis}

Numerous studies and interventions on child feeding have focused on mothers. However, consistently poor figures in child feeding and nutritional status in developing countries call for new directions to deliver better solutions. We expect that challenges often reported in scientific literature in relation to mothers' practice in child feeding can be directly or indirectly related to the role of fathers. Specifically, the economic and resource related challenges often mentioned by mothers as a big challenge in child feeding, may indicate that fathers' involvement is an equally important aspect in proper child feeding.

We hypothesise that involving fathers in child feeding programs will result in a relative improvement in child nutrition and development. Current knowledge of fathers' involvement in their young children's life is limited; therefore, knowing more about the extent of their involvement is essential for future intervention planning. Therefore, the purpose of this thesis was to assess fathers' knowledge, perceptions and practices in relation to child care and child feeding, and associated challenges.

We investigated fathers' roles in child feeding practice through the following research questions:

1) What are the important factors of child feeding practice?

2) What is the impact of fathers' knowledge and practices of child care on child feeding?

3) What are the challenges of fathers in child care and feeding practices?

4) How can fathers' involvement in child feeding practice be improved?

All studies were conducted in rural and urban districts of the Tigray region in Northern Ethiopia. The major objective of the study described in Chapter $\mathbf{2}$ was to identify and explore issues that considered important to child feeding in Ethiopia. Mothers and health workers participated in the study, and their experience of child growth, monitoring and promotion, benefits and barriers were assessed in a qualitative study. In Chapter 3, fathers' knowledge and practice of child feeding practice was assessed using a quantitative cross-sectional study. Additionally, children's dietary diversity assessed in 24 hour recall is presented. Fathers and mothers of children aged between 6-23 months participated in this study. 
In Chapter 4, fathers' routine child care and child feeding practices was investigated using a qualitative study. A model that could explain and level fathers' perceptions, practices and challenges regarding child feeding practices are presented in this chapter. In Chapter 5, health workers and fathers participated in a qualitative study which assessed father' experiences and challenges with child health education programs. The thesis concludes in Chapter 6 with major findings and general discussions. 


\section{References}

1. Black RE, Allen LH, Bhutta ZA, Caulfield LE, de Onis M, Ezzati M, et al. Maternal and child undernutrition: global and regional exposures and health consequences. Lancet 2008;371(9608): 243-60.

2. Shetty P. Community-based approaches to address childhood under-nutrition and obesity in developing countries. Nestle Nutr Workshop Ser Pediatric Program 2009;63:227-54.

3. Onyango AW, Borghi E, de Onis M, Casanovas MC, Garza C. Complementary feeding and attained linear growth among 6-23-month-old children. Public Health Nutr 2014; 17(9):1975-83.

4. Lowenstein LM, Perrin EM, Berry D, Vu MB, Pullen Davis L, Cai J, et al. Childhood Obesity Prevention: Fathers' Reflections with Healthcare Providers. Child Obes 2013;9(2):137-43.

5. Mallan KM, Daniels LA, Nothard M, Nicholson JM, Wilson A, Cameron CM, et al. Dads at the dinner table: A cross-sectional study of Australian fathers' child feeding perceptions and practices. Appetite 2013.

6. Morris SS, Cogill B, Uauy R. Effective international action against undernutrition: why has it proven so difficult and what can be done to accelerate progress? Lancet 2008;371:608-21.

7. Remans R, Pronyk PM, Fanzo JC, Chen J, Palm CA, Nemser B, et al. Multi-sector intervention to accelerate reductions in child stunting: an observational study from 9 sub-Saharan African countries. Am J Clin Nutr 2011;94(6):1632-42.

8. Stevens GA, Finucane MM, Paciorek CJ, Flaxman SR, White RA, Donner AJ, et al. Trends in mild, moderate, and severe stunting and underweight, and progress towards MDG 1 in 141 developing countries: a systematic analysis of population representative data. Lancet 2012;380(9844):824-34.

9. Nair MK, Radhakrishnan. Early Childhood Development in Deprived Urban Settlements. Indian Pediatr 2004;41(3):227-37.

10. Bhutta ZA, Ahmed T, Black RE, Cousens S,Dewey k, Giupliani E, et al. What works? Interventions for maternal and child under-nutrition and survival. Lancet 2008;371(9610):417-40.

11. Fikadu T, Assegid S, Dube L. Factors associated with stunting among children of age 24 to 59 months in Meskan district, Gurage Zone, South Ethiopia: a case-control study. BMC Public Health 2014;14:800.

12. Owoaje E, Onifade O, Desmennu A. Family and socioeconomic risk factors for undernutrition among children aged 6 to 23 Months in Ibadan, Nigeria. Pan Afr Med J 2014;17:161.

13. Saito K, Korzenik JR, Jekel JF, Bhattacharji S. A case-control study of maternal knowledge of malnutrition and health-care-seeking attitudes in rural South India. Yale J Biol Med 1997;70(2):149-60.

14. Tessema M, Belachew T, Ersino G. Feeding patterns and stunting during early childhood in rural communities of Sidama, South Ethiopia. Pan Afr Med J 2013;14:75.

15. Sarkadi A, Kristiansson R, Oberklaid F, Bremberg S. Fathers' involvement and children's developmental outcomes: a systematic review of longitudinal studies. Acta Paediatr 2008;97(2):153-8.

16. Swallow V, Macfadyen A, Santacroce SJ, Lambert H. Fathers' contributions to the management of their child's long-term medical condition: a narrative review of the literature. Health Expect 2012;15(2): 157-75.

17. Tamis-Lemonda CS, Shannon JD, Cabrera NJ, Lamb ME. Fathers and mothers at play with their 2- and 3year-olds: contributions to language and cognitive development. Child Dev 2004;75(6):1806-20.

18. Moore T, Kotelchuck M. Predictors of Urban Fathers' Involvement in Their Child's Health Care. Pediatrics 2004;113(3pt1):574-80.

19. Garfield CF, Isacco A. Fathers and the well-child visit. Pediatrics 2006;117(4):637-45.

20. JRank. Africa-Middle east. Countries and Thier culture [Cited 2015 Jan 1]. Available from: http://www.everyculture.com/Cr-Ga/Ethiopia.html.

21. Ministry of Health. Policies and Strategies, Addis Ababa 2014 [Cited 2014 Sep17]. Available from: http://www.moh.gov.et/web/Pages/policiesstrategies.

22. Ministry of health. fact sheet, Addis Ababa 2012 [Cited 2014 Sep17]. Available at: http://www.moh.gov.et/ factsheets.

23. Central Statistical Agency. Ethiopia Demographic and Health Survey report 2011, Addis Ababa2012.

24. Kidane A. Mortality estimates of the 1984-85. Ethiopian famine. Scand J Soc Med 1990;18(4):281-6. 
25. Henderson PL, Biellik RJ. Comparative nutrition and health services for victims of drought and hostilities in the Ogaden: Somalia and Ethiopia, 1980-1981. Int J Health Serv 1983;13(2):289-306.

26. Ministry of Health. Millenium Development Goal, Addis Ababa 2000 [Cited 2014 Sep17]. Available at: http://www.moh.gov.et/mdg

27. WHO. Global Strategy for Infant and Young Child Feeding, in Fifty-third World Health Assembly; 2000; Geneva.

28. WHO. Global Strategy for Infant and Young Child Feeding, Fifty-fourth World Health Assembly; 2001; Geneva.

29. Central statistics Agency. Trends in Nutritional Status of Children Under Age 5, Editor 2011: Addis Ababa.

30. Government of the Federal Democratic Republic of Ethiopia. National Nutrition Programme, 20131015: Addis Ababa.

31. Hagos S, Lunde T, Mariam DH, Woldehanna T, Lindtjørn B. Climate change, crop production and child under nutrition in Ethiopia; a longitudinal panel study. BMC Public Health 2014;14:884.

32. Crookston BT, Forste R, McClellan C, Georgiadis A, Heaton TB. Factors associated with cognitive achievement in late childhood and adolescence: the Young Lives cohort study of children in Ethiopia, India, Peru, and Vietnam. BMC Pediatr 2014;14.:253.

33. Aemro M, Mesele M, Birhanu Z, Atenafu A. Dietary Diversity and Meal Frequency Practices among Infant and Young Children Aged 6-23 Months in Ethiopia: A Secondary Analysis of Ethiopian Demographic and Health Survey 2011. J Nutr Metab 2013;2013:782931. 


\section{Chapter}

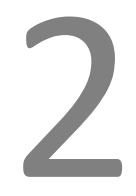

Practices and challenges of growth monitoring and promotion in Ethiopia: a qualitative study

Bilal SM, Moser A, Blanco R, Spigt M, Dinant GJ

J Health Popul Nutr 2014;32:441-51 


\begin{abstract}

\section{Introduction}

The use of growth monitoring and promotion (GMP) has become widespread. It is a potential contributor towards achieving the Millennium Development Goals of halving hunger and reducing child mortality by two-thirds in 2015. GMP appears to be a prerequisite for good child health but several studies have shown that there is a discrepancy between the purpose and the practice of GMP. The high prevalence of malnutrition in many developing countries seems to confirm this fact.
\end{abstract}

\title{
Methods
}

A descriptive qualitative study was carried out from April to September 2011. Focus group discussions and in-depth interviews were conducted among mothers and health workers. Data were analysed using a qualitative content analysis with the support of ATLAS.ti5.0 software.

\section{Results}

The results suggest that most mothers are aware of the need for regular weight monitoring. Health workers also seem to be well-aware of this need, and to practise GMP according to the international guidelines. However, there is a deficit in maternal knowledge with regard to child-feeding and a lack of basic resources to keep and/or buy healthy and nutritionally-rich food. Furthermore, the role of the husband is not always supportive of proper child-feeding.

\section{Conclusion}

In general, GMP is unlikely to succeed if mothers lack awareness of proper child-feeding practices, and if they are not supported by their husbands. 


\section{Introduction}

The overall health status of children in Ethiopia is poor ${ }^{1}$. According to the 2011 Ethiopian Demographic and Health Survey (EDHS) report, the prevalence of stunting was $44 \%$, underweight $29 \%$ and wasting $10 \%{ }^{2}$. These numbers are still one of the highest in sub-Saharan Africa and very far from ideal ${ }^{3}$. Currently, the Government of Ethiopia and a range of non-governmental organisations are working on prevention and promotion activities to fight malnutrition in children. One of these activities is growth monitoring and promotion (GMP). The World Health Organisation (WHO) defines GMP as a nutritional intervention that measures and charts the weight of children and uses this information to counsel parents so that they can take actions to improve child growth $^{4-6}$.

Since the 1990s, the use of GMP has become widespread ${ }^{7,8}$; it is one of the most clearly-visible child health activities, aimed at reducing malnutrition and has the potential to contribute towards reaching the Millennium Development Goals of halving hunger and reducing child mortality by two-thirds in $2015^{9,10}$. Ideally, in GMP, every child's weight is measured periodically, giving primary focus to children below the age of two years. The measurement starts at birth and should be performed on a monthly basis, accurately recorded on a growth chart and interpreted. Additionally, the health workers provide services, such as giving information through counselling, facilitating communication, and interacting with mothers in a way that aims to generate adequate maternal action to promote child growth. Furthermore, adequate supervision and supplies are provided for the health workers while strong links between GMP and therapeutic feeding units are established to address moderate and acute malnutrition problems $^{5,6}$. In Ethiopia, GMP is implemented through the use of growth charts, which are seen as monitoring and educational tools that help both health workers and mothers to visualise child growth and to take further action ${ }^{11}$.

Even though GMP would appear to be a prerequisite for good child health, several studies have shown that there is a discrepancy between the purpose and the practice of GMP. The high prevalence of malnutrition in many developing countries support this claim $^{3}$. A recent systematic review questioned the effectiveness and relevance of GMP programmes in general ${ }^{12}$.

A few studies have explored the issues behind this apparent lack of effectiveness. One qualitative study, conducted among an international panel of district medical officers, showed that the suboptimal function of GMP was mainly due to the lack of participation of caregivers and a poor understanding of the concept of growth monitoring ${ }^{13}$. Another institution-based prospective study conducted in Zambia mentioned poor community involvement, lack of support from health workers, poor referral systems and monitoring, and suboptimal supervision practices. Together with inadequate logistics and overruling poverty, these issues seemingly continue to challenge the effectiveness of $\mathrm{GMP}^{14}$. 
However, little research has been done to assess the real-world practice of GMP at a grassroots level - among those who actually perform GMP. It is also important that the problem is investigated in different contexts since the practice of GMP and underlying causes can differ significantly between countries, and researchers from different countries may be able to learn from the successes and failures of other countries. In that respect, Ethiopia is an interesting setting in which to study this issue. Malnutrition is widespread in Ethiopia, and there have been several reforms in the healthcare system with increased attention towards GMP, but with little success. Further research could shed light on the factors that influence successful implementation of GMP in Ethiopia.

The aim of this study was to gather insights into the real-world practice of GMP and to provide evidence-based information and recommendations for possible future successful implementations. We undertook a qualitative study with the following research questions:

1. How do mothers and health workers practise GMP?

2. What benefits and barriers do mothers and health workers experience?

\section{Methods}

\section{Study design}

We conducted a descriptive qualitative study to investigate the practice of GMP. We investigated the perspectives of mothers with children under two years of age, and of health workers, concerning perceived benefits and barriers to the use of GMP.

\section{Context}

Research was conducted in the Atsib district, located $65 \mathrm{~km}$ North of Mekelle, the capital city of the Tigray Region in Northern Ethiopia. Currently, there is one hospital, six health centres and six health posts in this district. The district is further divided into 18 kebelles, which are the smallest administrative units of the Ethiopian Government. Each kebelle covers an average of 5,000 people. The district has a population of 6,024 children under two years of age ${ }^{15}$.

GMP services are provided for children in the district by health workers with different professional backgrounds, such as health extension workers (HEWs), voluntary community health workers (VCHWs), maternal and child health $(\mathrm{MCH})$ and nutrition experts. According to the healthcare plan of the Ethiopian Federal Ministry of Health, HEWs are trained female health workers who are expected to improve skills and behaviours within the household and at the health post. One of their tasks is providing GMP through measuring weight, height, mid upper-arm circumference (MUAC) and 
educating mothers about breastfeeding, complimentary feeding, and other healthrelated issues ${ }^{11}$.

HEWs extend their reach through VCHWs who are also responsible for teaching the community about a range of health issues. Supervisors of HEWs are health workers with a background in nursing and/or midwifery. Their tasks are supervising and monitoring the work of HEWs and VCHWs by providing on-the-job training and reporting this information to the district $\mathrm{MCH}$ expert on a regular basis. $\mathrm{MCH}$ experts and $\mathrm{MCH}$ coordinators oversee different nutrition programmes at the district and regional health bureau level respectively. Mothers of children under two years of age attend GMP periodic follow-ups under the supervision of VCHWs.

\section{Participants and sampling}

The study population consisted of 24 mothers of children below two years and 14 health workers. A purposive sampling technique ${ }^{16}$ was applied. We invited mothers who participated in the GMP and were able to provide information about their experiences of the GMP. Health workers were included if they had more than one year's experience with the practice of GMP. There were no formal exclusion criteria for mothers or health workers.

We sampled the mothers on the recommendation of the local VCHWs. We sampled health workers by asking a key person - in this case the district health bureau manager, to identify eligible participants. The health bureau manger identified nurses $(n=2)$ who supervised HEWs. These nurse-supervisors were contacted to identify eligible HEWs $(n=4)$ and VCHWs $(n=4)$ for the study. Finally, $\mathrm{MCH}$ experts and the nutritional expert $(n=4)$ were approached by the district health bureau manager.

\section{Ethics}

Ethical approval was obtained from the Ethical Committee of the University of Mekelle and the regional health bureau, with registration number $\mathrm{CHS} / 465 / \mathrm{PH}-03$. Participants who were literate were given written information about the aim of the study, benefits, and confidentiality; written consent was obtained from these participants. For those participants who were non-literate, the purpose of the research and the confidentiality were explained by the interviewer/moderator; verbal consent was obtained, and the interviews were tape-recorded.

\section{Data collection}

Data collection took place from April to September 2011. A total of four focus group discussions (FGDs) and six in-depth interviews were carried out in the local language, Tigrigna. Three FGDs included the mothers of children under-two years, with eight mothers in each group. The in-depth interviews were carried out with one HEW, one 
HEW supervisor, one $\mathrm{MCH}$ coordinator, a nutrition expert, and two $\mathrm{MCH}$ experts from the Tigray regional health bureau. One FGD included the remaining eight health workers - four HEWs and four VCHWs.

The duration of each interview and FGD was between 60 and 90 minutes. All of the indepth interviews were conducted at the workplace of each health worker. The FGDs were held at locations that were accessible to participants, for example, at health posts and health centres. The interviews and FGDs were carried out by trained moderators and interviewers who were native speakers of the Tigrigna language and were able to speak and write English. For the in-depth interviews, a semi-structured open-ended interview guideline was prepared. For the FGD, a questionnaire was prepared with open-ended questions and probes (Table 2.1). The interview guidelines and questioning routes were prepared in English, and then translated into Tigrigna by two bilingual health workers.

Table 2.1 Interview and FGD guides for health workers and mothers.

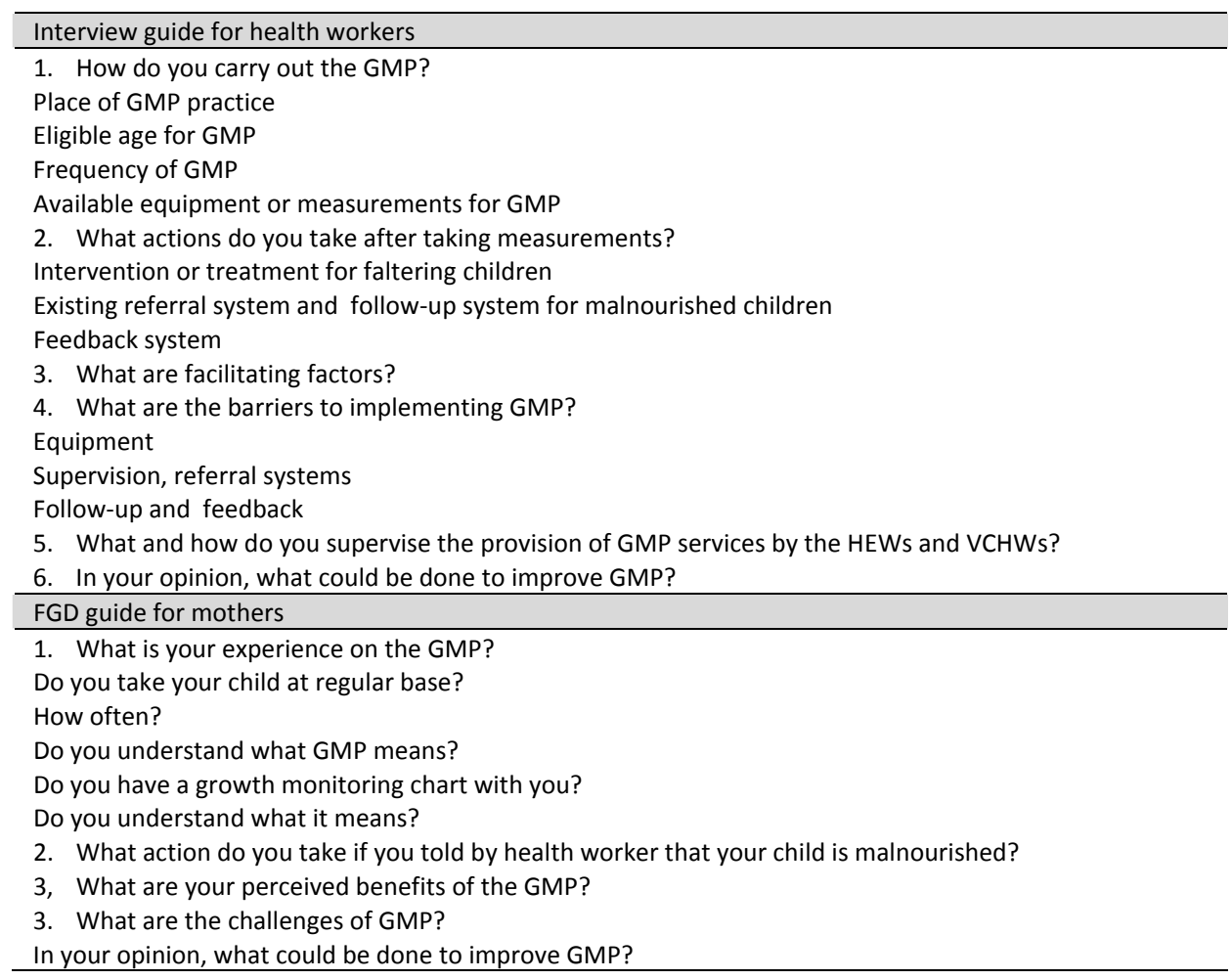

Data collection was carried out in three rounds: in the first round, two FGDs and two indepth interviews were conducted; in the second round, two FGDs and two in-depth interviews were again carried out; and lastly, two in-depth interviews were conducted. 
As data collection was performed in three iterative rounds, the questions were refined after each round, and the selection of participants was directed in order to gain more depth about the topic under study. For instance, after the first round of data collection, we made some changes to the probes to make them clearer to the participants and to avoid redundancy. Based on the summarised key findings of each session, we compared the session with the previous session to refine the guide questions as needed in order to answer the research questions in the next round.

Additionally, a few changes were made to the study participants; initially VCHWs were not part of the study but after the first round of data collection and results and knowing that VCHWs were the main providers of GMP for children, we included them in the study. We had also planned to interview physicians who were working in the hospital and treating malnourished children. However, we learned during the study that they were not involved in GMP. All in-depth interviews and FGDs were tape-recorded, and field notes were written. Data were transcribed verbatim into the local language Tigrigna and translated into English by the moderators/interviewers.

\section{Data analysis}

A qualitative content analysis approach was used and categories emerged from the data through the researchers; careful examination and constant comparison were made using inductive reasoning ${ }^{17}$. Ongoing data analysis took place throughout the study. The early introduction of the analysis phase was helpful in moving back and forth between category development and data collection and directed the subsequent data collection towards sources that were more useful for answering the research questions $^{17}$. First, the data were read in order to gain a general impression, and initial codes were developed. Then, open codes were assigned and compared and contrasted to formulate categories and subcategories, initially within and subsequently across the datasets. We continued analysing the categories in great detail until saturation of the categories occurred. Saturation occurred after the fourth focus group discussion. ATLAS.ti50 software was used for supporting the analysis ${ }^{18}$.

\section{Trustworthiness}

To meet the credibility criteria $^{16}$, we applied data triangulation, which included several mothers of children below two years of age and health workers with different personal experiences and professional backgrounds as study participants. Additionally, different data collection methods were utilised, such as in-depth interviews and FGDs, and field notes were used in the analysis. Moreover, two investigators collected and analysed the data. In order to prove the transferability of the findings to different settings and contexts, we provided detailed descriptions of the setting, sampling, sample-size, inclusion and exclusion criteria, interview procedure, and findings. 


\section{Results}

Overall, the research material displayed several discussions on GMP. The discussions dealt with mothers' perceptions of GMP and the GMP practice by both mothers and health workers. Finally, the benefits and challenges of GMP practices were also addressed in the discussions and interviews.

\section{Respondents}

Four focus group discussions and six in-depth interviews were conducted with a total of 38 participants. The 24 mothers of children below two years of age were between 18 and 40 years (mean age=27). Of the 24 mothers, $42 \%$ were illiterate (Table 2.2). All mothers except three were farmers. Three quarters (75\%) of mothers were married, and the remainder were divorced $(21 \%)$ or single $(4 \%)$. All mothers attended the discussion groups with their children, who were aged between 3 and 24 months (mean age=13 months). Of the 38 participants, 14 were health workers with a mean age of 29 years. All were female except three. The educational status of the health workers ranged from Grade 1-8 (elementary school) up to Grade 12+ (high school completed and above). The health workers had a range of professional experiences and backgrounds relating to GMP (Table 2.3).

Table 2.2 Characteristics of mothers.

\begin{tabular}{|c|c|c|c|}
\hline Variable & & Frequency & Tota \\
\hline \multirow[t]{7}{*}{ Age (completed years) } & $15-19$ & $1(4 \%)$ & 24 \\
\hline & $20-24$ & $8(33 \%)$ & \\
\hline & $25-29$ & $7(29 \%)$ & \\
\hline & $30-34$ & $3(13 \%)$ & \\
\hline & $35-39$ & $4(17 \%)$ & \\
\hline & $40-44$ & $1(4 \%)$ & \\
\hline & $45-49$ & $0(0 \%)$ & \\
\hline \multirow[t]{5}{*}{ Educational status } & Non-literate for modern education & $10(42 \%)$ & 24 \\
\hline & Can read and write & $0(0 \%)$ & \\
\hline & Grade 1-8 & $10(42 \%)$ & \\
\hline & Grade $9-12$ & $4(16 \%)$ & \\
\hline & Grade $12+$ & $0(0 \%)$ & \\
\hline \multirow[t]{2}{*}{ Occupation } & Farmer & $21(88 \%)$ & 24 \\
\hline & House wife & $3(12 \%)$ & \\
\hline \multirow[t]{5}{*}{ Marital status } & Married & $18(75 \%)$ & 24 \\
\hline & Divorced & $5(21 \%)$ & \\
\hline & Widowed & $0(0 \%)$ & \\
\hline & Single & $1(4 \%)$ & \\
\hline & Living with partner & $0(0 \%)$ & \\
\hline \multirow[t]{2}{*}{ Age of the child (months) } & $<12$ & $12(50 \%)$ & 24 \\
\hline & $12-24$ & $12(50 \%)$ & \\
\hline
\end{tabular}


Table 2.3 Characteristics of health workers.

\begin{tabular}{|c|c|c|c|}
\hline Variable & & Frequency & Total \\
\hline \multirow[t]{6}{*}{ Age (completed years) } & $15-19$ & $1(7 \%)$ & 14 \\
\hline & $20-24$ & $1(7 \%)$ & \\
\hline & $25-29$ & $6(43 \%)$ & \\
\hline & $30-34$ & $1(7 \%)$ & \\
\hline & $35-39$ & $4(29 \%)$ & \\
\hline & $40-45$ & $1(7 \%)$ & \\
\hline \multirow[t]{2}{*}{ Sex } & Male & $3(21 \%)$ & 14 \\
\hline & Female & $11(79 \%)$ & \\
\hline \multirow[t]{3}{*}{ Educational status (Schooling) } & Grade 1-8 & $3(21 \%)$ & 14 \\
\hline & Grade $9-12$ & $6(43 \%)$ & \\
\hline & Grade $12+$ & $5(36 \%)$ & \\
\hline \multirow[t]{5}{*}{ Occupation } & VCHW & $4(29 \%)$ & 14 \\
\hline & HEW & $5(36 \%)$ & \\
\hline & Supervisor & $1(7 \%)$ & \\
\hline & $\mathrm{MCH}$ expert & $3(21 \%)$ & \\
\hline & Nutrition expert & $1(7 \%)$ & \\
\hline \multirow[t]{4}{*}{ Background } & Minimum of Grade $4+6$ day training & $4(29 \%)$ & 14 \\
\hline & Grade 10 complete +1 year training & $5(36 \%)$ & \\
\hline & Nurse & $3(21 \%)$ & \\
\hline & Public health worker & $2(14 \%)$ & \\
\hline
\end{tabular}

\section{Mothers' perceptions of GMP}

GMP as a public health service for children did not spring immediately to mothers' minds unless the moderator raised the topic. All mothers were aware of immunisation services, which they also mentioned first when speaking about public health services for children (Table 2.4). However, mothers rarely mentioned GMP as a separate weightmonitoring programme for their children; they often mentioned it as a part of other child health or maternal health services or in combination. Others highlighted the discussion they had with the health workers about appropriate child-feeding, placing more emphasis on breastfeeding, such as frequency and duration of exclusive breastfeeding practices. A few also mentioned the discussion relating to complimentary feeding practices based on their child's status on the growth monitoring chart:

"Growth monitoring means we take our children to the health workers to measure the weight every month. The health workers tell us if our children gain or lose weight. If my child loses weight, the health worker recommends me to feed semi-fluid food which is not as thick as porridge or as thin as soup, but in between. She also advises me to come the next month to check my child condition. If the problem is serious, she refers the child to a health post for additional treatment and food supply, like supplementary foods. To the reverse, if my child has adequate growth, the health worker encourages me to keep that pattern." 
For some mothers, GMP was only linked to measuring mid-upper arm- circumference (MUAC) of the child and receiving information about the measurement outcome.

\section{Practice of GMP}

Both mothers and health workers talked about the monthly contact they had and their joint discussions about child-feeding practices. They also described the existing referral/follow-up system for malnourished children and the supervision system for monitoring and evaluating different activities under the GMP practice.

Most mothers and health workers mentioned that a regular GMP service was mainly provided for children below two years of age. A few health workers mentioned that regular GMP continued until the age of three years. All health workers highlighted the fact that all children below five years of age who came to the health institution, irrespective of the reason, were screened for malnutrition, using a weight board:

"Growth monitoring and promotion is provided for all children below five years of age. Currently, more emphasis is given for under-two children. The reason is: the physical and mental growth is very high in the first two years."

The frequency of GMP, as perceived by the mothers, ranged from every week to every two months. In general, regarding the frequency and age-range of GMP, both health workers and mothers spoke about what was written on the growth monitoring chart, a chart which is always kept with mothers of under-two children, and which is recorded monthly. The starting age for GMP was reported to be 6 months, although a few suggested it started at birth. Different places were mentioned for providing the GMP, for example, a health post, house-to-house visits, a central place which could be the health worker's or mother's house, or under a big tree. Most mothers and health workers said that the place for regular GMP was selected according to the preferences of mothers; it should be accessible and close to all mothers.

All mothers reported that VCHWs provided the GMP services for their children. They also explained the activities assigned to them, such as weighing the child, advising the mother, and organising a group discussion among mothers. All health workers confirmed this fact by saying that VCHWs were the immediate providers of GMP. In addition, referral and follow-ups were provided for children diagnosed as moderately and severely malnourished until the child's health returned to normal. Continuous and supportive supervision and on-the-job training were reported to be provided every week and every three months respectively by HEWs:

"VCHW provides the GMP services for mothers of under-two children, and they measure the weight of each child on a monthly basis and categorise them as being normal, underweight, and severely underweight. After taking the weight, mothers receive advice based on the child's status. Additionally, they also present anonymous results for a group discussion among the mothers, to help 
the community to reach consensus on the causes and solutions for the child's problem. When necessary, malnourished children are referred."

\section{Perceived benefits of growth monitoring and promotion}

A range of benefits to be gained from GMP were mentioned by the mothers. Some mothers explained the benefits of GMP in broad terms, such as to keep the child healthy, to introduce appropriate child-feeding practices, to reduce under-nutrition and child death, and to monitor child growth:

"I take my child because it is important. If I let my child stay in the house without growth monitoring, he may get sick and may even die. But if I take him to the growth monitoring, I will know the progress, and they will tell me whether my child is well-nourished or bad. Then, I will make corrections based on the advices I get from the health workers and my child will grow well."

Some of them described more specific benefits of GMP, especially relating to awareness of child's weight loss, and weight monitoring to avoid uncertainty:

"It helps us know the weight of the child and avoid uncertainty and wrong thinking about the child's weight. We compare our child's status with that of the child in the neighbourhoods and we may feel that our child is relatively smaller or bigger than others but, if we keep silent, we may not be sure whether our child is gaining or losing weight unless we measure the weight. So, knowing the weight status of the child helps mothers focus on their children."

A few mothers highlighted the benefit of GMP in relation to proper child growth and mental development and its long-term effects, such as future academic performance and skills:

"If we follow the growth of our children regularly, our children will have good mental development, and be happy during learning and have good skills in their jobs."

Health workers primarily mentioned that GMP reduced the prevalence of child malnutrition and gave an opportunity for creating awareness, providing counselling and continuous contact with the parents, opening the possibility that behaviour could be changed:

"Generally, growth monitoring and promotion provides a good opportunity to counsel and educate mothers about appropriate feeding practices. So, it is very important to increase public awareness and behavioural changes in the long run... we usually use it to identify the awareness problems easily. I think it is possible to change the society, using programmes, like growth monitoring. If you ask a mother or father, they don't want to see their children malnourished, 
except those having the awareness problems. So, growth monitoring is a good opportunity to convince them. I think we have a good opportunity to meet family members (the mother or father)."

\section{Challenges to GMP practice}

Various challenges were identified by both mothers and health workers, including a lack of awareness in mothers about childhood malnutrition and about the GMP programme. With regard to childhood malnutrition, there were mothers who said that there were no children affected by malnutrition in the community nowadays. Both mothers and health workers mentioned acute respiratory tract infection and diarrhoea as more serious problems than malnutrition. However, most health workers still considered malnutrition as one of the common child health problems. Additionally, many mothers considered thinness as a natural phenomenon for their children, such that they neither blamed themselves for not giving high-quality foods to their children nor did they think that they could prevent the problem. For some mothers, the possibility of getting supplementary food at the health post/centre took priority over knowing their child's status. These mothers expected to receive food or other incentives before deciding to attend GMP on a regular basis:

"The problem relating to not following growth monitoring is the absence of direct benefit. Mothers do not bother knowing their children's status but rather they usually look for FAFA (supplementary food)."

Because of this, they complained a lot about the absence of direct benefits and even refused to let health workers weigh their children. Some mothers dropped out from the GMP programme, especially after completing the immunisation schedule. However, a few mothers made a point of rebuking those who always expected incentives to attend the GMP appointment:

"Mothers have chicken, egg, wheat, and other crops in their house but they usually expect the government to provide them. It shouldn't be like that; the mother should follow growth monitoring and promotion continuously for the sake of their children's health without expecting any incentive."

There were also mothers who always missed their GMP appointments because they gave priority to household activities and social events. These mothers expected the health workers to remind them of the appointment each month. Health workers also noticed that some mothers were not happy when they put their child on the weightboard because they believed that measuring a child caused sicknesses, such as fever or diarrhoea:

"Our children got febrile and started to have diarrhoea after measurement." 
Likewise, there were mothers who even discouraged the health workers' efforts, thinking that health workers provided the GMP services for their own benefits. Neither did they appreciate the health workers' advice about their children. Mothers and health workers agreed that the majority of the mothers did not put the health workers' childfeeding advice into practice:

"The fact is that educations and discussions have not brought behavioural changes as required. They reach on consensus to do something during the discussion but they do not put it into practice."

Non-literacy was found to be another challenging issue for both mothers and health workers. Even though all mothers retained possession of the growth chart, not all could read or understand the information written on it:

"They all have the chart but whether they read and understand it, is questionable? If they are literate they read and understand it but if they are not, they give it to their children to read it."

Moreover, poverty was mentioned as a great obstacle to behavioural change in mothers in relation to feeding their children. Even though mothers might have a good understanding about types of foods that were necessary for their child's growth, they could not afford to buy those foods:

"Everybody knows that children will benefit from good care but the problem is poverty. When the health worker told me to feed my child egg, I may not be able to afford that, though I understand the importance of it. So, I may not be compliant because of poverty."

"We don't have money for other household expenses, like coffee, oil, and others.

So, we sell eggs, butter, honey, and other things to buy coffee and food-oil."

Besides poverty, health workers still believed that there was much room for awareness improvement, especially in why, what, and how to feed the child. In some cases, households were in a good economic position, and they had high-quality foods in their home; but there were reports of the custom of taking the high- quality foods to the market to earn more money. Cultural habits were also mentioned as a challenge, for example, giving the quality foods only to the fathers and waiting for a long time for a husband to have lunch; so, the child might miss a feeding time:

"Good food is served to husbands rather than to children and mothers."

In taking care of a malnourished child, due to either poor awareness or poverty, there were also mothers who shared out the supplementary foods intended for the underweight child, among their family members. There were even mothers who took the supplementary food to the market to earn money for other household expenses. Additionally, a shortage of food in the household due to seasonal change was a challenge that was mentioned repeatedly. 
Challenges in relation to the level of practical skill of the health workers were also identified. Some VCHWs were reported to have insufficient skills to take the child's weight record it on the growth chart accurately. The challenge of using the information appropriately to counsel mothers was also mentioned:

"The major challenges are the voluntary community health workers who don't have enough skills to do activities under GMP. We have seen a lot of mistakes in taking measurements and plotting on the growth chart and counselling the mothers."

The gap observed between referral, follow-up, and supervision appeared mainly to be related to a shortage of resources. For instance, a lack of well-organised checklists for supervision and of regular supervision itself (both as support and as refresher training), due to a shortage of transportation and budget, were mentioned by health workers. Furthermore, they reported the shortage of budget for equipment supply and maintenance on a regular basis, leading to a shortage of stationery materials such as pens and referral papers for the malnourished children:

"For shortage of budget for equipment supply and also for maintenance, there are equipment which are not functional. Transportation is a big challenge for supervisors to give supervision according to the plan."

Finally, the high caseloads upon health workers and the expectation of being paid for the service they provided were identified by health workers as additional challenges to the successful implementation of GMP. 
Table 2.4 Summary of results.

Mothers

Health workers

\section{Perceptions of child malnutrition}

- Perception of

child malnutrition

- Problems other than malnutrition

- Causes of

malnutrition

- Perceptions of GMP
$>$ Few malnourished children

$>$ No malnutrition problems

$>$ Acute respiratory tract infection, diarrhoea, measles, paralysis, swelling due to goitre, tetanus, vomiting, fever, skin infections, eye infections

$>$ Children's weight monitoring

$>$ Weight monitoring plus discussion on appropriate child feeding

$>$ Education about appropriate child-feeding (exclusive breastfeeding* and complimentary feeding ${ }^{+}$)

$>$ Education about breastfeeding

$>$ Mid-upper-arm circumference (MUAC $¥)$

GMP practice

- Age for GMP > Under-two, under-five

- Frequency of $>$ GMP

- Starting age

- Place

- Providers

- Activities

- Equipment

Perceived benefits

Challenges $>\quad$ Every week, every month, every two months

$>$ At 6 months, at birth

$>$ House-to-house, health post, central place

$>$ VCHW, HEW

$>$ Weighing, advising, group discussion

Keep the child healthy, appropriate feeding, reduce under-nutrition, reduce child death, to know the weight of the child, proper mental development, good academic performance, good skills during employment $>$ Wrong beliefs towards childhood malnutrition and GMP, awareness problem with regard to malnutrition, GMP, and childfeeding practice, illiteracy, poverty (shortage of money and foods)
A common child problem

Acute respiratory tract infection, diarrhoea

Awareness problem (on why, what, and how to feed child), shortage of food due to seasonal change, poverty
$>$ Under-two, under-three, under-five

$>\quad$ Every month

$>$ At 6 months, at birth

$>$ House-to-house, health post, central place

$>$ VCHW

$>$ Referring, follow-up, supervision

$>$ Weighing scale, weighing sack made of sack-cloth or plastic plate, using rope

$>$ Reducing child malnutrition, a good opportunity to have continuous contact with mothers, to educate mothers and create awareness, and behaviour change

$>$ Mothers' poor awareness, low level of skill of HEWs, lack of refresher training, shortage of transportation, shortage of budget and stationery materials (referral paper, pens), high caseload on health workers

*Exclusive breastfeeding: When the infant receives only breast milk, excluding all additional foods and drinks, even water; +Complimentary feeding: The transition from exclusive breastfeeding to family foods; ¥MUAC: In children, this is useful for assessment of nutritional status; it is the circumference of the left upper arm, measured at the mid-point between the tip of the shoulder and the tip of the elbow. 


\section{Discussion}

GMP is a public health service for children that does not come immediately to the mind of mothers unless the topic is raised, whereas immunisation is instantly mentioned. Nevertheless, most mothers are aware of the need for regular weight monitoring, and health workers also seem to be well aware of the relevance of GMP, and they appear to practise GMP according to the international guidelines. However, it would appear that mothers in Ethiopia no longer consider malnutrition to be a major problem. There also continues to be a lack of basic resources to keep and/or buy healthy and nutritionallyrich food. There is a lack of knowledge among mothers regarding what, when, and how to feed their children. A traditional family model where the role of the husband may not be supportive of proper child feeding seems to be another basic challenge. Together with the poor skills of health workers in weighing the children and counselling the mothers, these are considered direct or indirect reasons why malnutrition remains prevalent.

Mothers' awareness of GMP is low compared to their awareness of immunisation. Yet, the GMP practices mentioned by both mothers and health workers give the impression that GMP in Ethiopia is applied according to the guidelines from WHO and UNICEF ${ }^{4-6}$. It seems that both mothers and health workers in this study really value and appreciate GMP. This view challenges the conclusions mentioned in a recent critical review, in which mothers' acceptance of GMP was questioned. However, as with that review, we also found that attendance at GMP appointments is challenged once the vaccination schedule is completed ${ }^{12,13}$.

It is interesting to note that health workers complain about mothers but that the mothers in our study seem to be well aware of the need for proper GMP. Furthermore, mothers in our study mentioned reasons why other mothers did not comply with GMP. Thus, if we look only to the population in this study, we cannot say that GMP is largely problematic; neither can we say that there is a gross lack of awareness among mothers. Based on the local health policy information we received while undertaking the study, the local district figure for utilisation of GMP seems to confirm this finding. It appears that the attendance of mothers at GMP appointments in the study area is high (87\%). Considering both national and several international figures, it, therefore, seems that we selected a good area for our research. This also makes the target district an interesting area to investigate since it shows what low-income countries can do to implement proper GMP. However, according to the district health officer, there are no activities in this district that cannot be found in other districts ${ }^{15}$. Nevertheless, the health workers in this district had a good knowledge about the programme, they knew their responsibilities very well, and they were very dedicated to their jobs. The community response to the programme and to new activities was remarkable.

On the other hand, challenges in the practice of GMP still call for modesty. The challenges reported in our study are quite similar to challenges found in the study 
conducted in Zambia, such as poverty that makes it impossible for mothers to buy or keep healthy food for their children. In addition, traditional and cultural beliefs, such as the role of the husband, may not be supportive of proper child-feeding ${ }^{14}$. They reported that challenges exist not only at the level of mothers but also at the level of health workers. Similar to other studies, low levels of skill of VCHWs, for example, in taking measurements, accurately recording them on the growth charts and using that information to counsel mothers, were found to be challenges to the implementation of $\mathrm{GMP}^{13,14,19-22}$.

The limitation and strengths of this study deserve mentioning. It is possible that there might be a selection bias among mothers as we approached all mothers through the providers of GMP, and those selected had a good awareness of GMP and regularly attended the GMP appointments; this may affect the representativeness of the data. The strength of this study, however, lies in the credibility of the data obtained from a range of participants, including several health workers with different personal experiences and professional backgrounds and mothers of under-two children. Furthermore, different data-collection methods, such as in-depth interviews, FGDs, and field notes contributed to the strength of this study.

Regardless of whether or not a well-functioning GMP programme is in place, the current evidence drives us to suspect that poor child-feeding practices are due to a lack of awareness/knowledge, beliefs, way of life, and poverty. Therefore, further quantitative study is needed to assess the extent to which each factor influences childfeeding practices. Moreover, the role of the husband/father in child-feeding practice needs to be explored in greater depth, particularly in developing countries where decision-making and income-generation are mainly dominated by husbands.

In general, mothers' awareness of GMP is quite good, although incomparable with other child health services, like immunisation. Likewise, the practice of GMP seems to be conducted according to the standard guidelines. However, GMP is unlikely to succeed if mothers are unaware of proper child-feeding practices (behaviour), if they are not supported by their husbands, and if health providers do not receive adequate supervision and strong refresher training. Therefore, further research and interventions in relation to child-feeding practices, including both mothers and fathers, are necessary. Furthermore, it is vital that encouragement and support are provided for health workers in order to develop their knowledge and the skills necessary to promote healthy growth of children. 


\section{References}

1. Seid AK. Health and nutritional status of children in Ethiopia: do maternal characteristics matter? J Biosoc Sci 2013;45(2):187-204.

2. Central Statistic Agency. Ethiopian demographic and health survey report 2011, Addis Ababa 2012.

3. Black RE, Allen LH, Bhutta ZA, Caulfield LE, de Onis M, Ezzati M, et al. Maternal and child undernutrition: global and regional exposures and health consequences. Lancet 2008;371(9608):243-60.

4. Griffiths M, Rosso JD. Growth monitoring and the promotion of healthy young child growth: evidence of effectiveness and potential to prevent malnutrition. Washington, DC: Manoff Group 2007.

5. United Nations Children's Fund. Revisiting growth monitoring and its evolution to promoting growth as a strategic program approach: building consensus for future program guidance. New York, 2007.

6. United Nations Children's Fund. Experts' consultation on growth monitoring and promotion strategies: program guidance for a way forward. New York, 2008.

7. Msefula D. How can growth monitoring and special care of underweight children be improved in Zambia? Trop Doct 1993;23(3):107-12.

8. Nabarro D, Chinnock P. Growth monitoring-inappropriate promotion of an appropriate technology. Soc Sci Med 1988;26(9):941-8.

9. World Health organization. Health and Millennium Development Goals. Department of MDGs, Health and Development Policy (HDP) and the Department of Measurement and Health Information Systems (MHI), 2005.

10. Stevens GA, Finucane MM, Paciorek CJ, Flaxman SR, White RA, Donner AJ, et al. Trends in mild, moderate, and severe stunting and underweight, and progress towards MDG 1 in 141 developing countries: a systematic analysis of population representative data. Lancet 2012;380(9844):824-34.

11. Ministry of Health. National Nutrition programme, Addis Ababa, 2008.

12. Roberfroid $D$, Kolsteren $P$, Hoerée $T$, Maire $B$. Do growth monitoring and promotion programs answer the performance criteria of a screening program? A critical analysis based on a systematic review. Trop Med Int Health 2005;10(11):1121-33.

13. Roberfroid $D$, Lefèvre $P$, Hoerée $T$, Kolsteren $P$. Perceptions of growth monitoring and promotion among an international panel of district medical officers. J Health Popul Nutr 2005;23(3):207-14.

14. Charlton KE, Kawana BM, Hendricks MK. An assessment of the effectiveness of growth monitoring and promotion practices in the Lusaka district of Zambia. Nutrition 2009;25(10):1035-46.

15. Ministry of Health. (2011). Tigray regional Health bureau 2001 [Cited 18th August, 2014]. Available at: http://www.moh.gov.et/tigrayhb.

16. Lincoln YS, Guba EG. Naturalistic inquiry. California, CA: Sage Publications 1985.

17. Strauss AL, Corbin JM. Basics of qualitative research: grounded theory procedures and techniques. California, CA: Sage Publications 1990.

18. ATLAS.ti software. 5.0. ATLAS.ti Scientific Software Development GmbH, Germany 2004.

19. Iyanuoluwa O-BA, Esther A-OO, Adeleye AA. Primary health care workers' role in monitoring children's growth and development in Nigeria, West Africa. Glob J Health Sci 2011;3(1):30-9.

20. Wright CM, Sachs M, Short J, Sharp L, Cameron K, Moy RJ. Designing new UK-WHO growth charts: implications for health staff use and understanding of charts and growth monitoring. Matern Child Nutr 2012;8(3):371-9.

21. Ashworth A, Shrimpton R, Jamil K. Growth monitoring and promotion: review of evidence of impact. Matern Child Nutr 2008;4(Suppl 1):86-117.

22. Dixon RA. Cost-effectiveness of growth monitoring and promotion. Lancet 1993;342(8867):317. 


\section{Chapter}

The influence of father's child feeding knowledge and practices on children's dietary diversity: a study in urban and rural districts of Northern Ethiopia, 2013

Bilal SM, Dinant GJ, Blanco R, Crutzen R, Mulugeta A, Spigt M Matern Child Nutr 2014 Dec 17. doi: 10.1111/mcn.12157 


\begin{abstract}
Introduction

Infant and young child feeding has been recognised as an essential element to improve growth of children, especially in developing countries where malnutrition among children and its dire consequences are very prevalent. However, little attention has been paid on the influence of fathers on child feeding practices despite their importance in raising well-adjusted, happy and successful children. Therefore, this study aimed to assess the influence of fathers' child feeding knowledge and practice on children's dietary diversity.
\end{abstract}

\title{
Methods
}

A community based comparative cross sectional study was conducted among 850 eligible urban and rural households with children of 6 to 23 months. The father and mother of the child were interviewed on children's dietary diversity and fathers' knowledge and practice of child feeding.

\section{Results}

Nearly half (46\%) of the children in the rural district did not meet the minimum dietary diversity, and in the urban district the rate was even worse (72\%). Grains were the common food group given to the children in both districts, whereas flesh food was the least commonly consumed food group. Additionally, low vitamin A-rich food and other fruit and vegetable consumption seem a problem in both districts. Almost all dimensions of fathers' knowledge and practice were significantly related to children's minimum dietary diversity; fathers' knowledge of food groups was an important predictor ( $p$-value $<0.001$ ) in both districts.

\section{Conclusion}

Interventions that focus on the fathers' knowledge of child feeding, especially about food groups, are recommended to improve children's dietary diversity in the study communities. 


\section{Introduction}

Numerous efforts have been made to alleviate child malnutrition in developing countries where poor socio-economic status, food insecurity and poor child feeding practices are still common ${ }^{1-7}$. Since the early 2000s, infant and young child feeding (IYCF) has been issued as an essential element to improve growth of children ${ }^{8-12}$. Implementation of the guiding principles of IYCF is essential in developing countries where the consequences of children's malnutrition, such as stunting, underweight and wasting, are highly prevalent ${ }^{5,13-19}$. One of the core indicators of IYCF is dietary diversity, which is a proxy for adequate micronutrient density of foods and liquids other than breast milk. According to a recent study conducted in 21 developing and developed countries, less than half of the countries met the minimum dietary diversity (MDD) ${ }^{20}$. Similarly, the 2011 Ethiopian Demographic and Health Survey (EDHS) showed that only $5 \%$ of children were fed according to minimum standards with respect to dietary diversity $^{18}$. A recent Oxfam report showed that Ethiopia's diet is one of the least nutritious diets in the world ${ }^{21}$. Another study in developing countries confirmed this fact $^{22}$.

Most of the studies and interventions on the parents' role in IYCF have focused on mothers, not fathers ${ }^{23}$. Despite the fact that fathers are primary caregivers, like mothers, and are very important in raising well-adjusted, happy and successful children, most of the studies are superficial and only showed the positive impact of fathers' educational and economic status on child health and nutrition status ${ }^{16,24-26}$. Even in the developed world, where childhood obesity is evident, only a few studies engage fathers in areas of child care and health ${ }^{27,28}$.

Along with the fathers' socio-economic status, their knowledge on child feeding and related practices needs to be assessed to develop more successful interventions in the future. This is especially relevant in developing countries where household income generation and decision-making are mainly controlled by fathers. Therefore, we assessed the knowledge and practices of child care and feeding among Ethiopian fathers from both urban and rural districts, and investigated the association with children's dietary diversity. We chose to select both urban and rural districts in our study, because we expected that there might be important differences between these settings.

\section{Materials and methods}

\section{Setting and subjects}

We conducted the study in two different districts: one rural district, Atsibi, and one urban district, Adigrat, located in Tigray Region in Northern Ethiopia. More than three 
quarters of the population in Tigray region are farmers. However, centuries of erosion, deforestation and overgrazing have left the region with dry and treeless plains, hills and plateau. The communities are served by health centers that provide primary health care to children through health extension workers and volunteer health development army. The primary health care activities include immunisation, growth monitoring (measuring weights and height on a regular basis), and educating mothers about breastfeeding and complementary feeding based on WHO's recommendations and few curative services ${ }^{29,30}$. Considering that the child's first two years of life are a 'critical window of opportunity' for prevention of growth faltering ${ }^{15}$. The participants were fathers of children in the age of 6 to 23 months. In order to assess children's dietary diversity in 24 hour recall, mothers also participated in this study. There were more than 5,000 children of 6 to 23 months in each of the two districts ${ }^{31}$.

\section{Study design and sampling}

A community based comparative cross sectional study was conducted. To calculate the required sample size we used the two population proportion formula for comparative studies $^{32}$. We wanted to be able to detect at least a difference of $10 \%$ in a positive outcome (good dietary diversity), between fathers with good and poor knowledge/practice, with $\alpha=0.05$ and $1-\beta=0.8$, in urban and rural districts. We figured that dietary diversity had improved in Ethiopia since the last measurements, so we estimated the prevalence of good dietary diversity in the poor knowledge/practice group to be close to $10 \%$. To be able to detect a difference of $10 \%$ (minimum $20 \%$ good dietary diversity), we calculated that we would need 380 subjects per group. Since we wanted to investigate the urban and rural population separately, and taking into account possible non-response, we aimed to include 425 households per district, hence a total of 850 households. Then, a systematic random sampling technique was applied to select eligible households of mothers and fathers of children 6 to 23 months old, 425 households in each (rural and urban) category, out of the list of children within this age range prepared by the local health workers in these districts.

\section{Data collection and quality control}

Data collectors, who had completed at least $10^{\text {th }}$ grade education, were trained using the local language, Tigrigna, before the data collection and intense training was given on the questionnaire and ethical issues. Regarding the questionnaire, each question in the questionnaire was explained to the data collectors and unclear items were discussed. They were also explained on ethics, confidentiality, anonymity and obtaining the signed consent papers from participants before the interview. There was continuous supervision throughout the data collection.

The interview questionnaire was developed based on a qualitative study we conducted in 2011, which was about the practice and challenges on one of the nutrition programs, 
growth monitoring and promotion, for infant and young children in Ethiopia and the WHO report on indicators for assessing IYCF practices ${ }^{29}$. A pretest was conducted before the actual data collection, in a similar setting as the study communities. During pretesting, the questions to fathers were adjusted to open-ended questions based on findings that fathers almost exclusively answered positively to yes/no questions about what they knew. After the data was collected, it was analysed for the completeness, accuracy and clarity by the principal investigators and supervisors.

The interview questionnaire comprised two parts. The first part focused on the sociodemographic characteristics of mothers and children's dietary diversity ${ }^{29}$ based on 24 hour recall, and mothers were interviewed about it. The second part focused on the socio-demographic characteristics of fathers and their knowledge and practice of child care and child feeding. A general description of all independent variables measured can be found in Table 3.1. To avoid socially desirable answers, possible answers were not mentioned to the fathers, but instead fathers had to mention the items independently. Minimum dietary diversity was assessed as the proportion of children 6-23 months of age who receive food from 4 or more out of the 7 food groups: grains, roots and tubers, legumes and nuts, dairy products (milk, yogurt, cheese), flesh foods (meat, fish, poultry and liver/organ meats), eggs, vitamin-A rich fruits and vegetables, and other fruits and vegetables ${ }^{29}$.

Table 3.1 Description and median (measurement scale) for each independent variable.

\begin{tabular}{|c|c|}
\hline $\begin{array}{l}\text { Variable (number of } \\
\text { options) }\end{array}$ & Description of answer options (median) \\
\hline $\begin{array}{l}\text { Fathers' knowledge of } \\
\text { the consequences of } \\
\text { malnutrition (number of } \\
\text { options }=11 \text {, median=1). }\end{array}$ & $\begin{array}{l}\text { Refers to weight loss, increased susceptibility to infectious diseases(illness), } \\
\text { delayed development (stunting or low height for age), reduced intellectual } \\
\text { development and learning, attention deficit disorder, impaired school } \\
\text { performance, memory deficiency, learning disabilities, reduced social skills, } \\
\text { reduced language development, reduced problem-solving abilities. }\end{array}$ \\
\hline $\begin{array}{l}\text { Fathers' knowledge of } \\
\text { important things to keep } \\
\text { the child healthy } \\
\text { (number of options }=11 \text {, } \\
\text { median=2). }\end{array}$ & $\begin{array}{l}\text { Refers to breast feeding soon after birth, exclusive breastfeeding up to six months } \\
\text { of age, beginning supplementary food at six months, timely and full } \\
\text { immunisations, going to a doctor if the child gets sick, supplementary vitamins, } \\
\text { clean house, clean water, clean food, adequate food, balanced diet, washing } \\
\text { hands with soap before eating, more money to buy food, and keeping the child } \\
\text { clean. }\end{array}$ \\
\hline $\begin{array}{l}\text { Fathers' knowledge of } \\
\text { food groups (number of } \\
\text { options }=7 \text {, median=4). }\end{array}$ & $\begin{array}{l}\text { Refers to grains (barley, wheat, corn), roots and tubers (potato, sweet potato), } \\
\text { legumes and nuts (lentils, peas, beans), dairy products (milk, yoghurt, cheese), } \\
\text { flesh foods (meat, fish, poultry and organ meats like: liver, kidney, heart), eggs, } \\
\text { vitamin-A rich fruits (ripe mango, ripe papaya, pumpkins) and vegetables (which } \\
\text { comes from green leafy vegetables like carrot, tomato,) and other fruits and } \\
\text { vegetables. }\end{array}$ \\
\hline
\end{tabular}


Table 3.1 (continued)

\begin{tabular}{|c|c|}
\hline $\begin{array}{l}\text { Variable (number of } \\
\text { options) }\end{array}$ & Description of answer options (median) \\
\hline $\begin{array}{l}\text { Fathers' knowledge of } \\
\text { child care (number of } \\
\text { options }=8 \text {, median }=2 \text { ). }\end{array}$ & $\begin{array}{l}\text { Refers to appropriate child feeding (breast feeding, complimentary feeding), } \\
\text { keeping the child clean (keeping the child's hygiene), spending time with the child } \\
\text { (playing with the child, looking after the child when the mother is not around), } \\
\text { helping mothers in child care (changing cloths, bathing the child, putting the child } \\
\text { to sleep), taking the child to health facilities (for vaccination, growth monitoring, } \\
\text { in case of illness), giving money to the mother to purchase necessary things for } \\
\text { the child (food, clothes, any materials), buying/bringing necessary things (meat, } \\
\text { fruits, clothing) for the child from the market/town and discussing the child's } \\
\text { health related issues with the mother. }\end{array}$ \\
\hline
\end{tabular}

Fathers' practice in Refers to if they changed their children's clothes on the previous day; if they routine childcare activities (number of options $=7$, median=4). bathed their children on the previous day; if they put their children to sleep on the previous day; if they played with their children at home on the previous day; if they took out their children on the previous day; if they took part in monitoring (watching) while their children played, moved, sat, stood, slept...etc. on the previous day; and if they took part in teaching their children how to behave and disciplining them on the previous day.

Fathers' practice in child Refers to if the fathers quieten their children when crying or calmed them after provision (number of the children fell or had pain; if they discussed their children's feeding with the options $=7$, median=5). mothers; if they discussed their children's health, hygiene, growth, and appetite with the mothers; if they looked after their children when the mothers were not around (working in the kitchen, going out), all within a week time; if they took their children to health facilities for vaccination, growth monitoring and other related services in the previous month; if they gave money to the mothers to purchase the necessary food for the children during the last week; and finally, if they checked, asked, were concerned about and attentive about their children's growth during the last month.

Fathers' participation in Refers to if fathers bought necessary food items for their children like eggs, meat, child feeding (number of milk, fruits, and vegetables during the last weekday from market/town; if they options=7, median=5). checked upon, asked or attended to the amount of food their children took on the previous day; whether they checked upon/asked about or attended to their children's frequency of meal on the last day; whether they tried to encourage their children to take food while the mothers were feeding them during the last day; if they checked, asked about or attended to the diversity of the food their children took during the last day; and if they checked, asked about or attentively observed their children's appetite on the last day.

\section{Ethics}

Before the study began, ethical clearance was obtained from the Ethical Committee of Mekelle University and approval letter from the Regional Health Bureau. Then, the Atsibi and Adigrat district health offices were informed through formal letters. After informing the participants about the aim of the project, written information about the benefits and confidentiality of the research was given to those who were able to read and write and verbal information was given otherwise. Then, written informed consent and verbal informed were obtained. 


\section{Data analysis}

The collected data were entered and analyzed using SPSS version $19^{33}$. The data was cleaned by the principal investigator and after cleaning the data, frequencies were generated and associations were tested. For the knowledge and practice questions in the questionnaire, we did not set an absolute minimum to distinguish between good and poor knowledge. Instead we used a relative cut-off-point by calculating the median for each variable for all participants and then applied it to the urban and rural districts. All our independent variables consisted of several sub-questions, so we had to decide how to use the independent variables in our regression models; continuous, or in two or more categories. We chose to make them dichotomous, firstly because the outcomes would be easier to interpret; odds ratios (ORs) for good knowledge/practice against poor knowledge/practice, instead of ORs for one more item answered correctly for that independent variable. In addition, the fact that the answers were highly skewed also made the median the best option in our view. In Table 3.1, we give a short description and the median for each the knowledge and practice variables in the questionnaire.

A chi-square followed by binary logistic regression was used to investigate which factors predicted dietary diversity. In addition, we entered all variables into a multivariate logistical regression model, using forward stepwise methods at a $95 \%$ confidence interval $(\mathrm{Cl})$ to determine the predictors of the minimum dietary diversity. P-values less than 0.05 were considered statistically significant and the result was presented with ORs and $95 \%$ Cls.

\section{Results}

\section{Descriptive characteristics}

Demographic characteristics of fathers, mothers and children are presented in Table 3.2. A total of 850 households with at least one child between 6 to 23 months participated in the study: 425 households from the rural district and 425 from the urban district. The response rate was $100 \%$ but $10(1 \%)$ questionnaires were excluded from the analysis because of major errors or incompleteness. 
Table 3.2 Descriptive characteristics of the children and their fathers and mothers.

\begin{tabular}{llcc}
\hline Variables & & Urban $(\mathrm{n}=420)$ & Rural( $\mathrm{n}=420)$ \\
\hline Age of the last child [Mean SD)] & Months & $14(5)$ & $14(5)$ \\
Age of the last child & $6-8$ months & $48(12 \%)$ & $60(14 \%)$ \\
& $9-23$ months & $371(88 \%)$ & $359(86 \%)$ \\
Sex of the last child & Male & $200(48 \%)$ & $231(55 \%)$ \\
Number of children in each & Female & $216(52 \%)$ & $188(45 \%)$ \\
household & $\geq 4$ & $321(77 \%)$ & $168(40 \%)$ \\
Mothers' education level & No education & $99(23 \%)$ & $252(60 \%)$ \\
& Primary(Grade 1-8) & $60(15 \%)$ & $310(75 \%)$ \\
& Secondary (Grade 9-12) & $165(40 \%)$ & $91(22 \%)$ \\
Fathers' education level & $>$ Secondary(12+) & $163(39 \%)$ & $10(2 \%)$ \\
& No education & $25(6 \%)$ & $2(0.4 \%)$ \\
& Primary(Grade 1-8) & $19(5 \%)$ & $215(51 \%)$ \\
& Secondary (Grade 9-12) & $135(32 \%)$ & $146(35 \%)$ \\
Mothers' occupation & $>$ Secondary(12+) & $198(47 \%)$ & $25(6 \%)$ \\
& House wife & $64(15 \%)$ & $2(0.4 \%)$ \\
Fathers' occupation & Farmer & $342(82 \%)$ & $10(2 \%)$ \\
& Merchant & $0(0 \%)$ & $407(97 \%)$ \\
& Governmental & $38(9 \%)$ & $1(0.2 \%)$
\end{tabular}

\section{Dietary diversity}

One quarter of the urban children (28\%) were fed on four or more of the seven food groups the day before the interview. In the rural district, more than half of the children (54\%) met the MDD. Figure 3.1 shows the common food groups fed to the children the day before the survey, and out of the seven food groups, grains (urban-91\%, rural-99\%), legumes and nuts (urban-62\%, rural-94\%) were the common food groups fed to children in both districts. Flesh foods (urban-3\%, rural-5\%) were the least common food groups fed to the children in both urban and rural districts. Additionally, vitamin-A rich and fruits and vegetables were uncommonly eaten food groups in both districts.

All fathers' knowledge predictors seem to be related to dietary diversity in both, urban and rural districts, except for knowledge of the consequences of malnutrition (Table 3.3). Fathers' knowledge of the important things to keep the child healthy was significantly associated with dietary diversity with OR of $3.43(95 \% \mathrm{Cl}: 2.19-5.37)$ and 2.58 (95\%Cl: 1.59-4.19). For fathers who had a good knowledge of food groups, the dietary diversity of their children was much higher, with an OR of $5.28(95 \% \mathrm{Cl}$ : $3.32-$ 8.38) and 8.38 (95\% Cl: 5.32-13.2). Fathers' knowledge of child care activities was significantly associated with minimum dietary diversity with OR of 4.62 (95\% Cl: 2.86 $7.48)$ and $2.88(95 \% \mathrm{Cl}: 1.94-4.29)$ in the urban and rural district respectively. 


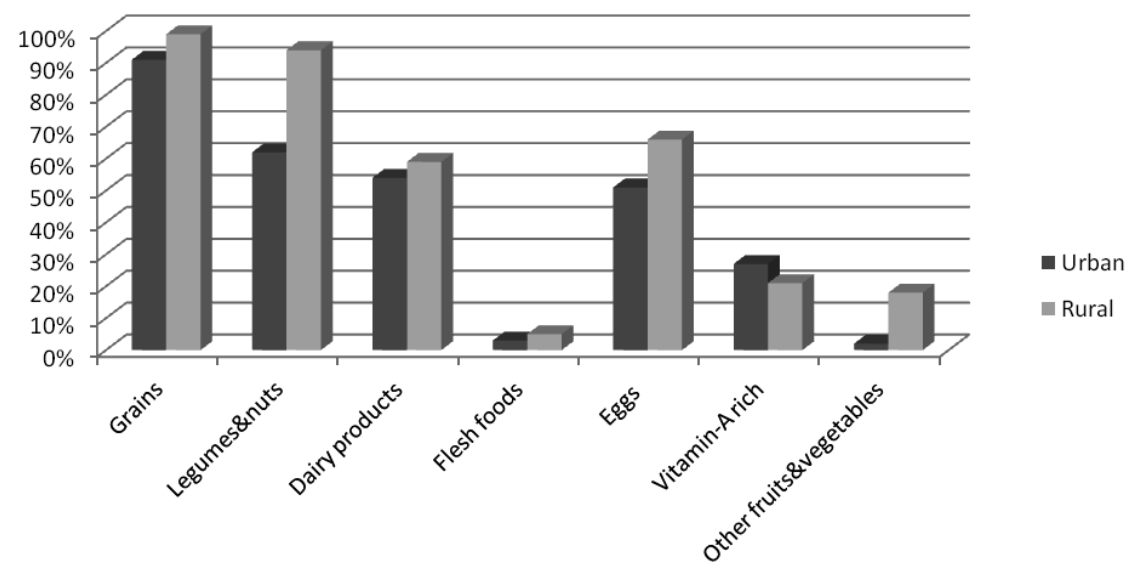

Figure 3.1 Percentage of each food group that are consumed by urban children vs. rural children.

Regarding practice, children whose fathers had a good practice of routine child care activities, better dietary diversity was reported with OR of 2.32 (95\% $\mathrm{Cl}: 1.49-3.61)$ and 1.73 (95\% Cl:1.08-2.77) in the urban and rural district respectively (Table 3.3). Again, for both, the urban and rural districts, a significant association was found between provision of necessary things and dietary diversity with OR of $3.43(95 \% \mathrm{Cl}: 2.15-5.46)$ and $1.73(95 \% \mathrm{Cl}: 1.08-2.77)$ respectively. With fathers who had a meaningful participation in child feeding activities, a significant association was found with dietary diversity in the urban district with an OR of $3.42(95 \% \mathrm{Cl}: 2.12-5.52)$, but not for the rural district. Lastly, the stepwise logistic regression showed that, in both urban and rural districts, fathers' knowledge of food groups became the most important determinant of children's minimum dietary diversity with ORs of $6.50 \quad(95 \% \mathrm{Cl}$ : $3.89-10.9)$ and 8.65 (95\% Cl: 3.10-18.9) respectively. 


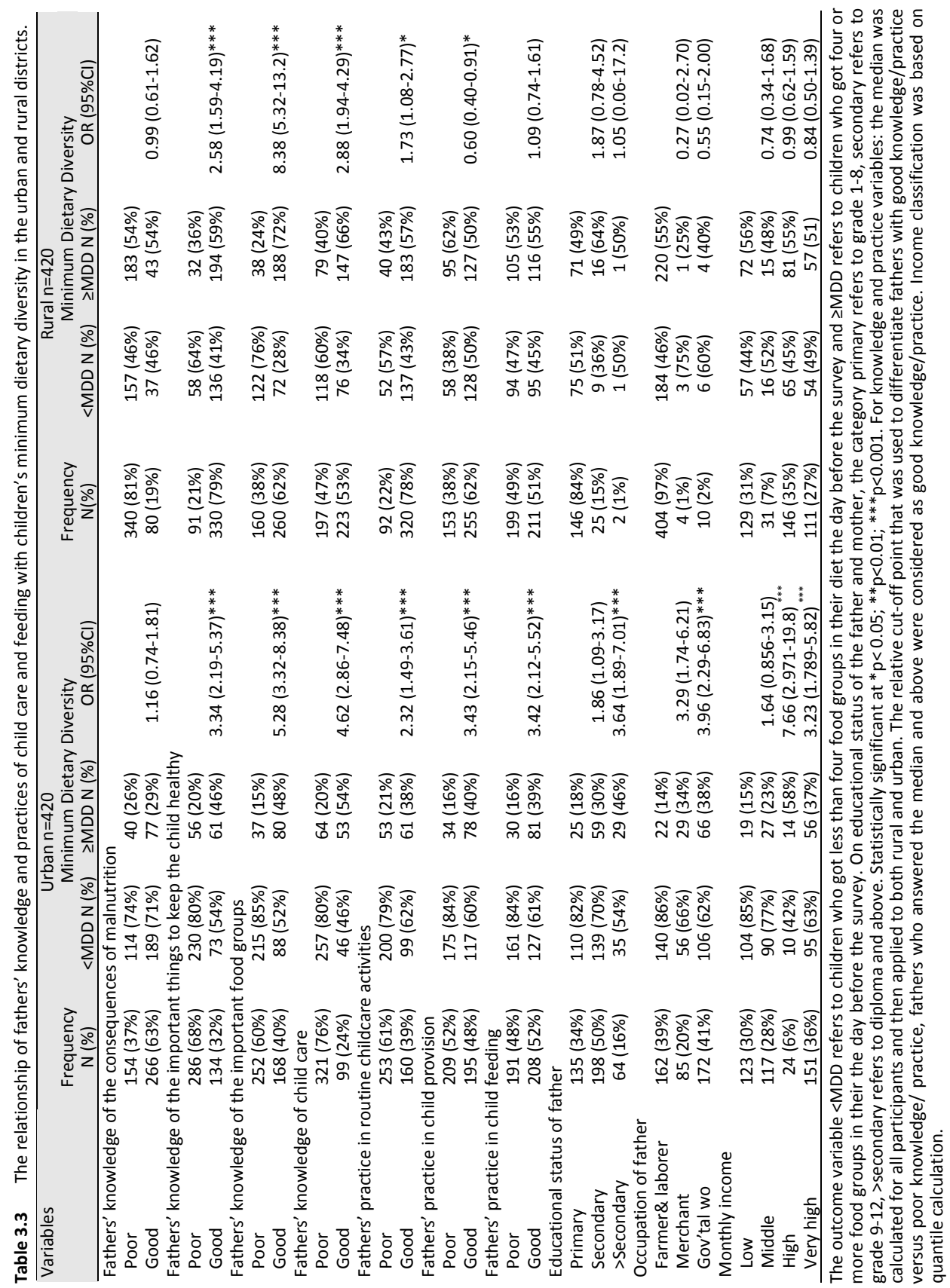




\section{Discussion}

Our study showed that dietary diversity was a serious problem in the urban district when compared to the rural district and that grains were the most common food groups fed to the children in both districts. Legumes and nuts were also commonly reported food groups. The majority of children were not given flesh foods. Additionally, vitamin A-rich food and other fruits and vegetables were also less commonly consumed food groups in both districts. Almost all dimensions of fathers' knowledge and practice that we measured and also the socioeconomic characteristics were significantly related to children's MDD, indicating the strong influence of the father on child nutrition. Fathers' knowledge of food groups was the main and independent predictor of child food diversity in both districts.

In this study, almost half of the children in the rural district did not meet the MDD of four food groups per day, and in the urban district the rate was even worse. We expected better report in the urban district but the result showed that children's dietary diversity in the rural district is much better. One possible reason could be that special attention has been given to the rural people, considering that the rural people have poor access to health care. Therefore, for the past decade health educations have been provided house to house by the community health workers for the people in the rural area, but not for the urban people. In general, our finding is consistent with other observational studies that calculated the percentage of children that had MDD in other developing countries such as India $(24.4 \%)^{34}$, Nepal $(30.4 \%)^{35}$ and Bangladesh $(42 \%)^{36}$. Although this illustrates that dietary diversity is a big concern in Ethiopia and other developing countries, it is a big improvement considering the result of a study conducted in 2010 in Ethiopia where only 5\% of the children met the MDD $^{18}$. It seems a lot of work is still needed to improve children's dietary diversity. Our study showed that improving fathers' knowledge and practice could be a prerequisite to meet children's dietary diversity. However, more studies are needed to investigate the influence of the fathers' role in children nutrition.

Possible reasons for the very low consumption of flesh foods among children could be affordability, and a tradition of having flesh only for special occasions. Further research is needed to determine the reasons behind this consumption deficit. Although assessing vitamin $A$ and fruit and vegetable intake is complicated, compared to previous studies conducted in Ethiopia and other African countries ${ }^{37,38}$, a big improvement has been reported. However, it is still below the recommendation line and it seems a common problem in both developing and developed countries ${ }^{39,40}$. According to a recent review, the problem of low fruit and vegetable consumption seems multi factorial, but includes at least product accessibility, availability, and distribution and consumers' behaviour ${ }^{41}$.

Our study confirmed the hypothesis that the fathers' knowledge and practice about food diversity is significantly associated with meeting the MDD. Although we could not 
find studies using the same concepts of father's knowledge and practice, our findings are in line with other observational studies: fathers who were involved in breast feeding, such as attending breast feeding sessions with mothers, involvement in decision making and helping the mother in the household, showed much better breast feeding practice than families with fathers who were less involved ${ }^{42-45}$. Similarly, better cognitive and language competence and nutrition status were reported among young children whose fathers were involved in child playing and child care activities ${ }^{46}$.

These findings from observational studies are also supported by intervention studies. A recent systematic literature review showed that involving fathers actively in the child's life, such as father's participation child care, enhanced a positive father-child interaction which also had a positive effect on child development ${ }^{47}$. Another community-based participatory intervention study highlighted that empowering both parents to play an active and equal role with the research team in intervention design and implementation of child feeding was reported as a promising approach to childobesity prevention ${ }^{48}$.

Certain limitations of this study require mentioning. First, to avoid socially desirable answers, open-ended knowledge and practice questions were used. This might have led to recall bias. However, we do not expect the recall bias to be differential, and thus we do not expect that the observed associations would be changed. Another limitation of this study could be that we developed the knowledge and practice questions and the cut-off-points ourselves, especially because for few questions the median number was one or two good answers out of 10 or more options. This had to be done because validated questionnaires on the concepts that we wanted to measure were not available. To give better insight into the questions we asked in this study, we provided a description of all the variables and answer categories. The final limitation of this study is of course that this study was a cross-sectional study. Whether there is really a causal relationship between fathers' knowledge and practice and dietary diversity should preferably be investigated in cohort studies and randomised trials.

Considering our results and the results of other observational and intervention studies, it seems reasonable to assume that interventions should be designed to involve the father in the process of child feeding in order to improve dietary diversity in small children in developing countries. Based on our findings, the knowledge and practices have an impact over and above more commonly regarded factors such as educational status and occupation. Therefore, interventions that enhance the fathers' knowledge of the important considerations to keep the child healthy - especially about food groups could be a priority. Concurrently, participatory interventions that increase the fathers' practice in any child care activities from the very beginning could be effective to increase fathers' understanding of children's needs. Interventions that improve both child feeding knowledge and practice of fathers are most likely crucial to improve children's dietary diversity. 


\section{References}

1. Nair MK, Radhakrishnan SR. Early childhood development in deprived urban settlements. Indian Pediatr 2004;41(3):227-37.

2. Bhutta ZA, Ahmed T, Black RE, Cousens S,Dewey k, Giupliani E, et al. What works? Interventions for maternal and child under-nutrition and survival. Lancet 2008;371(9610):417-40.

3. Morris SS, Cogill B, Uauy R. Effective international action against undernutrition: why has it proven so difficult and what can be done to accelerate progress? Lancet 2008;371:608-21.

4. Uauy R, Corvalan C, Dangour AD. Conference on 'Multidisciplinary approaches to nutritional problems'. Rank Prize Lecture Global nutrition challenges for optimal health and well-being. Proc Nutr Soc 2009:68(1):34-42.

5. Shetty P. Community-based approaches to address childhood under-nutrition and obesity in developing countries. Nestle Nutr Workshop Ser Pediatr Program 2009;63:227-54.

6. Remans R, Pronyk PM, Fanzo JC, Chen J, Palm C.A, Nemser B, et al. Multi-sector intervention to accelerate reductions in child stunting: an observational study from 9 sub-Saharan African countries. Am J Clin Nutr 2011;94(6):1632-42.

7. Wuehler SE, El Hafed Ould Dehah CM. Situational analysis of infant and young child nutrition policies and programmatic activities in the Islamic Republic of Mauritania. Maternal Child Nutr 2011;7(supp1):113-32.

8. United Nations Children's Fund. WHO organized Consultation. Geneva, 2000.

9. WHO. Global Strategy for Infant and Young Child Feeding-Fifty-ThirdWorld Health Assembly, Geneva, 2000.

10. WHO. Global Strategy for Infant and Young Child Feeding-Fifty-FourthWorld Health Assembly, Geneva, 2001.

11. WHO. Global Strategy for Infant and Young Child Feeding-Fifty-FifthWorld Health Assembly, Geneva, 2002.

12. Nguyen $\mathrm{PH}$, Menon $\mathrm{P}$, Ruel M, Hajeebhoy N. A situational review of infant and young child feeding practices and interventions in Viet Nam. Asia Pac J Clin Nutr 2011;20(3):359-74.

13. Michael W. Malnutrition and its effect in Ethiopian children. Global Citizenship: Ethiopia, 2006.

14. Black MM, Walker SP, Wachs TD, Ulkuer N, Gardner JM, Grantham-McGregor S, et al. Policies to reduce under nutrition includes child development. Lancet 2008;371(9611):454-5.

15. UNICEF. Recommendations from a Technical Consultation. Experts' consultation on growth monitoring and promotion strategies. Program guidance for a way forward, NewYork, 2008,

16. Willey BA, Cameron N, Norris SA, Pettifor JM, Griffiths PL. Socio-economic predictors of stunting in preschool children - a population-based study from Johannesburg and Soweto. S Afr Med J 2009;99(6): 450-6.

17. Asres G, Eidelman Al. Nutritional assessment of Ethiopian Beta-Israel children: a cross-sectional survey. Breastfeed Med 2011;6(4):171-6.

18. Central Statistical Agency. Ethiopia Demographic and Health Survey, Addis Ababa, 2011.

19. Beiersmann C, Bountogo M, Tiendrébeogo J, Louis VR, Gabrysch S, Yé M, et al. Malnutrition in young children of rural Burkina Faso: comparison of survey data from with 2009. Trop Med Int Health 2012; 17(6):715-21.

20. Onyango AW, Borghi E, de Onis M, Casanovas MD, Garza C. Complementary feeding and attained linear growth among 6-23-month-old children. Public Health Nutr 2014;17(9):1975-83.

21. Reaney P. Netherlands is Country with Most Plentiful: Oxfam. Reuters-The New York, 2014.

22. Daelmans B, Mangasaryan N, Martines J, Saadeh R, Casanovas C, Arabi M. Strengthening actions to improve feeding of infants and young children 6 to 23 months of age: summary of a recent World Health Organization/UNICEF technical meeting, Geneva, 6-9 October 2008. Food Nutr Bull 2009;30(2 Suppl):236-8.

23. Pryer JA, Rogers S, Rahman A. The epidemiology of good nutritional status among children from a population with a high prevalence of malnutrition. Public Health Nutr 2004;7(2):311-7. 
24. Kikafunda JK, Tumwine JK. Diet and socioeconomic factors and their association with the nutritional status of pre-school children in a low income suburb of Kampala City, Uganda. East Afr Med J 2006;83(10):565-74.

25. Nahar B, Ahmed T, Brown KH, Hossain MI. Risk factors associated with severe underweight among young children reporting to a diarrhea treatment facility in Bangladesh. J Health, Popul Nutr 2010;28(5):476-83.

26. Jesmin A, Yamamoto SS, Malik AA, Haque MA. Prevalence and determinants of chronic malnutrition among preschool children: a cross-sectional study in Dhaka City, Bangladesh. J Health Popul Nutr 2011; 29(5):494-9.

27. Anderson KE, Nicklas JC, Spence M, Kavanagh K. Roles, perceptions and control of infant feeding among low-income fathers. Public Health Nutr 2010;13(4):522-30.

28. Dearden K, Crookston B, Madanat H,West J, Penny M, Cueto S. What difference can fathers make? Early paternal absence compromises Peruvian children's growth. Matern Child Nutr 2013;9(1):143-54.

29. WHO. Indicators for Assessing Infant and Young Child Feeding Practices. Part III: Country Profiles, Geneva, 2010.

30. WHO. Indicators of Assessing Infant Young Child Feeding. Part II, Geneva, 2010.

31. Tigray Regional Health Bureau. Tigray Regional Health Bureau Report. Mekelle, 2011.

32. Rigby AS, Vail A. Statistical methods in epidemiology. II: a common sense approach to sample size estimation. Disabil Rehabil 1998;20(11):405-10.

33. Corp I. IBM SPSS Statistics forWindows, Version 19.0, Armonk-Editor, NewYork, 2010.

34. Khanal V, Sauer K, Zhao Y. Determinants of complementary feeding practices among Nepalese children aged 6-23 months: findings from demographic and health survey 2011. BMC Pediatr 2013; 13:131.

35. Mukhopadhyay DK, Sinhababu A, Saren AB, Biswas AB. Association of child feeding practices with nutritional status of under-two slum dwelling children: a community-based study from West Bengal, India. Indian J Public Health 2013;57(3):169-72.

36. Kabir I, Khanam M, Agho KE, Mihrshahi S, Dibley MJ, Roy SK. Determinants of inappropriate complementary feeding practices in infant and young children in Bangladesh: secondary data analysis of Demographic Health Survey 2007. Matern Child Nutr 2012;8(Suppl1):11-27.

37. Getaneh T, Assefa A, Tadesse Z. Dietary practices and xerophthalmia in under-fives in Jimma town, southwest Ethiopia. East Afr Med J 2000;77(6):313-5.

38. MacKeown JM, Faber WM. Frequency of food items consumed by young rural and urban African children- essential knowledge to provide dietary advice in caries prevention. Int Dent J 2004;54(5): 284-90.

39. Blissett J. Relationships between parenting style, feeding style and feeding practices and fruit and vegetable consumption in early childhood. Appetite 2011;57(3):826-31.

40. Lauzon B, Jones L, Oliveira A, Moschonis G, Betoko A, Lopes C, et al. The influence of early feeding practices on fruit and vegetable intake among preschool children in 4 European birth cohorts. Am J Clin Nutr 2013;98(3):804-12.

41. Rekhy R, McConchie R. Promoting consumption of fruit and vegetables for better health Have campaigns delivered on the goals? Appetite 2014;79:113-23.

42. Ingram J, Johnson D, Greenwood R. Breastfeeding in Bristol: teaching good positioning, and support from fathers and families. Midwifery 2002;18(2):87-101.

43. Moestue $\mathrm{H}$, Huttly S. Adult education and child nutrition: the role of family and community. J Epidemiol Community Health, 2008;62(2):153-9.

44. Pontes $\mathrm{CM}$, Osorio MM, Alexandrino AC. Building a place for the father as an ally for breast feeding. Midwifery 2009;25(2):195-202.

45. Sasaki Y, Ali M, Kakimoto K, Saroeun O, Kanal K, Kuroiwa C. Predictors of exclusive breast-feeding in early infancy: a survey report from Phnom Penh, Cambodia. J Pediatr Nurs 2010;25(6):463-9.

46. Tran BH. Relationship between paternal involvement and child malnutrition in a rural area of Vietnam. Food Nutr Bull 2008;29(1):59-66.

47. Magill-Evans J, Harrison MJ, Rempel G, Slater L. Interventions with fathers of young children: systematic literature review. J Adv Nurs 2006;55(2):248-64.

48. Davison KK, Jurkowski JM, Li K, Kranz S, Lawson HA. A childhood obesity intervention developed by families for families: results from a pilot study. Int J Behav Nutr Phys Act 2013;10:3. 


\section{Chapter 4}

The view of fathers on their role in young child care and child feeding: a qualitative study among

Ethiopian fathers

Bilal SM, Spigt M, Czabanowska K, Mulugeta A, Blanco R, Dinant GJ

Submitted 


\section{Abstract}

\section{Introduction}

The role of fathers in proper nutrition of young children has not been a frequent topic of studies. Mothers are usually the primary caregivers for young children. If the father is responsible for the financial choices of the household, they also may decide on the purchasing of nutrient-rich food for the baby. Therefore, we wondered to what extent fathers were involved in raising children.

\section{Methods}

A qualitative study was conducted on fathers and mothers who have children between 6 to 23 months. In-depth interviews and focus group discussions were carried out. A thematic analysis was completed to identify emergent themes within the data.

\section{Results}

Fathers' perceptions and practices of routine child care and feeding seem to be improved from the past. However, being busy with work, lack of knowledge, traditional beliefs and financial reasons were the common setbacks that held fathers back from practicing routine child care and feeding. Fathers are also variable in their perception and practices and challenges. In general, three types of fathers identified based their perception, practice and challenges of routine child care and feeding.

\section{Conclusion}

Our findings provide new insight to the literature in describing fathers' roles and challenges in routine child care and feeding practices. We have developed a model that could help researchers, programmers, policy makers and health workers to approach fathers in different child intervention research and plans. Our findings suggest that targeting fathers may be a worthwhile approach and that it seems justifiable to plan interventions involving fathers. However, assessing fathers' experiences in child healthrelated education programs is an important prerequisite for any intervention plan. 


\section{Introduction}

The way in which people feed their children has been an important topic in both highand low-income countries in order to prevent child malnutrition ${ }^{1,2}$. This is especially important in developing countries where child under-nutrition remains a serious public health problem: child feeding is not only a matter of having healthy food but also of fulfilling the basic needs of a child ${ }^{2-6}$.

Many governmental and non-governmental organisations have invested in programs that inform the public about the importance of appropriate child feeding ${ }^{7-13}$. These programs will often be received by mothers, as they are most often the primary caregivers for young children. However, a previous study of our group suggested that fathers could have a crucial role in the successful implementation of such advice ${ }^{14}$. If for example, the father is responsible for financial choices of the household, the decision to buy nutrient-rich foods for the baby also depends on him. Therefore, we wondered to what extent fathers were involved in raising the children.

The role of the father in proper nutrition of young children has not been a frequent topic of studies. Several studies emphasise that mothers play a crucial role in children's life, while the fathers' role often comes after and is usually addressed quite superficially, by merely emphasising the impact of the fathers' socioeconomic status on child health outcomes ${ }^{15-17}$. Socioeconomic status often was found to be the important predictor of child health and related outcomes.

Few studies have looked at other aspects of fathers' involvement in children's life, and most often these studies concerned fathers of children with specific and serious health problems such as autism, obesity, psychological or behavioural problems ${ }^{18-22}$. These studies stressed the importance of the father in reducing child health problems. Different studies have highlighted the fathers' influence when it comes to motivating children for education and school readiness ${ }^{23-25}$, while other studies showed the positive influence of fathers' supportiveness in breastfeeding, such as verbal encouragement and active involvement in breastfeeding activities ${ }^{26}$. A systematic review of longitudinal studies and one cross-sectional study showed that mothers usually adopt the primary caregiver role, and that the father usually supports the mother $^{22,27}$.

While the available research agrees on the importance of the involvement of fathers in child care, research has largely focused on high-income populations, which is not translatable to the practices and challenges of those in low-income settings. Therefore, data from these bodies of research cannot be used to develop programs for lowincome populations. With this knowledge deficit in mind, our study aimed to investigate the perceptions, practices and challenges of fathers from low-income settings, in routine child care, particularly in relation to child feeding practices. 


\section{Materials and methods}

\section{Study area and design}

The study was conducted in the Tigray Region of Northern Ethiopia, and used a qualitative approach. Ten in-depth interviews and one focus group discussion (FGD) were carried out among ten fathers, who had children between 6 to 23 months. To validate fathers' comments, mothers (from different households) also participated in the study, and one in-depth interview and one FGD was conducted among these mothers.

\section{Data collection}

The following questions were addressed during the interviews and FGDs (Table 4.1).

Table 4.1 Interview guides for in-depth interviews and FGD.

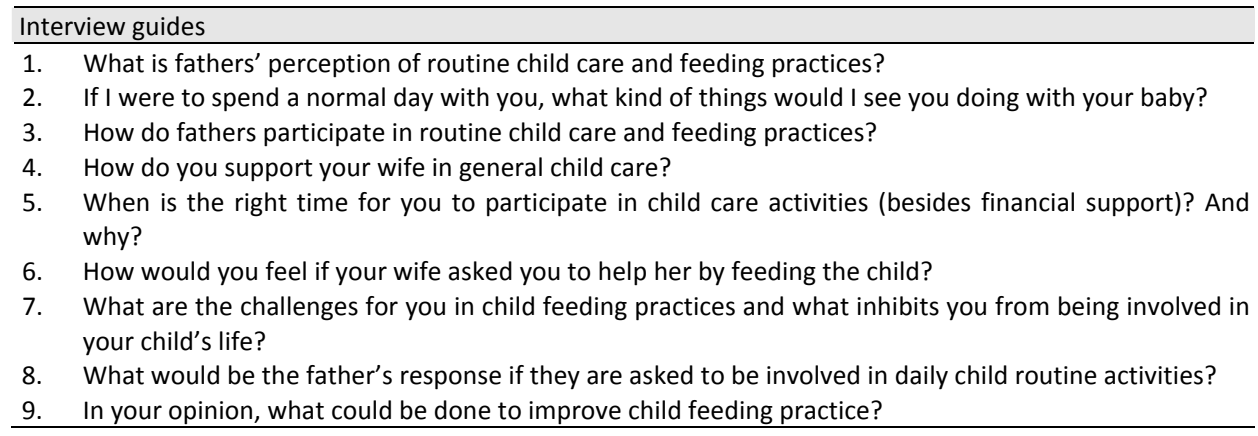

The in-depth interviews and FGDs were conducted using the local language, Tigrigna, at the nearest health centre. The duration of each interview and discussion were between 60-120 minutes. A purposive sampling technique ${ }^{28}$ was applied to select the study participants. There were no formal exclusion criteria to select fathers and mothers. The participants were selected based on the recommendation of community health workers, who selected fathers and mothers who they thought would be able to provide useful information about their experiences on child care and feeding practices.

Open coding was used during the interviews, and then elaborated later. As new concepts appeared, the researcher revisited the participants with the questions (with some amendments and additional question). The interview and discussion process lasted until saturation point, when no new information was provided ${ }^{29}$. The interviews were conducted by trained moderators and interviewers who were native speakers of the Tigrigna language and able to speak and write in English. For the in-depth interviews and FGD, semi-structured open ended interview guidelines were prepared. 


\section{Data analysis}

The study applied a thematic analysis ${ }^{30}$ to a careful examination, to identify, analyse and extract emerging themes from the data. This technique minimally organises and describes the data set in rich detail. Ongoing data analysis took place throughout the study. Early involvement in the analysis phase was helpful to move back and forth between development of themes and data collection, and direct the subsequent data collection towards sources that were more useful for answering the research questions. The researchers first familiarised themselves with the data where upon initial codes were developed. The open codes were then assigned to identify and categorise the phenomena found in the text. Axial coding was then performed by fitting themes into a basic frame of generic relationships. Finally a single story line constituted using selective coding. We continued analysing the categories in great detail until saturation $^{29}$. ATLAS.ti50 software was used to support the analysis ${ }^{31}$.

\section{Trustworthiness}

According to Guba and Lincoln, the quality of qualitative research should be assured by meeting standards of trustworthiness, through addressing credibility and transferability $^{28}$. To meet credibility, we included mothers from different districts. Additionally, in-depth interviews, FGDs and field notes were used in the analysis. Two investigators also participated to collect and analyse the data. To strengthen the transferability of the findings to different settings and contexts, our study provided descriptions of the setting, sampling, sample size, inclusion and exclusion criteria, interview procedures and findings.

\section{Ethics}

Ethical approval was obtained from the Ethical Review Committee of Mekelle University and the Regional Health Bureau (registration number: CHS/0136/PH-05). Participants who were literate were provided written information about the aim of the study, benefits and confidentiality. A written consent was subsequently obtained from these participants. For those participants who were illiterate, the purpose of the study and confidentiality were explained by the interviewer/moderator and then verbal consent was obtained. This procedure was tape recorded.

\section{Results}

The average age of fathers who were involved in this research was 40 years, and all fathers were capable of reading and writing. All fathers except one had attended formal education. Farming was the occupation of all fathers and the main source of their 
income was, on average, \$US601 per year. The mean age of their children was 13 months, and half of the children were female. The mean age for mothers was 26 years and the majority were housewives with no formal education. Based on the thematic data analysis, three major themes emerged from the data: 1) fathers' perception of routine child care and feeding; 2) fathers' practice of routine child care and feeding; and 3) challenges of fathers' involvement in routine child care and feeding practices.

\section{Fathers' perception of routine child care and feeding}

Some fathers did not perceive routine child care practice as their responsibility. They considered all child care responsibilities, from morning to evening, as the mothers' responsibility, so for some men it seemed that mothers were the only responsible caregivers in the child's daily life. These men were very distant from the routine life of their family, and they only felt responsible for income-generating activities. In this role, they perceived that they were giving full priority to their family, because they were fulfilling their responsibility as needed. These fathers usually spent their time outside of their home, and, if there was any leisure or free time, they often preferred to spend it with friends rather than their family.

The majority of the fathers still perceived child care mainly as a responsibility of mothers, however they were also involved in routine child care activities, although this was often mentioned in a way of helping the mother. For example, "...majority of the activity is that of the mother, but I help her when she is involved in some other activities ..." Their role was often conditional on several factors, such as the age of the children (between 6-8 months was considered as the right time for fathers to be involved in child care activities). Some fathers also mentioned 5 years or more as a right time for them to be involved in child care activities.

"I wash her body after eight months just after she is comfortable to be hold. Before that age, it is difficult to hold the baby body, even to change their cloths... during this age; it is the mother who takes care of the baby."

According to fathers, time also seemed an important factor. Most fathers perceived that the one who spends more time with the child is more responsible for child care and feeding. Therefore, their role in child care was dependent on the time they were at home and this time was often limited. They were also selective in child care activities and responsibilities. In general, it can be concluded that these fathers have time and activity boundaries.

"..., I meet my child only few hours per day. But the child spends many hours with her mother whereas with me just very few. ...for example I go to work in the morning leaving my child behind and I meet her in the evening. But when I get home, I help my wife.... The one who will be responsible is the one who spends most of the time with the family." 
Few fathers mentioned that they were equally responsible as mothers in child care practices. They did not have boundaries in child care activities, nor even in household activities. They felt responsible and they considered that taking care of the child should start at birth and should continue until he/she could lead his/her life independently:

"From the time of birth until he/she starts to lead his/her own life independently, he/she needs the care of his father and his mother."

"Full involvement might be difficult but sharing it could be acceptable especially by the new generation. However, I can't say that it would be fully accepted..... In the past, all household chores were considered to be the responsibility of the mother, but now I can say almost half of the community husbands are helping the mother. As long as she is involved in different activities of the father, he should also be involved in mothers' activities..."

The view of the fathers was generally confirmed by the mothers. Mothers agreed on the improvement of fathers' perception of routine child care and feeding activities, compared to their past experiences. However, they all underlined that because of the deep cultural and traditional beliefs and practices in the community, routine child care and feeding activities and related issues still weighed heavily on the mothers' shoulder.

"... Traditional and cultural influence favours for males. Therefore, almost all activities related to child care, feeding and food preparation are considered to be the responsibility of mothers."

\section{Fathers' practice of routine child care and feeding}

Playing with the child was the first thing that came to fathers' mind when asked about the kind of activities that we would see them doing with their baby, if we were to spend a normal day with them. Playing activities were described in different ways, for example, "physical playing", "tricking while feeding" and "making different musical sounds". Preparing the child's food, feeding the child, giving money to the mother to buy food or other things for the child, bringing food from the garden, and buying food and other child needs from the market/town were other activities that were often mentioned by fathers.

"Oh, regarding food preparation... I have nothing to do with that, I only bring the items. In addition, I feed him, entertain and trick him. Especially, playing with the child is my job"

Additionally, calming down the child when crying, bathing the child, and changing clothes of the child were other activities that were mentioned. However, the majority of fathers often underlined that they would do these activities only if the mother was busy with other household activities or if the mother was not around. The majority of the fathers also often mentioned that they discussed child care issues with their wives. The 
discussion points that were often mentioned included "... whether the baby eats or not..."

Additional discussion points, in relation to child feeding included decisions on what food to buy from the market/town, what food to bring from the garden and the foods that were available at home. Other discussions points between mothers and fathers concerned other child needs and child health educations that were provided by health care workers. Regarding other health-related activities, few fathers attended the health education even if it was given in their homes. Taking the child for vaccination/ immunisation or any child health-related activity was seldom mentioned by fathers.

Mothers also confirmed that common activities of fathers in relation to routine child care and child feeding included playing with the child, giving money to the mothers to buy necessary things and providing food from the garden. Buying food and other child needs from the market/town were other activities mentioned as typical fathers' activities. Mothers also confirmed that attending child health related education, taking the child to vaccination or other child care visits were rarely done by fathers. In general, all mothers agreed that compared to their past experience, fathers' practice in routine child care and feeding has shown some improvement.

\section{Challenges to fathers' involvement in routine child care and feeding practices}

Being busy with work activities (such as farming and other income generation activities) made it difficult for fathers to spend time with their child, being involved in their child's life and to attend child health-related education.

"I meet my child only for few hours....my child spends many hours with her mother because I go to work in the morning and I come back home and meet her in the evening."

Poor understanding of the importance of child care and feeding among fathers, along with financial problems, were also mentioned as major factors that inhibited fathers from practicing the little knowledge they had. Accessibility and shortage of food were also mentioned.

"...for some of the fathers, economical/financial problems were huge challenges even if they have plenty of knowledge about feeding practices. On the other hand, there were other groups who have the money but do not have the knowledge... There were also some extravagant individuals who waste the money on non-essential issues or they simply save the money without spending it on their child's needs. And there were fathers who have the knowledge as well as the money but they do not want to buy anything for their children."

Incorrect perceptions, beliefs and bad habits of fathers have also been mentioned as challenges to practice child care and feeding activities appropriately. Many still 
considered child care and feeding activities as only the mothers' responsibility. Additionally, many fathers seemed resistant for change or new ideas. They indicated they would not feel proud of taking care of their babies; they find themselves careless, or they simply give priority to themselves instead of their children and sadly keep good foods for special occasions.

The majority of mothers confirmed the challenges of the fathers' perceptions, cultural and traditional beliefs that indicated child care is only the mother's responsibility. They also mentioned the knowledge and information gap between mothers and fathers, because the fathers are not participating in child health-related education. They also emphasised that this knowledge gap indirectly affected mothers' financial capacity and hindered them from providing all the necessary care, foods and materials for their children.

\section{Model for fathers' perception, beliefs, practice and challenge of routine child care and feeding}

This study identified three general types of fathers (Figure 4.1). The first group is fathers who do not feel part of routine child care, and they fully believe child care is only the mothers' responsibility. They consider making money and/or farming to be their responsibility for their family. Their knowledge on child care and child needs is very poor and they are largely unaware of the challenges that the mother and child face every day. Therefore, the entire burden of taking care of the baby weighs on the mothers' shoulder. These fathers are very traditional; and believe that they are fulfilling their childcare responsibilities as needed. Therefore, it might be very difficult to change this group's behaviours and will probably be very difficult to involve them in any innovative program on child related issues.

"We should tell the truth. It is not because I do not have time, but we both should do our part, so it is better if the mother do her part, take care of the child, and I do my part, farming, rather than leaving my activities undone."

The second group of fathers perceive child care as being both the mothers' and fathers' responsibility. However, they do not feel completely responsible for child care, but set preconditions such as: "if I am free", "if I do not have other activities to do", "if I am at home", or "when the mother is busy with other household activities". This group of people understand the need to help the mother. They are, however, selective on the activities they do. As this group of fathers also has other priorities, they may be reluctant to attend any education on child care, resulting in a knowledge gap on this issue. However, they seem happy to respond to the mothers' needs in relation to routine child care, and they are helpful and open for child related innovations and changes. Therefore, this group of fathers require a good approach or system, considering their time and interests, to boost their knowledge and help them feel 
responsible for their children. Targeting this group to implement changes in behaviours and beliefs thus could prove less challenging.

"Buying food is her responsibility and it is the mother who should prepare the food. But I can feed her if I come home while the child is being fed, but it is her mother who feeds the child most of the time. Because it is her mother who spends much time with her. But I can be involved in buying (supporting financially) the food."

The third group of fathers which were few in number perceive child care and child feeding as a shared responsibility between mother and father. This group is also willing to be part of child's life and to give care from childhood to adulthood:

"... If you had spent a day with me, you could see me giving all the care for my daughter."

They also seem familiar with their responsibility in the house, by responding to the mothers' needs, providing all the necessary things to their child and being attentive and open to the necessary/new information and educations provided in relation to the child's health. Moreover, they are ready for changes. Therefore, involving them in child care activities and different intervention programs is likely to be the least challenging.

"We all help each other equally, the only difference between the mother and me is that she carried and delivered the baby ..."

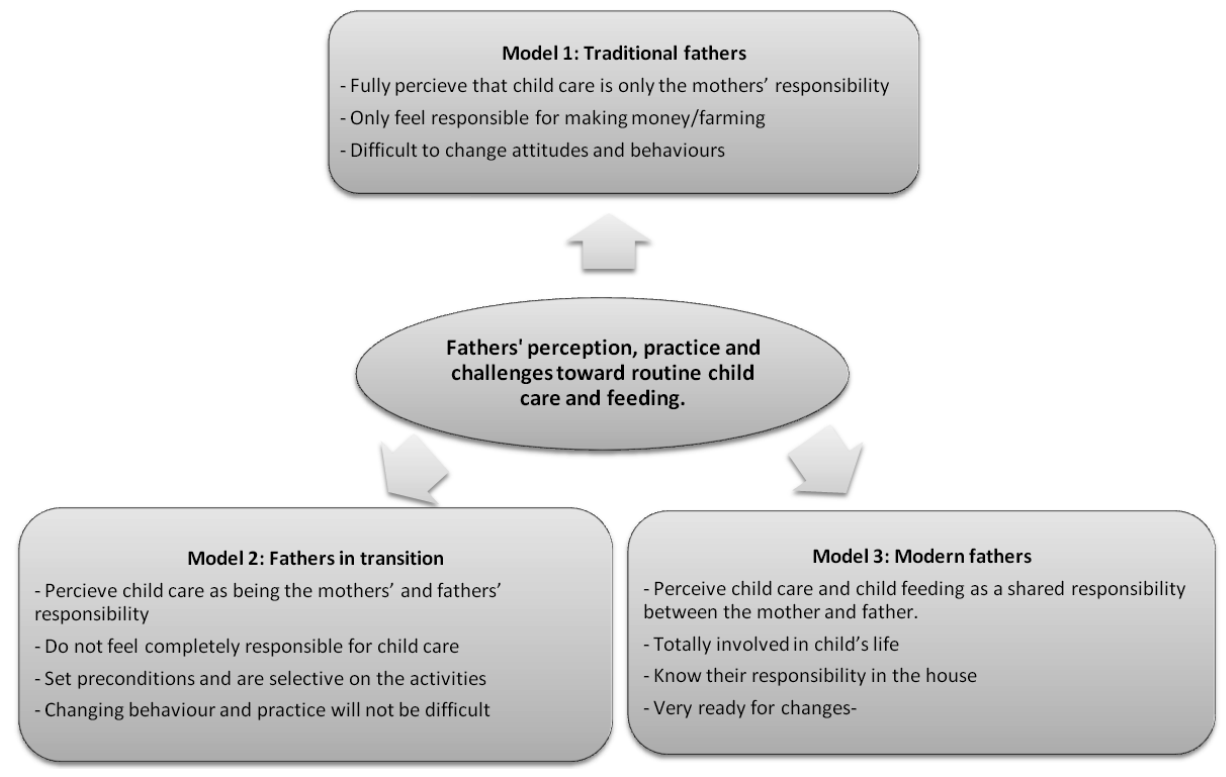

Figure 4.1 A model to describe fathers' perception, beliefs, practice and challenges toward routine child care and feeding. 


\section{Discussion}

Our study showed that fathers' perceptions and practices of routine child care and feeding seem to be improved from the past. However, except for income-generation and providing necessary things for the child, the majority of fathers still fully or partially perceived routine child care and feeding practice as being the mothers' responsibility. Besides income generation activities, playing with the child seemed the only interesting activity for the fathers. Attending child health related education and taking the child for immunisation or any child health related visits seemed insignificant activities in the fathers' minds. Common setbacks that held fathers back from practicing routine child care and feeding included being busy with work, lack of knowledge, traditional beliefs and financial reasons.

There were very few fathers who fully perceived that child care was a shared responsibility between mothers and fathers, however the majority fell into the category of fathers who felt partially responsible, and who were only involved in the activities that interested them. Even though it was difficult to find studies similar to our topic of interest, these results are generally consistent with our expectations and with other related studies that showed that work, lack of information, poor knowledge, economic issues, absence of recognition of their role, lack of engagement during the education process, and lack of commitment from health professionals to engage fathers, are common challenges that inhibit fathers from being fully involved in routine child care $^{25,27,32,33}$. Therefore, in order to increase their engagement in children's life we required much stronger interventions that could overcome these setbacks.

For many fathers, their involvement in child care appeared to extend only to making money for the family. This is a reason why many researchers often address household income to indirectly address fathers' roles in child health related outcomes or issues $^{15-17}$. Fathers who consider income generation as their only responsibility are very traditional and it could be very challenging to engage them in their child's daily life, in areas other than financial support. The very limited involvement of this group of fathers in their children's life could directly affect their knowledge toward child care and their support in decision making and financial support in the family. This might increase the economic burden toward mothers. Therefore, approaching this group of fathers is not only a matter of introducing a strong system about child care, but it needs more work to break the chain of traditional beliefs and perception toward child care and family value.

In line with our finding, fathers to go to the health centres seems a universal problem $^{34-36}$. Parental discussions seem to be the source of information for fathers. Most fathers rely on second hand information passed only by their wives. Fathers are neither attending health education nor visiting child health care centres. Therefore, we suspect that fathers' child care practices and their appeal to mothers' needs in relation 
to the child can be misguided. More research is needed to assess fathers' engagement and challenges in different child health related education programs.

Some limitations of this study should be mentioned. The data from mothers was weak, as there is a deep cultural belief that mothers should not talk badly about their partners. We experienced that mothers' disclosure of their partners' ill-perceptions and poor practice of child care in front of other mothers during the FGD was difficult. The majority of mothers preferred to remain quiet during the discussion, or only gave very short responses by referring to the comments of others. As a result, the data obtained were mainly dominated by the fathers' opinion. However, having interviews and FGDs with fathers about this issue in detail in a low-income setting is hard to find, therefore we consider the data we obtained to be highly valuable.

Our finding added new insight to the current literature describing fathers' roles and challenges of routine child care and feeding practices. We have developed a model that could provide further insight to help researchers, programmers, policy makers and health workers to approach fathers in different modalities in relation to the design, research and planning of child care and feeding interventions. For that reason, in order to engage fathers in children's' lives, knowing their perceptions, practices and challenges, and customizing approaches towards them based on the model the fathers fits into. This approach could be a more effective way to reach fathers. In line with other studies and our expectations, this study suggests that targeting fathers may be a worthwhile approach and it seems justifiable to plan interventions that involve fathers. However, assessing their engagement and experiences in child health related education programs is an important prerequisite for any intervention plan. 


\section{References}

1. Onyango AW, Borghi E, de Onis M, Casanovas MD, Garza C. Complementary feeding and attained linear growth among 6-23-month-old children. Public Health Nutr 2014;17(9):1975-83.

2. Shetty P. Community-based approaches to address childhood under-nutrition and obesity in developing countries. Nestle Nutr Workshop Ser Pediatr Program 2009;63:227-54.

3. Remans R, Pronyk PM, Fanzo JC, Chen J, Palm C.A, Nemser B, et al. Multi-sector intervention to accelerate reductions in child stunting: an observational study from 9 sub-Saharan African countries. Am J Clin Nutr 2011;94(6):1632-42.

4. Morris SS, Cogill B, Uauy R. Effective international action against undernutrition: why has it proven so difficult and what can be done to accelerate progress? Lancet 2008;371:608-21.

5. Nair MK, Radhakrishnan SR. Early childhood development in deprived urban settlements. Indian Pediatr 2004;41(3):227-37.

6. Dubowitz T, Levinson D, Peterman JN, Verma G, Jacob S, Schultink W. Intensifying efforts to reduce child malnutrition in India: an evaluation of the Dular program in Jharkhand, India. Food Nutr Bull 2007;28(3):266-73.

7. WHO. Global Strategy for Infant and Young Child Feeding, in Fifty-third World Health Assembly, Geneva, 2000.

8. WHO. Global Strategy for Infant and Young Child Feeding, Fifty-fourth World Health Assembly, Geneva 2001.

9. Black MM, Walker SP, Wachs TD, Ulkuer N, Gardner JM, Grantham-McGregor S, et al. Policies to reduce under nutrition includes child development. The Lancet 2008;371(9611):454-5.

10. Sanghvi T, Martin L, Hajeebhoy N, Abrha TH, Abebe Y, Haque R, et al. Strengthiening systems to support mothers in infant and young child feeding at scale. Food Nutr Bull 2013;34(3 Suppl):156-68.

11. Sanghvi T, Jimerson A, Hajeebhoy N, Zewale M, Nguyen GH. And young child feeding practices in different country settings. Food Nutr Bull 2013;34(3 Suppl):169-80.

12. Shi L, Zhang J. Recent evidence of the effectiveness of educational interventions for improving complementary feeding practices in developing countries. J Trop Pediatr 2011;57(2):91-8.

13. Morgan JB, Williams P, Foote KD, Marriott LD. Do mothers understand healthy eating principles for low-birth-weight infants? Public Health Nutr 2006;9(6):700-6.

14. Bilal S M, Moser A, Blanco R, Spigt M, Dinant GJ. Practices and Challenges of Growth Monitoring and Promotion in Ethiopia: A Qualitative Study. J Health Popul Nutr 2014;32(3):441-51.

15. Tessema M, Belachew T, Ersino G. Feeding patterns and stunting during early childhood in rural communities of Sidama, South Ethiopia. Pan Afr Med J 2013;14:75.

16. Owoaje E, Onifade O, Desmennu A. Family and socioeconomic risk factors for undernutrition among children aged 6 to 23 Months in Ibadan, Nigeria. Pan Afr Med J 2014;17:161.

17. Tamis-LeMonda CS, Shannon JD, Cabrera NJ, Lamb ME. Fathers and mothers at play with their 2- and 3year-olds: contributions to language and cognitive development. Child Dev 2004;75(6):1806-20.

18. Neander K, Engström I. Parents' assessment of parent-child interaction interventions - a longitudinal study in 101 families. Child Adolesc Psychiatry Mental Health 2009;3(1):8.

19. Swallow V, Macfadyen A, Santacroce SJ, Lambert H. Fathers' contributions to the management of their child's long-term medical condition: a narrative review of the literature. Health Expect 2012;15(2):15775.

20. Mallan KM, Daniels LA, Nothard M, Nicholson JM, Wilson A, Cameron CM, et al. Dads at the dinner table: A cross-sectional study of Australian fathers' child feeding perceptions and practices. Appetite, 2013.

21. Lowenstein LM, Perrin EM, Berry D, Vu MB, Pullen Davis L, Cai J, et al. Childhood Obesity Prevention: Fathers' Reflections with Healthcare Providers. Child Obes 2013;9(2):137-43.

22. Sarkadi A, Kristiansson R, Oberklaid F, Bremberg S. Fathers' involvement and children's developmental outcomes: a systematic review of longitudinal studies. Acta Paediatr 2008;97(2):153-8.

23. Martin A, Ryan RM, Brooks-Gunn J. When fathers' supportiveness matters most: maternal and paternal parenting and children's school readiness. J Fam Psychol 2010;24(2):145-55. 
24. Tulananda O, Roopnarine JL. Mothers' and fathers' interactions with preschoolers in the home in northern Thailand: relationships to teachers' assessments of children's social skills. J Fam Psychol 2001;15(4):676-87.

25. NICHD Early Child Care Research Network. Factors associated with fathers' caregiving activities and sensitivity with young children. J Fam Psychol 2000;14(2):200-19.

26. Mannion CA, Hobbs AJ, McDonald SW, Tough SC. Maternal perceptions of partner support during breastfeeding. Int Breastfeed J., 2013; 8(4).

27. Schoppe-Sullivan SJ, Kotila L, Jia R, Lang SN, Bower DJ. Comparisons of levels and predictors of mothers' and fathers' engagement with their preschool aged children. Early Child Dev Care 2013;183(3-4): 498-514.

28. Lincoln YS, Guba EG . Naturalistic inquiry. California, Sage Publications: California,1985.

29. Matthew B., Huberman A. M, Johnny S. Qualitative Data Analysis: A Methods Sourcebook. SAGE Publications, 2013.

30. Gregory S, Kathleen M. M, Emily E. Applied Thematic Analysis SAGE Publications, 2011.

31. ATLAS.ti Scientific Software Development GmbH. ATLAS.ti software, Germany, 2004.

32. Tohotoa J, Maycock B, Hauck YL, Howat P, Burns S, Binns CW. Dads make a difference: an exploratory study of paternal support for breastfeeding in Perth, Western Australia. Int Breastfeed J 2009;4:15.

33. Moore T, Kotelchuck M. Predictors of Urban Fathers' Involvement in Their Child's Health Care. Pediatrics 2004;113(3pt):574-80.

34. Macfadyen A, Swallow V, Santacroce S, Lambert H. Involving fathers in research. J Spec Pediatr Nurs 2011;16(3):216-9.

35. Garfield CF, Isacco A. Fathers and the well-child visit. Pediatrics 2006;117(4):637-45.

36. Tiedje LB, Darling FC. Promoting father-friendly healthcare. J Matern Child Nurs 2003;28(6):350-7. 


\section{Chapter 5

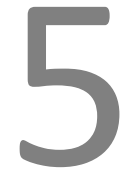

How to improve fathers' involvement in young child feeding? A qualitative study in Ethiopia

Bilal SM, Blanco R, Czabanowska K, Crutzen R, Dinant GJ, Spigt M Submitted 


\begin{abstract}
Introduction

Information on the involvement of fathers in their children's lives appears to be very limited in research, apart from using their name to trace the child. Existing studies illustrate that health workers, policies and the existing health education programs often favour mothers and seem unwelcoming to fathers' involvement. Therefore, the aim of this study was to develop a theory which will provide an insight into fathers' experiences on child feeding education, and that could be used as a ground to improve fathers' involvement in child feeding practices.
\end{abstract}

\title{
Methods
}

We carried out a qualitative study to investigate fathers' experience in relation to young child feeding education based on a grounded theory approach. Fathers and health workers participated in the study, and both in-depth interviews and focus group discussions were carried out in the rural Tigray region of Northern Ethiopia.

\section{Results}

Second-hand information passed through mothers and posters seemed the main sources of information for fathers on how to care for their children. The main reasons for fathers not being involved in child health education concerned low attention and poor recognition given to them by health workers. Other challenges faced by fathers concerned being busy in income generation activities and their perception of child health education. Despite the cost, courage, distances, and cultural difficulties, the primary choice to approaching fathers in health education was house to house education that also involved mothers.

\section{Conclusion}

Our study suggests that house to house education involving both the father and mother could be an ideal approach to reach fathers. Health workers and policies should make fathers feel they are welcome and responsible in their children's lives. Improvements in father-child interaction seem to also have a positive effect on the father-child relationship. The effectiveness of interventions such as house to house education should be investigated to determine if child feeding practices can improve as a result of educating fathers in the company of mothers. 


\section{Introduction}

Apart from using the fathers' name to trace their children, involving the father in their children's life, even in research, appears to be very limited ${ }^{1}$. In the developed world, the influence of fathers in the context of children's obesity and chronic health problems is being studied ${ }^{2-6}$. However, the role of fathers as caregivers in children's life is still largely forgotten, especially in young children when it is probably needed most.

More than half of young child deaths are due to diseases that are preventable and treatable through simple, affordable interventions ${ }^{7}$. Malnutrition contributes to approximately $50 \%$ of deaths in children under-five years of age in low-income countries $^{8}$. Since the year 2000, Infant Young Child Feeding (IYCF) has been considered an essential element to ensure the growth, health and development of children to their full potential ${ }^{9,10}$, especially in developing countries where child malnutrition remains a common problem ${ }^{7}$.

However, educations related to child feeding are often targeted to mothers. For instance, the Ethiopian government has introduced an innovative community-based strategy, using Health Extension Workers (HEWs) and the Health Development Army ${ }^{11}$, to increase the health care awareness through participatory learning and action meetings in villages and households. IYCF is one of the topics being taught by HEWs in every household in Ethiopia, by giving more emphasis to mothers.

Even though existing evidences and health workers' opinions often emphasise a very low engagement of fathers in children's lives, they strongly suggested the importance of involving fathers in children's. Such as previous observational studies demonstrated that enhancing fathers' engagement in their child's health care seemed to rely on recognition of the father's role by the health workers and strong support of the fathers' involvement $^{12,13}$. Similarly, a systematic review suggested a strategy that includes inviting fathers to attend health care related visits, and for health workers to speak directly to fathers as well as mothers ${ }^{14}$. Another systematic review recommended an intervention that could enhance father-child interaction such as kangaroo care - a method of holding the baby that involves skin-to-skin contact, and participation with the child in a pre-school program ${ }^{15}$. Additionally, adapting the fathers' work schedule to support child care and increasing fathers' knowledge and confidence in their parenting role seem mandatory steps ${ }^{13}$.

In general, the available studies illustrate that health workers, policies and existing health education programs, often favour mothers and seem unwelcoming to the fathers' involvement. However, this literature only shows the perspectives of the developed world. These evidences are limited and it fails to grasp the real world practice and challenges of fathers in developing countries. Therefore, the aim of this study was to develop a theory which will provide a real insight and understanding of fathers' experience on child feeding education in the context of a developing country. Ethiopia has been used as an example. 


\section{Methods}

\section{Design}

We carried out a qualitative study to investigate fathers' experience in relation to young child feeding education based on a grounded theory approach which is a systematic methodology in the social sciences involving the discovery of theory through the analysis of data ${ }^{16}$. In this research the Strauss and Corbin's approach was followed, which describes flexible guidelines for the analysis process. After each round of data collection, researchers analyse and code the data, and use insights from the analysis process to inform the next iteration of data collection. Thus, prior coded data guides subsequent theoretical sampling decisions. This process continues until a strong theoretical understanding of an event, object, setting or phenomenon has emerged.

\section{Study site, participants and sampling}

Atsib, the study site, is located $65 \mathrm{~km}$ North of Mekelle, the capital city of the Tigray Region in Northern Ethiopia. In this district there is currently one hospital, six health centres and six health posts. The district is further divided into 18 kebelles, the smallest administrative units of Ethiopian government. Each kebelle covers on average 5,000 people. The district has 6,024 children under two years of age ${ }^{17}$.

Ten fathers of under-two children, who were able to provide information about their experience in IYCF practices, were selected on the recommendation of HEWs, the primary health care providers at the health post who regularly visit households in the region. The fathers were selected from five different districts to participate in this study. There were no formal exclusion criteria for fathers of under-two children. To validate fathers' experience on child care feeding practices, eight health workers (4 HEWs, 2 HEW supervisors and 2 maternal and child health experts) who were involved in IYCF education and supervision, also participated in this study. The health workers were approached through the district health bureau manager. A purposive sampling technique ${ }^{18}$ was applied to select the study participants.

\section{Ethics}

Ethical approval was obtained from the Ethical Committee of the University of Mekelle and the regional health bureau (registration number: $\mathrm{CHS} / 0136 / \mathrm{PH}-05$ ). Participants who were literate were given written information about the aim of the study, benefits and confidentiality. Written consent was subsequently obtained from these participants. For those participants who were illiterate, the purpose of the research and confidentiality information was explained by the interviewer/moderator. Verbal consent was obtained and the procedure was tape-recorded. 


\section{Data collection}

Data collection took place from March 2013 to March 2014. In-depth interviews and two focus group discussions (FGDs) were carried out using the local language Tigrigna. The in-depth interviews were carried out among 10 fathers. The first FGD was conducted among 8 fathers who had participated in an in-depth interview. The two fathers who were participated in the in-depth interviews couldn't avail themselves on the date of the FGD although they were informed in advance. The second FGD was conducted among 8 health workers. The duration of each in-depth interview ranged between 60-90 minutes, while the FGDs ranged between 90-120 minutes. Open coding was performed during the interviews and elaborated later. As new concepts appeared, the researcher returned with new questions to the participants. The data collection process lasted until saturation (when no new information was provided). ${ }^{18}$ All in-depth interviews and FGDs took place at the nearest health centre. The interviews and FGDs were conducted by trained interviewers and moderators, who were native speakers of the Tigrigna language and able to speak and write in English. For the in-depth interview, semi-structured open ended interview guidelines were prepared (Table 5.1).

Table 5.1 Key questions used in Interview and FGD.

What is the father's experience of child care and feeding educations?

How do fathers benefit from child care and feeding education/information?

What are the major challenges for fathers to engage in child care and feeding educations and practices?

What should be done to overcome the challenges of fathers?

What should be done to improve fathers' involvement in child care and feeding educations and practices?

The interview, FGD guidelines and questioning routes were prepared in English before translation into the local language, Tigrigna, by two bilingual health workers. All indepth interviews and FGDs were recorded and field notes were taken. All data were transcribed verbatim in Tigrigna and translated into English by the moderators/ interviewers. The transcribed text was not returned to the participants as most were illiterate, however it was checked by the interviewers. This technique increases the authenticity of the data and amounts to what Lincoln and Guba described as a "member check"18.

\section{Data analysis}

We applied a constant comparative method ${ }^{19}$ through the researcher's careful examination and constant comparison to extract the emergent categories from the data. Ongoing data analysis took place throughout the study. The early involvement in the analysis phase was helpful to move back and forth between category development 
and data collection, and direct the subsequent data collection towards sources that are more useful for answering the research questions.

Different coding pathways were carried on. First, the researchers familiarised themselves with the data, upon which initial codes were developed. Second, open codes were assigned to identify and categorise phenomena found in the text. Axial coding was then conducted, which involved fitting themes into a basic frame of generic relationships. Last, selective coding was conducted to identify the core categories and develop a single storyline ${ }^{16}$. We continued analysing the categories in great detail until saturation. ATLAS.ti50 software was used to support the analysis ${ }^{20}$.

\section{Quality assurance}

According to Guba and Lincoln, the quality of qualitative research should be assured by meeting the standards of trustworthiness, such as credibility and transferability ${ }^{18}$. To meet credibility standards, we applied data triangulation. This included the recruitment of several participants such as fathers and health workers as study participants. There were only farmer fathers in these rural areas; however, health workers with different personal experiences and professional background participated. Additionally, in-depth interviews, FGDs and field notes were used in data analysis, and besides the researcher, two investigators with health background and who had experience in qualitative research participated to collect and analyse the data. The two investigators participated in the analysis process by providing the field note summary after each interview and FGD, and that was helpful for developing the categories by moving back and forth between category development and data collection. To prove the transferability of our findings to different settings and contexts, we provided thorough descriptions of the setting, sampling, sample size, inclusion and exclusion criteria, interview procedure and findings.

\section{Results}

A total of 10 in-depth interviews and two FGDs were conducted with a total of 18 participants. The socio-demographic characteristics of the participants are presented in Table 5.2. Four major themes emerged from the data (Figure 5.1): 1) Fathers' experience of current child care and feeding education; 2) Impact of child care and feeding education; 3) Challenges and proposed solutions; and 4) Implications for improving fathers' involvement in child care and feeding practice. The core category which seemed to unite all themes concerned the implications for improving fathers' involvement in child care and feeding. 
Table 5.2 Socio-demographic characteristics of fathers and health workers.

\begin{tabular}{|c|c|c|c|}
\hline Socio-demographic characteristics & & Fathers & Health workers \\
\hline Average age & (Yrs) & $40(S D=2)$ & $31(\mathrm{SD}=2)$ \\
\hline \multirow[t]{2}{*}{ Sex } & Male & 10 & 4 \\
\hline & Female & - & 4 \\
\hline \multirow[t]{4}{*}{ Education status } & No education & 1 & - \\
\hline & Primary & 8 & - \\
\hline & Secondary & - & 6 \\
\hline & Higher education & 1 & 2 \\
\hline \multirow[t]{5}{*}{ Occupation } & Farmer & 10 & - \\
\hline & Teacher & - & - \\
\hline & Health worker & - & 8 \\
\hline & Government office Worker & - & - \\
\hline & Other & - & - \\
\hline Average number of children & & $5(S D=1)$ & NA \\
\hline Average age of the last child & & 13 months & NA \\
\hline \multirow[t]{2}{*}{ Sex of the last child } & Male & 5 & NA \\
\hline & Female & 5 & NA \\
\hline
\end{tabular}

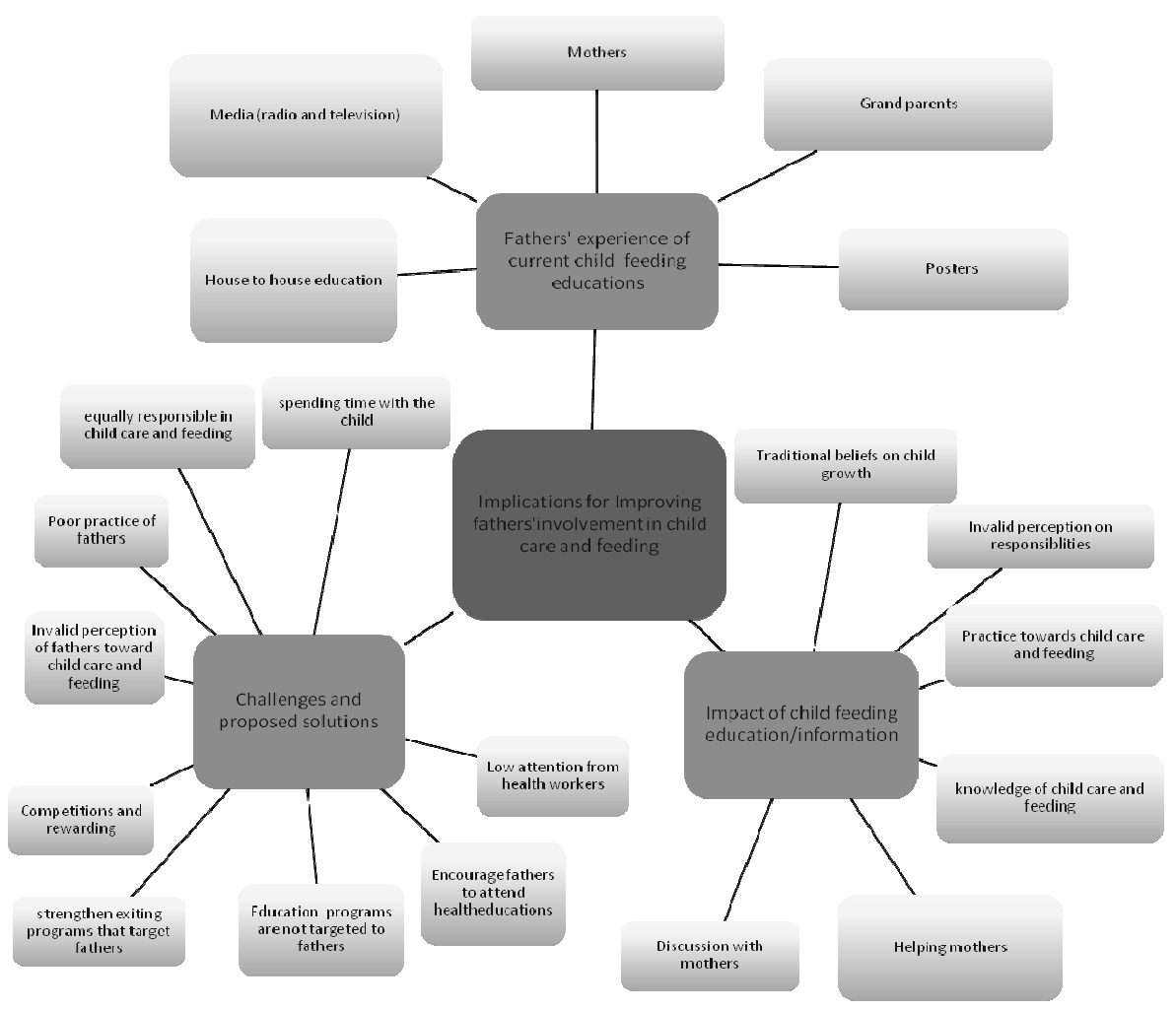

Figure 5.1 Improving fathers' child care and feeding practices: a Theoretical Model. 


\section{Fathers' experience of current child feeding education}

Fathers reported that house to house health education, mainly directed toward mothers, was the main source of information they received about child feeding. Fathers also mentioned a poster showing how well-fed children look like as another source of information. In addition, radio, television, informal/formal meetings in the villages, and grandmothers were other sources of information.

"Health extension workers and health experts give house to house health education for pregnant mothers, during the postnatal period, and to households with a young child. They also give us posters to post in our house. We also listen to radios where a lot of health education is broadcasted.... If we go to town, we watch television, and we put that into practice. For instance: if the food ingredients that we saw on the television are available, we prepare the food with those ingredients. If we don't have those ingredients, we just prepare the food from what is already available, and if it is necessary we buy some of the ingredients from the market.... My mother is old and she wants us to feed our daughter in a traditional way, for example: she told us to add butter to the child's porridge but we did not do that because we feared that it would be difficult for the baby to digest. But my mother in-law is younger and she follows the modern way of child feeding."

Health workers confirmed that house to house education was the place where they provide health education to fathers. Other places to involve fathers in different education schemes included information given at other meetings and the health care centre. Information was given on a range of topics, for example, the varieties of food groups, necessary food items from the garden, food that can be bought from the market or town, and how to help mothers in child care and feeding.

Regarding the education tools used, posters were the main instrument that HEWs used to teach fathers. Posters using the local language showed how well-fed children should look like, the appropriate time to start complementary feeding other than breast feeding and the different food ingredients to be used in child feeding. These posters were erected in each household with young children, in the health care centres and they were often used in meetings to support education. Additionally, demonstrations on child food preparation and experience sharing in the village were teaching methods used to reach fathers. Health workers emphasised that the education was resource centred and based on everybody's economic capacity.

"We teach fathers using different methods, house to house together with the mother, in the meeting at sub-district level and at health care settings. We teach them how they can help mothers, for example: since the money is with the father, we tell the father to buy what the mother wants for the kid. In a meeting, we do demonstrations on how to prepare child porridge using different cereals. 
To support our teaching, we often use posters that are prepared in local language, so it is clear for everybody to understand."

\section{Impact of education/information}

The majority of fathers stated that the education has improved their perception and practice toward child care and feeding. Additionally, compared to the past, incorrect cultural and traditional beliefs have been reduced. For instance, the strong belief that 'children can grow up by their own luck' has changed, while psychological, emotional, financial and material (food and cloth) readiness among parents, even to welcome and to take of care the new baby have also been changing.

"Mother gets prepared before the child is born, i.e. she prepares cloth and food ahead, the baby is handled in hygienic way, his feeding patterns are also kept well, unlike the previous. The gaps between meals are well controlled, and the baby food is handled hygienic. The feeding is not aimed only to fill his stomach but to build the baby's body. We fathers buy cloths to the baby... If the mother is busy and does not have somebody to help her, we carry the baby. So the change is visible between the previous generation children and the current children. As a result, this generation children are very clever and their brain is sharp."

Moreover, the perceptions of fathers that child care activities are only the mothers' responsibility have changed. Fathers pay more attention to the child; they spend more time with them, play with them, take responsibility for their own children and give care when needed, for example, to feed the child, calm the child when crying, buy necessary things for the child and help the mother in household activities when she is busy.

Fathers' knowledge about when to start child feeding after the breast milk, what to feed the child (balanced food/different food groups) and general knowledge in appropriate child feeding has improved. For example, all fathers mentioned that their children need to eat three or more meals per day, and the majority of fathers underlined the importance of continuing breast milk. In relation to food diversity, fathers often mentioned porridge made of wheat, barley, sorghum, lentils, beans, teff and other cereals. In addition, eggs, milk and milk products were food items mentioned by the fathers. Meat, vegetables and fruits were often mentioned as part of important food groups, however they highlighted that these food items were neither affordable nor easily accessible. Additionally, the health workers often emphasised for fathers to feed their child whatever they had at hand, 'the main thing is the baby should not be hungry in any way, so we should give the baby anything we have at hand'.

Fathers' knowledge towards the short and long term benefits of appropriate child feeding has improved. These benefits include good physical growth, positive school performances and decreased child mortality. Again, traditional beliefs that resulted in keeping the good food for fathers have changed from 'sweet and good foods for fathers' to 'sweet and good food for children'. Confirming fathers' opinions of 
perception, awareness and involvement in child care and feeding practice, most health workers agreed on the changes and the improvement compared to their past experiences.

"The feeding practice we adhere to these days is different from the past. Previously, attention was not given to kids and especially fathers were not that much involved. But nowadays fathers are taking responsibility; their involvement in the child's life has improved, even starting from the date of birth. Previously these activities were considered as only the mothers' responsibilities."

\section{Challenges and proposed solutions}

Even though fathers' perceptions, awareness, knowledge and practices toward child care and feeding educations have improved compared to the past, many challenges were mentioned by fathers that hold them from being involved in education programs. Some fathers complained about the low attention from health workers toward involving fathers, such that they were not given serious attention, and not expected or not invited to participate in house to house educations. According to fathers' understanding, the health education seems only to target mothers, not fathers. As a result, there is a knowledge/cultural gap between fathers and mothers.

"Even when we are at home by chance, the health workers only call mothers to attend the education, but sometimes they might tell fathers to look after the baby. We usually get information about child feeding mainly through mothers because majority of the educations are provided for mothers"

The majority of health workers confirmed that most child related educations mainly target mothers, not fathers. Major reasons mentioned by the health workers concerned the fathers' absence in this kind of event or meeting, and fathers' perceptions of considering child care and feeding practices as only the mothers' responsibility. Additionally, fathers being busy with other activities, as a result, fathers did not have time to spend with their child and could not see their child's need, problems and the mother's challenges in the house.

The perception and practice of fathers who consider child care and feeding activities as only the mothers' responsibility, needs to be tackled. 'In order to improve the feeding practice of children, fathers should worry equally about their children, like mothers do which involves: thinking about child food, needs, health, and discussing with mothers about their child.'

"If the father spends more time with his family, he can closely follow his family and feel the real fatherhood that makes him to be more responsible." 
Moreover, attention is needed from health workers to improve fathers' participation in health education programs. Fathers also emphasise that existing programs targeting fathers, should be strengthened, such as rewarding, giving recognition or certifying households who participated in the education programs and changed their children's life because of the education could be a boost.

Again, gender specific cultural and traditional beliefs, such as considering fathers to be the only decision makers in the house, or considering women to know nothing, to stay at home and to listen and respect what the husband says without commenting, and the idea that fathers cannot be challenged by mothers, seem to be gradually changing. However, health workers and fathers underlined that the gender specific beliefs are still something that should be tackled in order to bring both fathers and mother to the same level of understanding through discussion.

\section{Implications for improving fathers' involvement in child care and feeding}

All fathers agreed on the importance of child health related education programs that are provided to both mothers and fathers together. The fathers' opinion was supported by health workers, in that providing education for mothers and fathers together is the ideal approach. This approach may help to get parents to a similar level of understanding of child care and feeding. It also provides a good opportunity to resolve the knowledge and cultural gap, and create a good environment in the house for appropriate child feeding practices.

"Teaching both father and mother together can be an innovative strategy that could bring a paradigm shift in child care and feeding practices .... If the husband makes a promise in front of the mother and care provider (like: I will do this and that or I will improve this and that), there is a high probability of keeping his promises. The same goes for mothers. They could also have similar understanding; this gives a chance to support each other. For example: if the mother has a difficulty of understanding what health workers teach or demonstrate on porridge preparation, the father will remind her, even he could assist her in the preparation process."

Additionally, this format gives mothers a chance to expose their challenges in front of the care providers, who can assist in finding a solution and resolving those challenges on the spot, making the child feeding practice easier. This format also reduces the child caring and feeding burden felt by mothers, especially the financial burden. "......but when you teach the mother alone, she can say what I would do alone because the money is with the father." These might also create a chance for fathers to start taking responsibility in child caring and feeding practices, even in general child care. Additionally, rewarding and certifying households with good performance of child care and feeding practice could be a positive stimulus for fathers. 
Few health workers disagreed on teaching both mothers and fathers together, and most were in favour of the concept. Due to the culture in developing countries that usually many women would feel overshadowed by men and ashamed to talk in front of them. Hence, until this cultural problem is addressed, approaching fathers and mothers separately is suggested by some as a temporary approach.

"Teaching both the mother and the father together and having a discussion with them might be a problem because women are overshadowed by men. They may not ask and/or give answers equally. The solution for this would be to let them discus on their own forum that is with the female development army and then they can express their idea and secrets freely in an open manner. Teaching together might be a solution only after addressing the cultural problems when females start to express their ideas equally to their male counterparts. However, for now teaching them separately is much better."

Despite the time and human resource shortage, house to house education was the first approach mentioned by fathers and health workers. This would provide an opportunity to reach fathers, or even the whole family. Careless and resistant fathers could especially be reached through house to house education. To promote sharing of experiences and the inclusion of all individuals, different meetings in the community were also suggested by both fathers and health workers. However, teaching fathers in a large meeting could suffer disadvantages of low attendance, fathers not taking education seriously and poor concentration. The use of posters, role models and demonstrations were other suggested means of education.

\section{Discussion}

The major themes of this study concerned fathers' experiences of current child care and feeding education, the impact of child care and feeding education, challenges and forwarded solutions, and implications for practice. Second-hand information passed through mothers and posters seemed the main sources of information for fathers on how to care for their children. However, resource-intensive house to house education together with mothers became the primary choice to approach fathers in health education. The main reasons for fathers' lack of involvement in child health education concerned low recognition from health workers, fathers' income generation activities and stereotypical invalid perceptions and beliefs.

In line with previous studies, our findings showed that fathers' perception and understanding toward child care and feeding education have improved. As a result, fathers seemed to be open to health information and advice about child care and feeding $^{21,22}$. However, low encouragement and recognition from health workers 
appeared to be challenges for fathers to become engaged in child care and feeding education ${ }^{12,13}$. This finding is supported by previous studies, showing that health care professionals' low awareness, recognition and appreciation of the positive influence of fathers on child health outcomes were important factors ${ }^{12,13}$.

Getting a father to go to the health centre seems a universal issue. Nevertheless, different observational studies in developed countries have shown that the fathers' involvement in children's life, such as child obesity prevention, improving breast feeding practices, better cognitive development, having a healthy baby and family, a good relationship between parents and reducing economic burden within the family ${ }^{11,14,21,23}$ could be effective approaches, and these areas have become of interest to researchers. This is supported by our finding that all fathers who had exposure to the education programs reported a positive impact on their beliefs, perceptions and knowledge of child foods and child feeding. Steady progress has been reported in understanding and supporting mothers in household activities and their discussion with mothers.

However, studies highlighted the preconditions for effectiveness, such as to create opportunity for fathers to spend time with their child on a regular basis, regular education or multiple exposures to education, to build a system so that a mother and father can participate together, and to mandate enough support and encouragement from health workers. Given these challenges, it seems necessary to plan and develop educational programs based on fathers' interests and opinions.

A limitation of this study is the selection of fathers. All fathers were farmers, so findings are limited to the experiences of farming fathers in these rural areas, and this might skew the representativeness. However, health workers with different personal experiences and professional backgrounds were asked, to increase the credibility of the data. Additionally, different data collection methods, such as in-depth interviews and FGDs were conducted, and field notes were used in the analysis.

Overall, the existing child care and feeding educations are not targeted to fathers, only mothers. Additionally, poor attention from health workers and invalid perceptions and beliefs of fathers toward child care and feeding are major challenges. The theoretical model on improving fathers' child care and feeding practices developed in this study can guide health care workers and designers of community interventions in the development of child health education programs to make them more effective, inclusive and participatory with respect to fathers. Therefore, the house to house education that involves both parents seems to be the ideal approach to reach fathers and improve their role in child care and feeding practice. Additional training for health workers seems mandatory in order to reach fathers.

In general, this approach may lead to reducing the knowledge and cultural gap between fathers and mothers, thereby creating an opportunity to improve mother-father discussions, enhancing fathers' support in financial and other activities, and reduce the child care burden of mothers. Additionally, posters could be an ideal educational tool to 
reach fathers, especially in a country where more than $80 \%$ of the population reside in rural setting with no access to electricity. The effectiveness of such interventions should be further investigated. 


\section{References}

1. Macfadyen A, Swallow V, Santacroce S, Lambert H. Involving fathers in research. J Spec Pediatr Nurs, 2011;16:216-219.

2. Davison KK, Jurkowski JM, Li K, Kranz S, Lawson HA. A childhood obesity intervention developed by families for families: results from a pilot study. Int J Behav Nutr Phys Act 2013;10:3.

3. Neander K, Engström I. Parents' assessment of parent-child interaction interventions - a longitudinal study in 101 families. Child Adolesc Psychiatry Mental Health 2009;3:8.

4. Swallow V, Macfadyen A, Santacroce SJ, Lambert H. Fathers' contributions to the management of their child's long-term medical condition: a narrative review of the literature. Health Expect, 2012;15:157-75.

5. Lowenstein LM, Perrin EM, Berry D, Vu MB, Pullen Davis L, Cai J, et al. Childhood Obesity Prevention: Fathers' Reflections with Healthcare Providers. Child Obes, 2013;9:137-143.

6. Mallan KM, Daniels LA, Nothard M, Nicholson JM, Wilson A, Cameron CM, et al. Dads at the dinner table: A cross-sectional study of Australian fathers' child feeding perceptions and practices. Appetite., 2013.

7. WHO. Children: reducing mortality, in Media center 2012.

8. Black RE, Morris SS, Bryce J. Where and why are 10 million children dying every year? Lancet, 2003; 361:2226-34.

9. WHO. Global Strategy for Infant and Young Child Feeding, in Fifty-third World Health Assembly, Geneva, 2000.

10. WHO. Global Strategy for Infant and Young Child Feeding, Fifty-fourth World Health Assembly, Geneva,2001.

11. Government of the Federal Democratic Republic of Ethiopia. National Nutrition Programme, 2013-1015: Addis Ababa.

12. Moore T, Kotelchuck M. Predictors of Urban fathers' involvement in their child's health care. Pediatrics, 2004;113:574-80.

13. Garfield CF, Isacco A. Fathers and the well-child visit. Pediatrics 2006;117:637-45.

14. Sarkadi A, Kristiansson R, Oberklaid F, Bremberg S. Fathers' involvement and children's developmental outcomes: a systematic review of longitudinal studies. Acta Paediatrica, 2008;97:153-8.

15. Magill-Evans J, Harrison MJ, Rempel G, Slater L. Interventions with fathers of young children: systematic literature review. J Adv Nurs, 2006;55:248-64.

16. Strauss AL, Corbin JM. Basics of qualitative research: grounded theory procedures and techniques. Vol. 270p. 1990, Sage Publications: California.

17. Ministry of Health. Tigray regional Health bureau, Addis Ababa 2011 [Cited on 8/8/2014]. Available at: http://www.moh.gov.et/tigrayhb.

18. Lincoln YS, Guba EG. Naturalistic inquiry. Vol. 146 p. 1985, Sage Publications: California.

19. Matthew B, Huberman A.M, Johnny S. Qualitative Data Analysis: A Methods Sourcebook. 2013, SAGE Publications.

20. ATLAS.ti Scientific Software Development GmbH. Atlas.ti 5.0, 2004: Germany.

21. Sarah J, Letitia K, Rongfang J, Sarah N, Daniel J. Comparisons of levels and predictors of mothers' and fathers' engagement with their preschool aged children. Early Child Dev Care, 2013;183:498-514.

22. Fägerskiöld A. Support of fathers of infants by the child health nurse. Scand J Caring Sci, 2006;20:79-85.

23. Mannion CA, Hobbs AJ, McDonald SW, Tough SC. Maternal perceptions of partner support during breastfeeding. Int Breastfeed J, 2013;8:4. 
Chapter

General discussion 
Chapter 6 


\section{General discussion}

The studies presented in this thesis, using quantitative and qualitative methods, highlighted the poor practices of young child feeding in Ethiopia. The economic and resource-related challenges mentioned in our studies and in previous research have brought fathers' roles in child feeding to attention. Our studies showed that fathers' knowledge and practice in child care and feeding were significantly related to children's feeding practice, indicating the strong influence of the father on child nutrition.

Fathers are variable in their perceptions and practices. We observed traditional fathers, fathers in transition and modern fathers. These fathers differed in their beliefs, perceptions, and practice of child care and feeding. To improve child feeding practice and accelerate the intervention process, intervention programs should take these differences into account, though the critical first step still remains targeting fathers together with mothers in house to house education.

Considering the small number of studies on the fathers' role in young child feeding in developing countries, we are compelled to relate our findings to the existing literature from developed world studies on the father's role in childhood obesity and chronic health problems. One observational study from Australia stated that fathers who were more concerned about their child becoming overweight reported higher perceived responsibility for child feeding and were more controlling of what and how much their child ate ${ }^{1}$. Similarly, a literature review indicated that the father's involvement in children's health care can positively impact the child's well-being ${ }^{2}$. Other observational studies underlined that the active involvement of fathers, such as through observation and playing with the child, has a big contribution to the child's development ${ }^{3-6}$.

Our findings strengthen existing literature, in that the knowledge and active participation of fathers in child care and feeding practice has a significant impact on the child's health. Our findings further promote an appreciation and understanding of the positive impact of fathers' routine involvement in their children's lives. Hence, there is a plausible significant benefit in encouraging fathers to be more involved in their children's life.

A major challenge identified during our studies is the deep-rooted perception by some fathers that child care is only the mother's responsibility. This barrier has been mentioned in other studies about the father's role in child care. For example, a study conducted on fathers' attendance of child care services in Chicago showed that some fathers did not attend child care visits because they perceived child care as only the mother's responsibility ${ }^{7}$. Another study indicated that the fathers' greater time commitment to paid work and earning money probably leads them to perceive that they have less responsibility in routine child care practices ${ }^{1}$. This is in line with our studies. The most commonly reported excuses by fathers for their limited involvement in child care and feeding practices concerned being busy in agriculture and other business activities. 
We feel that the situation in Ethiopia is slightly worse than in modern (developed) countries. For example, in Ethiopia, men and women have clear roles, defined by their gender. Rural families tend to have more gender-specific roles than urban families where mothers are usually responsible for looking after the children and domestic activities. They are usually considered to be subordinate to their husbands, and expected to work at home while fathers work in the field or have a job elsewhere ${ }^{8}$. We feel that activities engaging the father and child, for example, a daddy's day, which is a common practice in developed world where the father takes a day off from work, to take care of the child alone, would be hard to imagine in an Ethiopian setting ${ }^{9}$. Such a day off would not only be very strange for Ethiopian fathers, but mothers would be very reluctant to request it of them. In future, we expect that father involvement will improve if there are corresponding improvements in the Ethiopian economy, work opportunities for mothers and increased exposure to foreign cultures, for example, through the media.

Along with the detailed description of challenges on fathers' involvement in child care and feeding, a clear model from our study has emerged, based on the level of fathers' beliefs, perception and practice of child care and feeding. This model encompasses three categories of fathers: traditional fathers, fathers in transition and modern fathers. The majority of fathers are likely to fall into the categories of traditional fathers and fathers in transition. This model might be used to identify and classify fathers, and to approach fathers with the most appropriate intervention plan, but it will require much effort and work to bring all fathers to the modern level in Ethiopia.

Our study results suggest that a more specific approach is needed to reach fathers, in order to improve their active involvement in child care and feeding. In view of existing literature relevant to our study, one observational study suggested that involving fathers in a group/parenting education was important to improve breast feeding practice $^{10}$. In addition, interventional and observational studies reinforced the importance of fathers' involvement in child health programs, to improve father-child interaction and to improve fathers' skills in interacting with their babies ${ }^{11,12}$. Another study showed that programs designed to involve fathers in decision-making about their children's use of preventive health services has the potential to increase timely immunisation coverage levels ${ }^{13}$. Other studies have highlighted the possible benefits of involving fathers in child health programs ${ }^{3,14,15}$.

Our studies may aid the design of an ideal approach to enhance fathers' practice in child care and feeding, especially for fathers of poor socio-economic status and those who are influenced by different cultural and traditional beliefs. Our studies suggest that involving fathers in house to house education programs together with mothers could be the best method to improve fathers' knowledge and involvement in child care. The high immunisation coverage reported in low income countries confirms the strong influence of fathers who had participated in the decision to send children for immunisations ${ }^{13,16}$. Our findings suggest that house to house education might improve 
father-child interaction, improve their knowledge toward appropriate child feeding and enhance their role as providers of necessary materials and financial support. Moreover, it creates an opportunity to improve mother-father discussions and promotes an active role for fathers in decision making. This in turn may improve child feeding practices and reduce the child care burden from mothers through meeting the child's appropriate diet and needs on a daily basis.

Conducting studies on this topic in the Ethiopian setting is challenging. The profiling of fathers was originally planned to incorporate both fathers' and mothers' opinions. However, this was not possible due to a deep cultural belief that mothers should not talk negatively about their partners. We experienced that, among mothers, disclosing their partners' wrong perceptions and poor child care practices in front of other mothers during the FGD, was not considered appropriate. The majority of mothers preferred to remain quiet during the discussion, or only gave very short responses by referring to the comments of others. According to the literature, this is an important issue in qualitative research and has been described before. Known as 'information cascades', these response patterns occur when, during a group discussion, late responders agree with the remarks of early responders, not just because the late responders think the early responders are right, but also because they perceive their reputation will be damaged if they dissent from the early responders ${ }^{17}$.

Another study has referred to this phenomena as the 'group effect' where, in an unfamiliar situation, we are likely to shape our behaviour to match that of others ${ }^{18}$. During our data collection we witnessed that mothers were giving very short responses by referring to the comments of others, and this resulted in a protective attitude towards their partners' inefficacy. Fortunately, we were also able to discuss the issues with the fathers. Information from fathers about this issue in detail in a low-income setting is scarce, thus we were very happy with the rich data we obtained from the fathers in our interviews and FGDs.

FGDs and in-depth interviews were the predominant methods used to obtain data. Considering the limited existing research on our topic of interest and the absence of validated questionnaires on the concept we wanted to measure, we considered the use of FGDs and in-depth interviews as appropriate. However, it is undeniable that this approach may have affected the validity of our results. A selection bias might have occurred, as our selection of fathers and mothers of under-two children was obtained through health providers, participating to the FGDs and in-depth interviews. Those selected may have already had good knowledge and practices of child care and this may affect the representativeness of the data. However, the broad range of participants, including several health workers with different personal experiences and professional backgrounds may have reduced any possible bias.

Open-ended questions in our cross-sectional study were targeted to minimise socially desirable answers. This may have caused a recall bias, though we do not expect it to have a significant impact because of our use of questionnaires of 24 hour and less than 
a month recall. Therefore, we do not expect that the observed associations would be different. Given the broad cultural diversity and traditions of the Ethiopian population, only a relatively small proportion of the country took part in our study, and therefore the results may not be generalisable to the whole of Ethiopia. However, we believe the role of fathers in child care is a universal issue. This study provides important groundwork for a future intervention study on targeting fathers in child care.

Apart from obtaining correct information from participants, data collection itself was a significant challenge: rural houses can lie very far apart, and recruiting the fathers for the interview proved difficult. We chose to conduct the interviews at their houses, and this seemed the right place to speak both mothers and fathers. However, fathers were often away from home, for work/farming/business and dealing with external family. As a result, it was often not possible to have fathers present at the first visit, so data collectors had to visit households several times to get all the data. Considering the widely dispersed housing in rural districts, the data collection process was tiresome and time-taking. Given that fathers were not always available for visits, we were obliged to do more visits to get the information from fathers, and for this reason we had to budget more money and time than initially planned. However, we succeeded in getting the information we needed.

Child health studies and programs which have been targeted to mothers have changed child health in Ethiopia in recent decades. However, we believe that people have been unaware of the direct and indirect impact of fathers on the interventions that have been targeted toward mothers. Previous studies only provided a global suggestion to involve fathers in the future studies or intervention plans. Conversely, our studies show not only the importance of father involvement, but provide insight to researchers and programmers of child intervention programmes to appreciate the significant role of fathers in child feeding practice, and include them in the design of future interventions. In strengthening the limited evidence of fathers' involvement in child care practices and challenges, our studies contribute to the model of classifying fathers into three categories: traditional fathers, fathers in transition and modern fathers. This model can help programmers to identify and classify fathers according to their beliefs, perception and practice. This might aid the design of clear intervention plans for each group of fathers, and provide the most appropriate intervention for their respective needs.

Improving fathers' knowledge of child care and feeding, by targeting fathers as well as mothers in house to house education programs, could be a worthwhile approach for meeting the requirements for satisfactory child feeding practices. Other essential objectives include increasing father-child interaction, father-mother discussion, and enhancing the active involvement of fathers in the provision of necessary items and financial support for the child.

Fathers should be approached in a way that is suitable to their level of understanding and challenges. The existing educational programs and approaches are designed to mainly target mothers, without knowing fathers' level of understanding and challenges 
of child care and feeding ${ }^{19}$. Therefore, the overall goal of future interventions should be to improve fathers' knowledge, perceptions and practices towards child care and feeding, in order to increase fathers' involvement in child care and feeding practices. Future education programs require a strong collaboration between health workers and health policy makers in creating a welcoming environment for fathers. These programs should make them feel responsible for their children's life.

The target group should be fathers of children 6 to 24 months old, since fathers are the main source of income in many households. The economic and resource-related challenges mentioned in our studies and in previous research also emphasise the important role of the father. The intended intervention should also target the mothers, since mothers are the main providers of food and child care in many households. Future interventions should be integrated into the existing system. In Ethiopia, that would be the innovative community-based strategy of using Health Extension Workers (HEWs) and the Health Development Army (HDA), recently introduced by the Ethiopian government $^{19}$. The HEWs and the HDA should increase the health care awareness through participatory learning and action meetings in villages and households. Child feeding is one of the topics being taught by HEWs and the HDA in every rural household in Ethiopia. However, the health workers and health supervisors should be trained on the intervention that we are intended to do. Additionally, the district health centres and health posts should support the program and should evaluate how such a project benefits the community.

House to house education about child care and feeding should be designed for each category of fathers (traditional fathers, fathers in transition and modern fathers). Checklists should be developed to assess the fathers' knowledge, perceptions, practices and challenges of child care and feeding by using our model, prior to the intervention. Therefore, every father should get the education that is targeted to their level of beliefs, perceptions, and practice of child care and feeding.

For instance, traditional fathers strongly perceive that child care is only the responsibilities of mothers, and they only feel responsible for making money. We believe that traditional fathers should receive basic education that could challenge their strong beliefs and perception of child care, and could help them to start being involved in child care practices. For example, teaching them how being involved in their child's life on a routine basis could help them to understand their child's needs and challenges. Further, being more involved in their child's life could stimulate fathers to work more to provide the child with necessary items. This group of fathers need an easy pathway to start being involved in child care practices.

Fathers in transition perceive child care as being both the mothers' and fathers' responsibility. They are, however, selective on the activities they do, and make excuses for the very limited involvement in their children's lives. This group should receive education that could strengthen their positive perception toward child care, and generate opportunities to increase their involvement in child care practices. 
Modern fathers are the most advanced in terms of fathers' involvement in child care. They perceive child care as a shared responsibility between mothers and fathers, although they have minor challenges to put their knowledge into practice. This group should not receive basic education about child care responsibility, and they do not need pressure to participate in child care on a daily basis. They already have a good perception and knowledge about child care and feeding, and are also very involved in their child's life. Therefore, they should only receive education to advance their knowledge, or provide professional support to solve any minor challenges faced in practicing child care and feeding.

To strengthen the education programs, a group discussion involving the father, mother and health worker should be carried out, on the specific challenges that limit the father from practicing child care in routine basis. These challenges might differ from father to father. Therefore, discussing them along with possible solutions should help to improve the practice of fathers in child care and feeding. The discussion should be supported by giving assignments for fathers based on the proposed solutions that were mentioned by both father and mother. Follow-up visits should also be scheduled with the health worker, to continue advancing fathers' knowledge through house to house education and work activity monitoring.

Intervention programs should be evaluated using different indicators, including fathers' knowledge of child feeding, fathers' practices in child care and feeding, and infant and young child feeding practices. At the end of the intervention, we would expect fathers' knowledge, perceptions and involvement in child care and feeding to have improved. The ultimate goal of increasing fathers' involvement in child care is to improve infant and young child feeding practices and reduce malnutrition among young children. Therefore, indicators of infant and young child feeding should be measured. Dietary diversity and other indicators of infant and young child feeding practices should be measured before and after the intervention using the WHO standard indicators, Minimum Meal frequency and Minimal Acceptable Diet ${ }^{20}$.

We believe that participatory research interventions are an ideal method to evaluate our intervention plan. This format provides a chance for the participants to have control over the intervention, both in the process and actions. This approach is also suitable to incorporate all the important components that we intended, such as inquiring, discussion and decision ${ }^{21,22}$. Therefore, this research approach would be appropriate in reaching our objective: to improve fathers' knowledge, perceptions and practices towards child care and feeding, and to increase fathers' involvement in child care and feeding practices. 


\section{References}

1. Mallan KM, Daniels LA, Nothard M, Nicholson JM, Wilson A, Cameron CM, et al. Dads at the dinner table: A cross-sectional study of Australian fathers' child feeding perceptions and practices. Appetite 2013.

2. Swallow V, Macfadyen A, Santacroce SJ, Lambert H. Fathers' contributions to the management of their child's long-term medical condition: a narrative review of the literature. Health Expect, 2012;15:157-75.

3. Magill EJ, Harrison MJ, Rempel G, Slater L. Interventions with fathers of young children: systematic literature review. J Adv Nurs, 2006;55:248-64.

4. Sarkadi A, Kristiansson R, Oberklaid F, Bremberg S. Fathers' involvement and children's developmental outcomes: a systematic review of longitudinal studies. Acta Paediatrica, 2008;97:153-8.

5. Dubowitz T, Levinson D, Peterman JN, Verma G, Jacob S, Schultink W. Intensifying efforts to reduce child malnutrition in India: an evaluation of the Dular program in Jharkhand, India. Food Nutr Bull, 2007;28:266-73.

6. Tamis-Lemonda CS, Shannon JD, Cabrera NJ, Lamb ME. Fathers and mothers at play with their 2- and 3year-olds: contributions to language and cognitive development. Child Dev, 2004;75:1806-20.

7. Garfield CF, Isacco A. Fathers and the well-child visit. Pediatrics, 2006;117:637-45.

8. JRank. Africa-Middle east. Countries and Thier culture [Cited 2015 Jan 1]. Available from: http://www.everyculture.com/Cr-Ga/Ethiopia.html.

9. Hauari H, Hollingworth K. Understanding fathering in Britain today. Pract Midwife, 2012; 15(7):13-5.

10. Engebretsen IM, Moland KM, Nankunda J, Karamagi CA, Tylleskär T, Tumwine JK. Gendered perceptions on infant feeding in Eastern Uganda: continued need for exclusive breastfeeding support. Int Breastfeed J, 2010;5:13.

11. Benzies K, Magill-Evans J, Harrison MJ, MacPhail S, Kimak C. Strengthening new fathers' skills in interaction with their 5-month-old infants: who benefits from a brief intervention? Public Health Nurs, 2008;25:431-9.

12. Doherty WJ, Erickson MF, LaRossa R. An intervention to increase father involvement and skills with infants during the transition to parenthood. J Fam Psychol, 2006;20:438-47.

13. Brugha RF, Kevany JP, Swan AV. An investigation of the role of fathers in immunisation uptake. Int J Epidemiol, 1996;25:840-5.

14. Mbekenga CK, Pembe AB, Christensson K, Darj E, Olsson P. Informal support to first-parents after childbirth: a qualitative study in low-income suburbs of Dar es Salaam, Tanzania. BMC Pregnancy Childbirth, 2011;11;98.

15. Lu H, Zhu X, Hou R, Wang DH, Zhang HJ, While A. Chinese family adaptation during the postpartum period and its influencing factors: A questionnaire survey. Midwifery, 2012;28:222-7.

16. Oyo-Ita A, Nwachukwu CE, Oringanje C, Meremikwu MM. Interventions for improving coverage of child immunisation in low- and middle-income countries. Cochrane Database Syst Rev, 2011;7.

17. Easley D, Kleinberg J. From the book Networks, Crowds, and Markets:Reasoning about a Highly Connected World, in Cambridge University Press, 2010.

18. Wooten DB. Informational influence and the ambiguity of product experience: Order effects on the weighting of evidence. Journal of Consumer Psychology, 1998;7:1.

19. Government of the Federal Democratic Republic of Ethiopia. National Nutrition Programme, 20131015: Addis Ababa.

20. WHO. Indicators for Assessing Infant and Young Child Feeding Practices. Part III: Country Profiles, Geneva, 2010.

21. Cornwall A, Jewkes R. What is participatory research? Soc Sci Med, 2010;41(12):1667-76.

22. Härter M, Müller H, Dirmaier J, Donner-Banzhoff N, Bieber C, Eich W. Patient participation and shared decision making in Germany-history, agents and current transfer to practice. Z Evid Fortbild Qual Gesundhwes, 2011;105(4):263-70. 
Summary 


\section{Summary}

Chapter 1 introduces the child feeding practice and fathers' role in the context of developed and developing countries. Knowing the extent of fathers' involvement and the challenges of child care in real world practice is essential and a prerequisite for future intervention planning. Therefore, the purpose of this thesis is to assess fathers' knowledge, perception and practice in relation to child care and child feeding, and the challenges associated with it through the following research questions:

1) What are the important factors of child feeding practice?

2) What is the impact of fathers' knowledge and practices of child care on child feeding?

3) What are the challenges of fathers in child care and feeding practices?

4) How can fathers' involvement in child feeding practice be improved?

Chapter 2 covers a descriptive qualitative study carried out from April to September 2011. Focus group discussions and in-depth interviews were conducted among mothers and health workers who participated in the Growth and Monitoring Programme (GMP). GMP is a nutritional intervention that measures and charts the weight of children and uses this information to counsel parents so that they can take action to improve child growth. Data were analyzed using a qualitative content analysis technique. The results suggest that most mothers were aware of the need for regular weight monitoring, while health workers also seemed to be well-aware and practice GMP according to the international guidelines. Regardless of whether a well-functioning GMP programme is in place, current evidence drives us to suspect poor child-feeding practices, due to a lack of awareness, knowledge, beliefs, way of life, and poverty. Moreover, the role of the husband/father was not always supportive of proper child-feeding. A GMP is unlikely to succeed if mothers lack awareness of proper child-feeding practices, and if they are not supported by their husbands/fathers.

The influence of fathers' child feeding knowledge and practice on children's dietary diversity was assessed using a community-based comparative cross-sectional study, and presented in Chapter 3. A total of 850 eligible urban and rural households with children of 6-23 months participated. The mother and father of the child were interviewed on children's dietary diversity and fathers' knowledge and practice of child feeding. Nearly half (46\%) of the children in the rural district did not meet the minimum dietary diversity, and in the urban district, the rate was even worse (72\%). Grains were the common food group given to the children in both districts, whereas flesh food was the least commonly consumed food group. Additionally, low vitamin A-rich food and other fruit and vegetable consumption were a problem in both districts. Almost all dimensions of fathers' knowledge and practice were significantly related to children's 
minimum dietary diversity, indicating the strong influence of the father on child nutrition.

In Chapter 4, the extent of fathers' involvement and challenges in child care and feeding practices were studied using a qualitative study among fathers and mothers who have children between 6 to 23 months. In-depth interviews and focus group discussions were carried out. A thematic analysis was completed to identify emergent themes within the data. Fathers' perceptions and practices of routine child care and feeding seemed to have improved on the past. However, apart from income-generation and providing necessary items for the child, the majority of fathers still fully or partially perceived routine child care and feeding practice as being the mothers' responsibilities. Being busy with work, lack of knowledge, traditional beliefs and financial reasons held fathers back from practicing routine child care and feeding. Our findings provide new insight to the literature in dividing fathers into three different categories: traditional fathers, fathers in transition and modern fathers, based on their beliefs, perceptions, practice and challenges of child care and feeding. This model could help researchers, programmers, policy makers and health workers to approach and target fathers. Our findings suggest that targeting fathers may be a worthwhile approach and that it seems justifiable to plan interventions involving fathers. However, assessing fathers' experiences in child health-related education programs is an important prerequisite for any intervention plan.

More qualitative findings on fathers' experience in relation to young child feeding education are presented in Chapter 5. Fathers and health workers participated in the study, and both in-depth interviews and focus group discussions were carried out in the rural Tigray region of Northern Ethiopia. The main reasons for fathers not being involved in child health education concerned low attention and poor recognition given to them by health workers. Other challenges faced by fathers concerned being busy in income generation activities and their perception of child health education. Despite obstacles including cost, distances and cultural difficulties, our study suggests that house to house education involving both the father and mother could be an ideal approach to reach fathers. Additionally, health workers and policies should make fathers feel they are welcome and responsible in their children's lives. Improvements in father-child interaction seem to also have a positive effect on the father-child relationship. However, the effectiveness of interventions such as house to house education should be investigated to determine if child feeding practices can improve as a result of educating fathers in the company of mothers.

Finally in Chapter 6, major findings are compared and discussed in relation to existing knowledge. Conclusions were drawn that house to house education program came out to be a worthwhile approach in order to meet all children's appropriate feeding 
practices through improving fathers' knowledge toward child care and feeding. Increasing father-child interaction, father-mother discussions and enhancing the active involvement of fathers' in the provision of necessary things for the child development were considered mandatory. Continued collaboration of family, community health workers and other health workers is essential to support fathers' involvement and improve child health outcomes. Moreover, creating a welcoming program and policy for fathers and making them feel responsible in their child's life is something that should be reminded to the health workers and health policy makers. Lastly, in this chapter, approaches that could raise questions regarding the validity of our study were discussed and justified accordingly. These included the predominant use of FGDs and in-depth interviews due to the limited evidence and absence of validated questions on our topic, open ended questions that were used in the cross sectional study targeted to minimise socially desirable answers, and potential representation bias in respect to our sample size and selection process. 
"qm,\$तP (Summary in Amharic) 


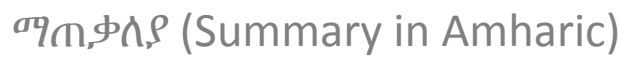

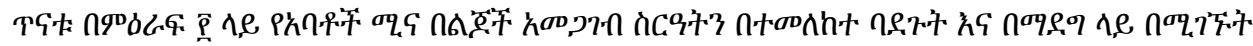

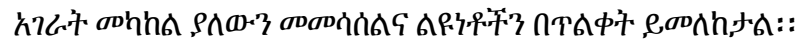

П74.

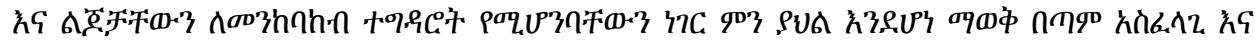

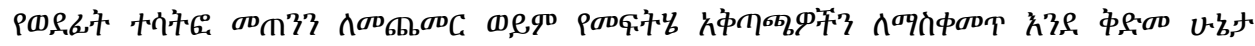

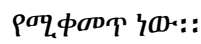

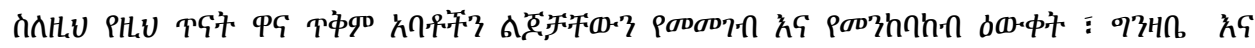

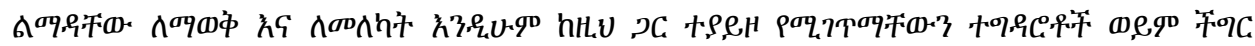

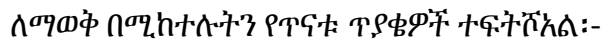

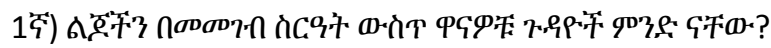

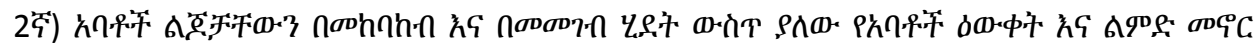

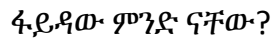

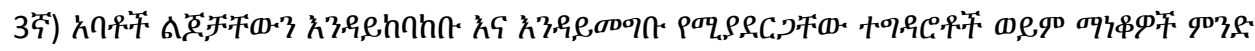
STo-?

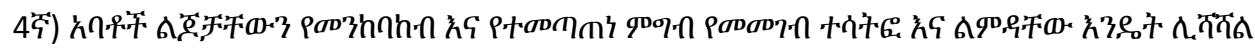

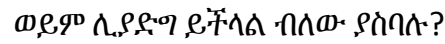

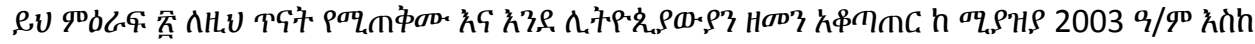

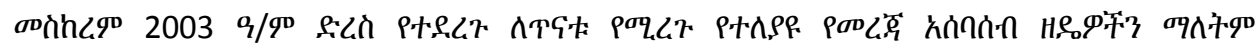

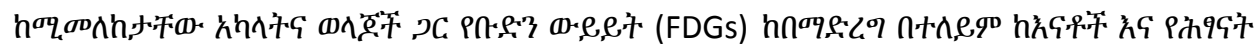

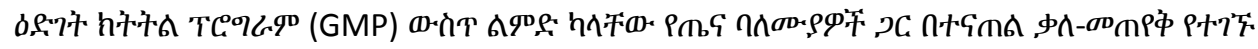

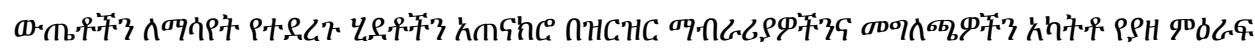

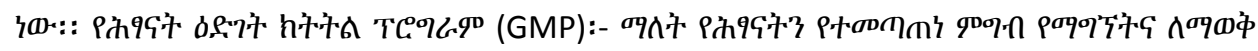

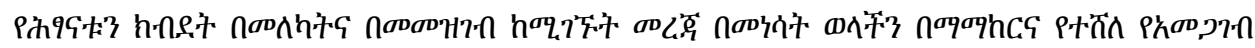

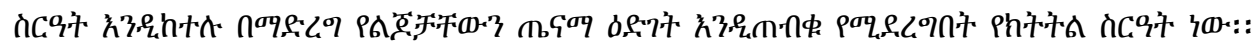

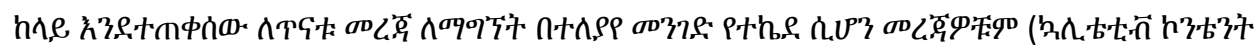

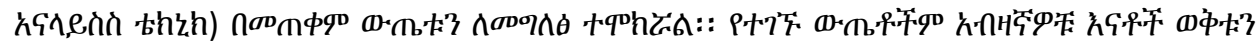

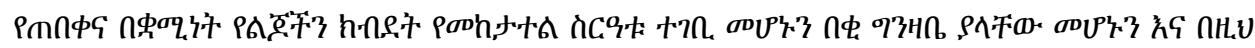

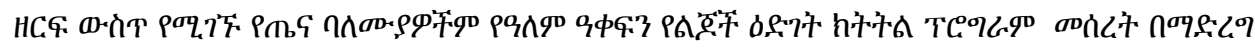

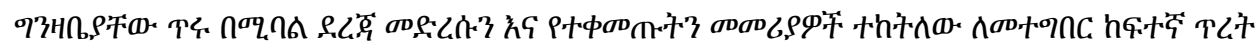

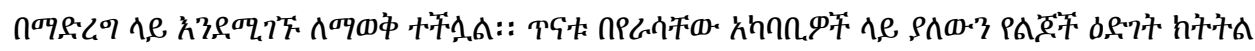

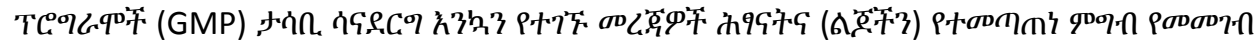

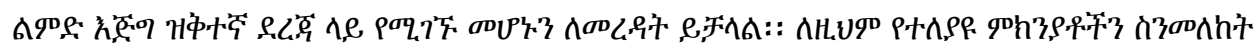

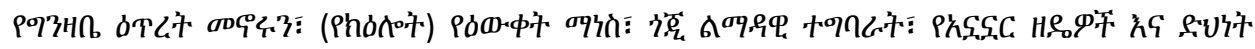

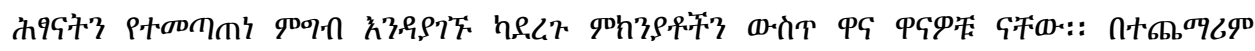

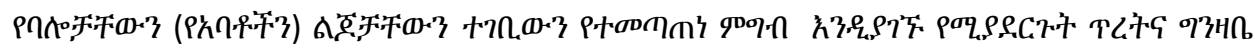

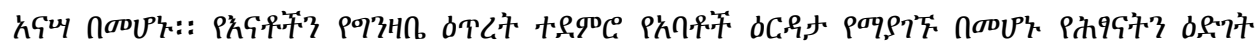

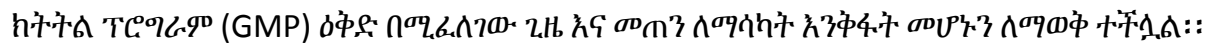




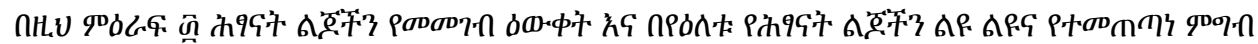

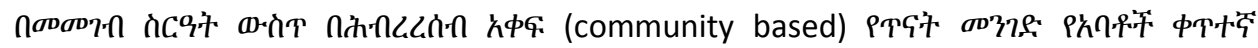

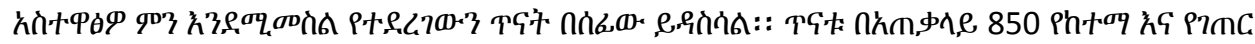

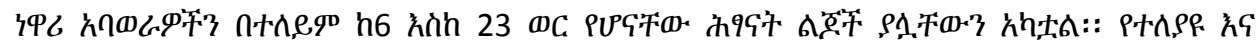

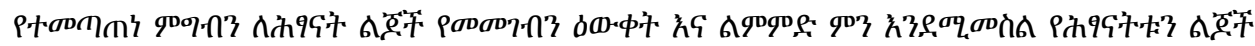

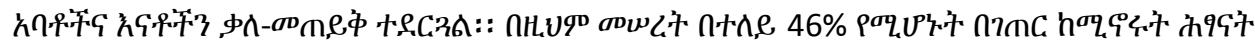

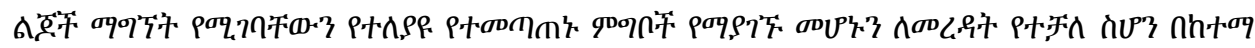

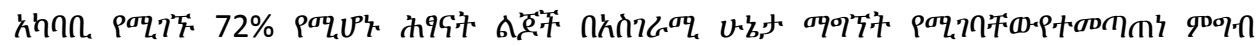

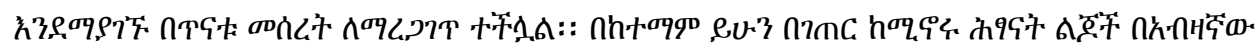

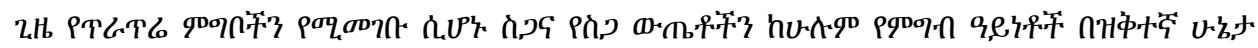

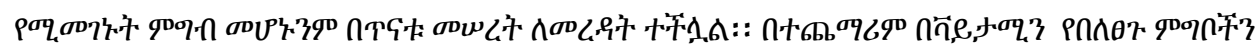

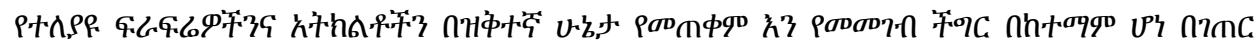

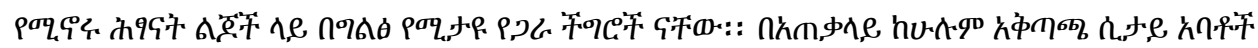

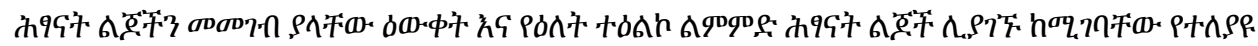

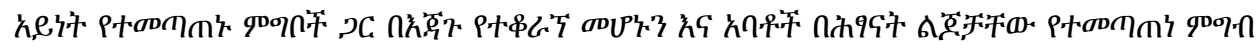

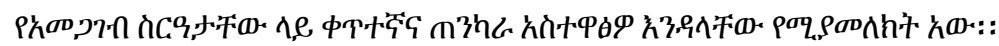

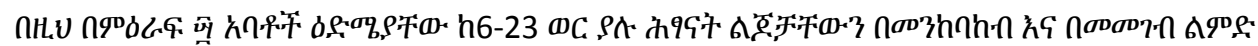

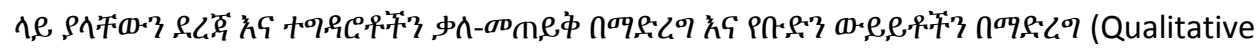

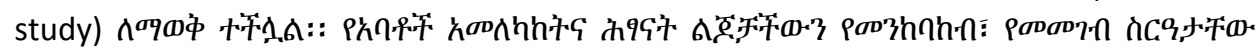

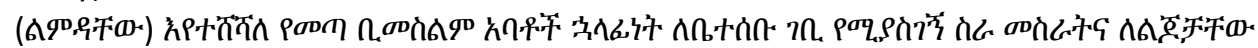

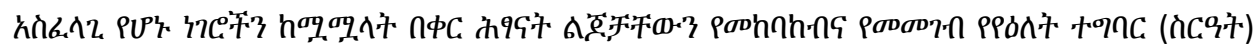

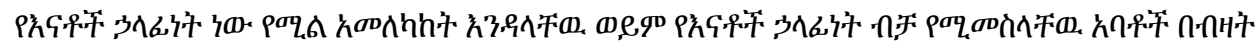

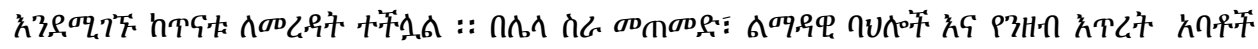

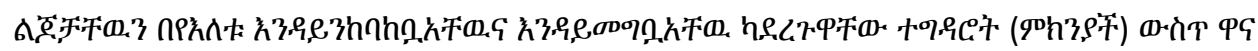

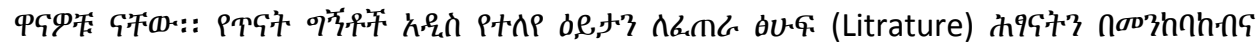

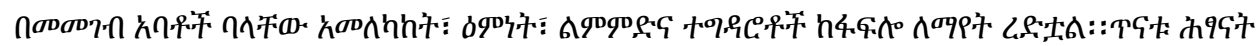

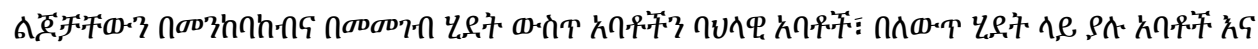

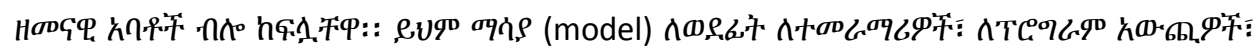

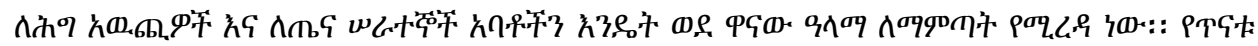

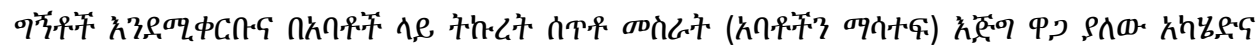

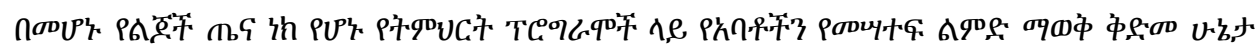

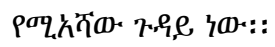

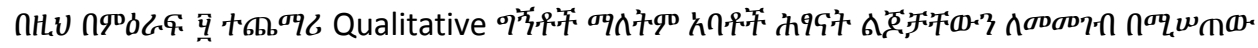

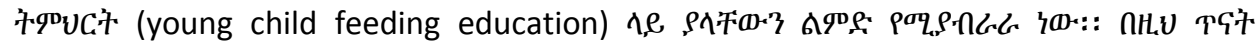

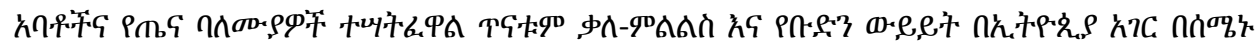

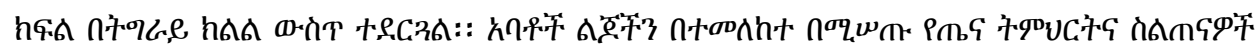
入,

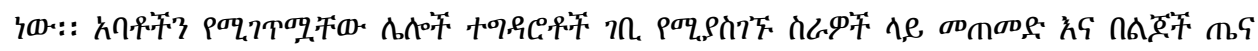
市 


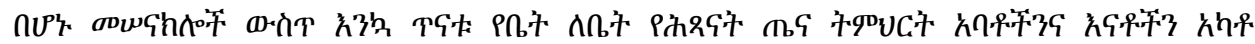

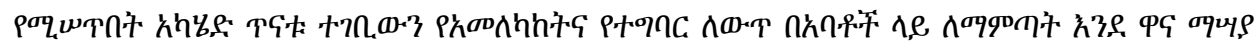

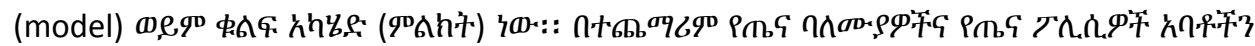

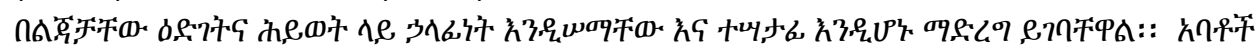

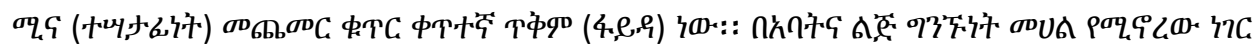

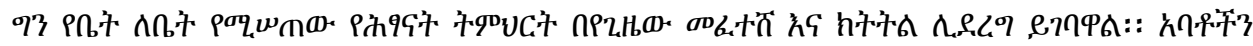
वัก+

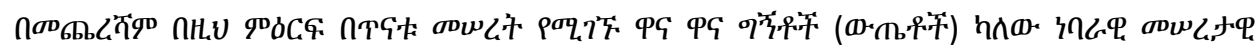

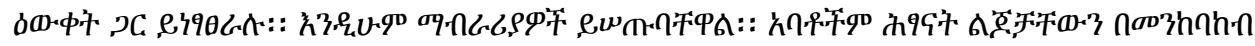

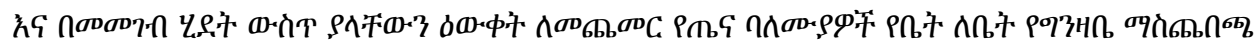

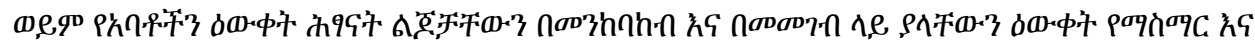

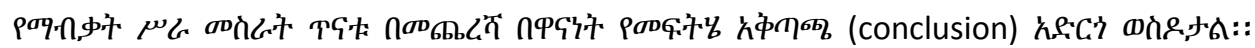

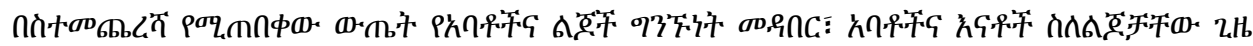

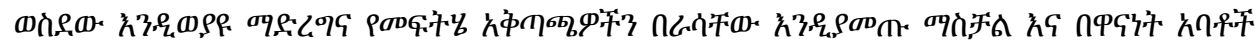

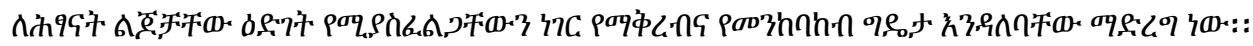

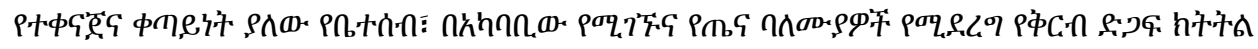

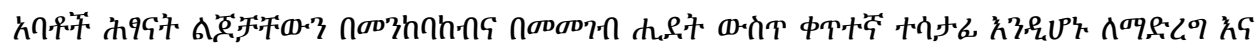

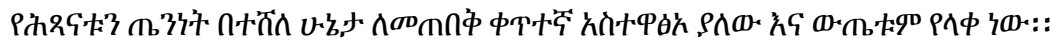

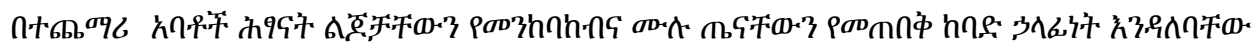

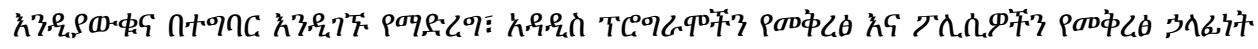

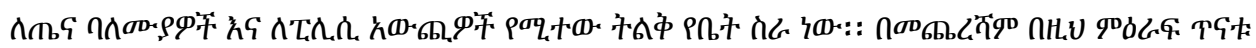
n+hל,

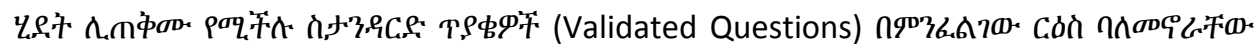

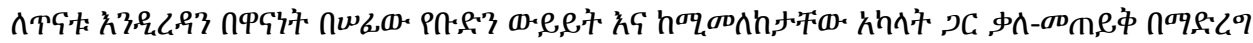

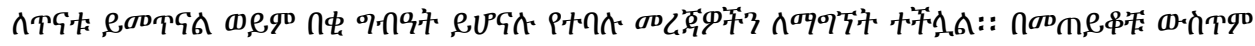

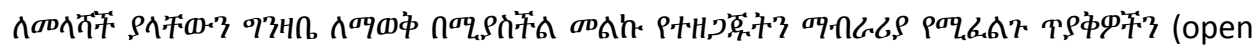

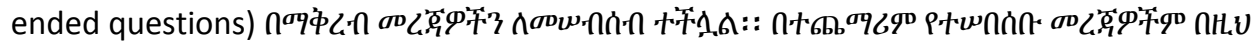

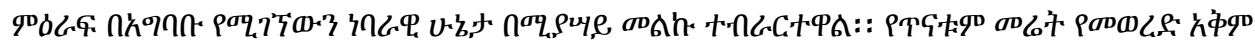

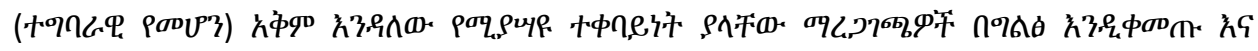

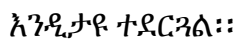




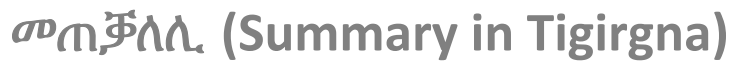




\section{${ }^{\boldsymbol{m}} \boldsymbol{m}, \Phi \Lambda \Lambda$ (Summary in Tigirgna)}

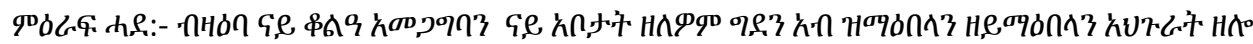

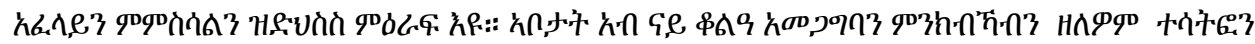

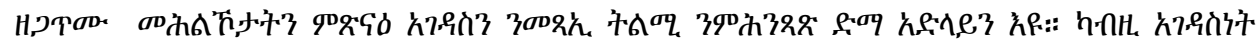

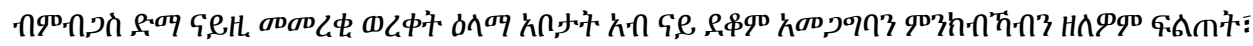

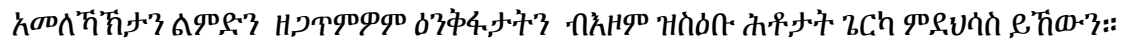

द, \$ล9 久

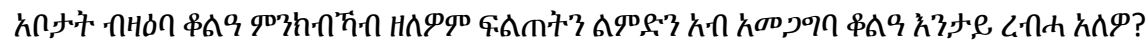

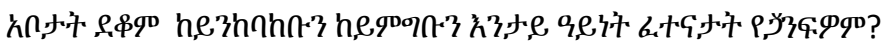

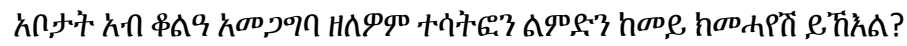

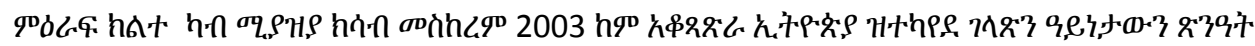

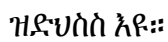

Ge r.

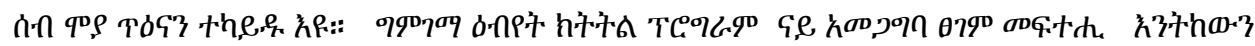

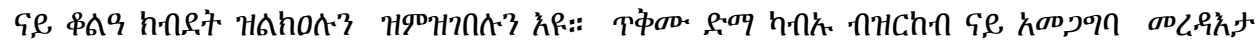

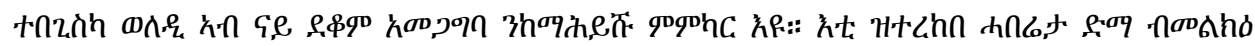

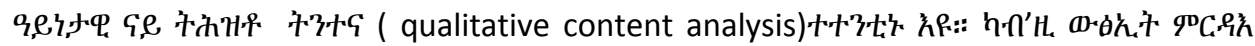

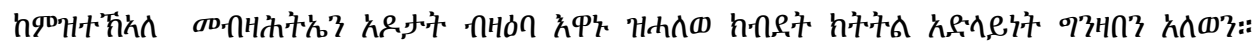

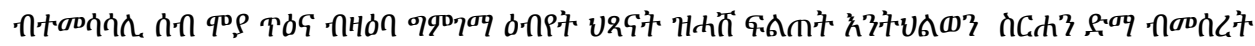

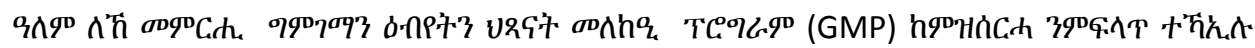

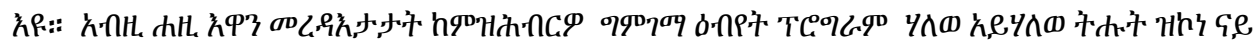

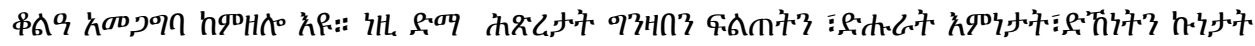

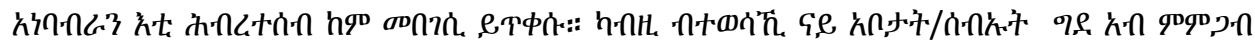

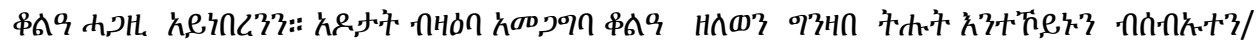

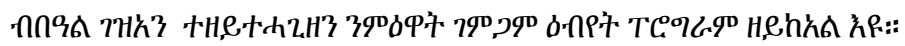

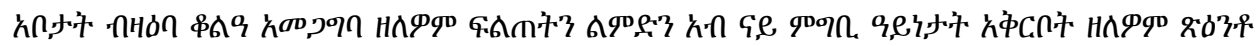

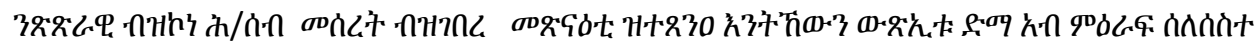

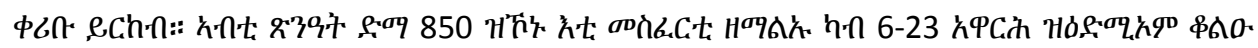

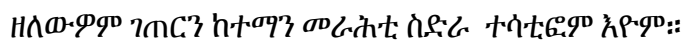

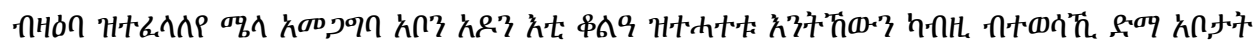

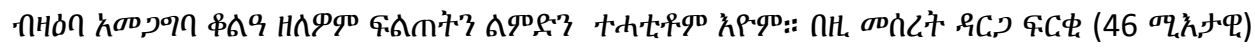

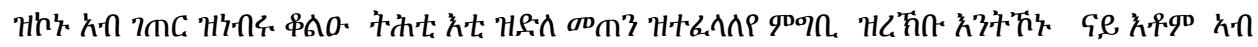

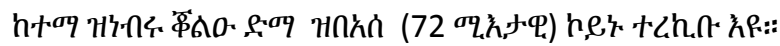

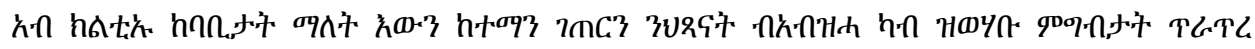

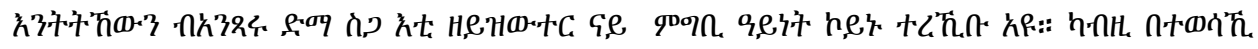

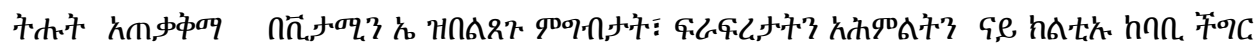

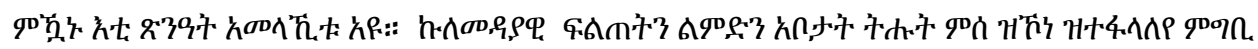

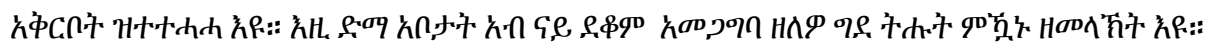




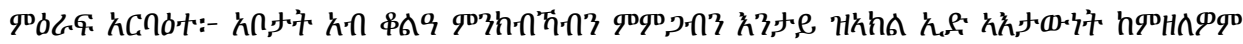

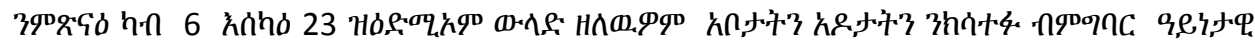

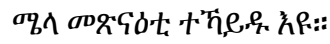

'九nt.

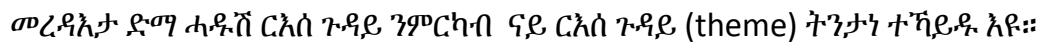

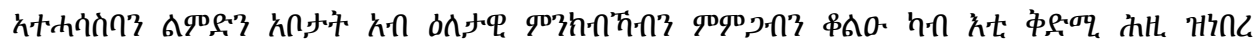

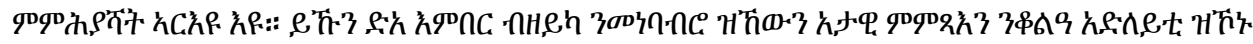

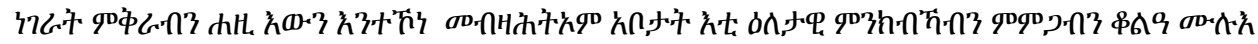

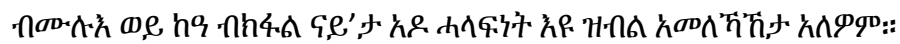

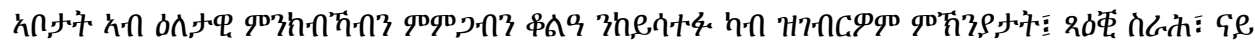

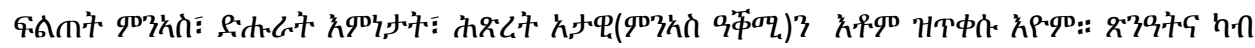

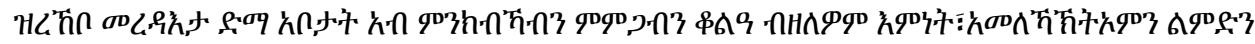

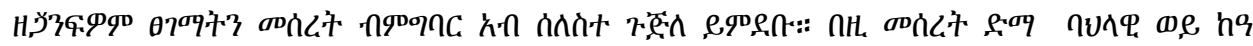

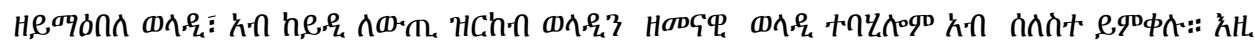

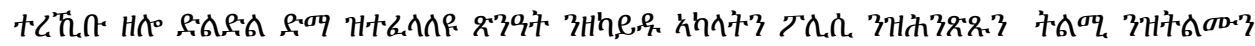

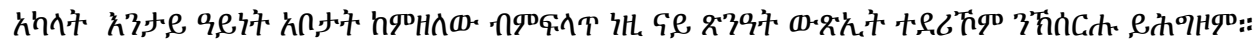

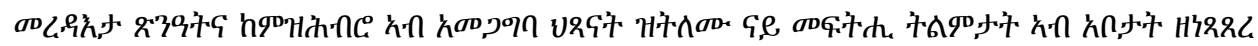

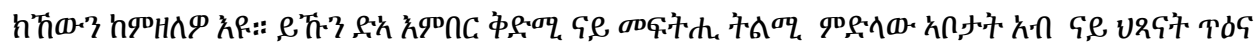

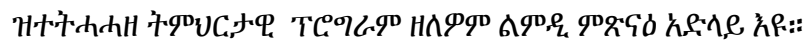

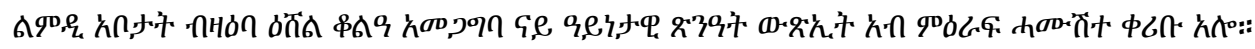

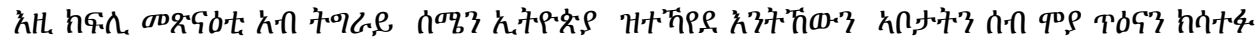

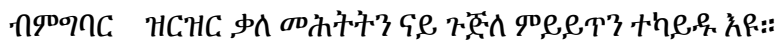

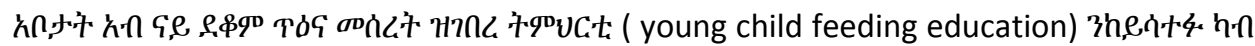

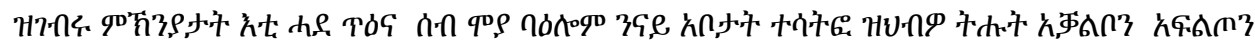
h90

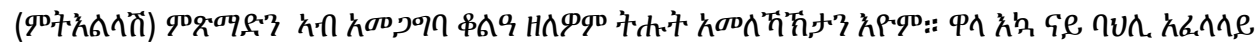

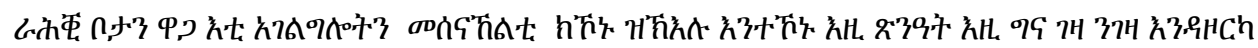

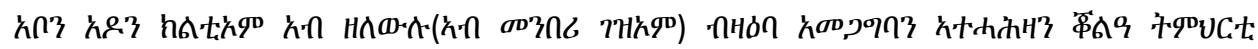

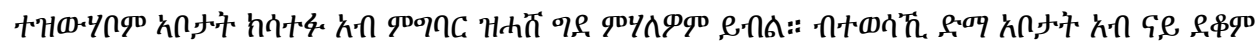

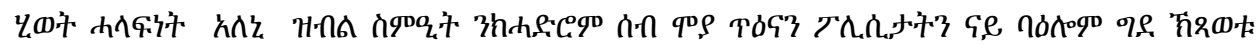

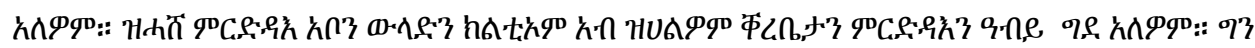
е.व

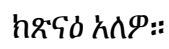

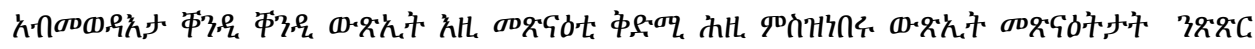

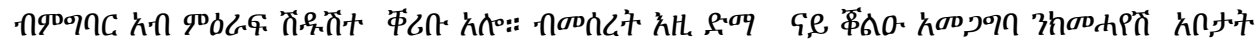

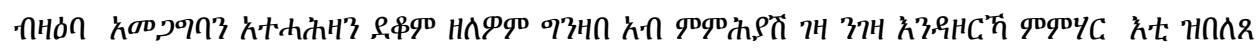

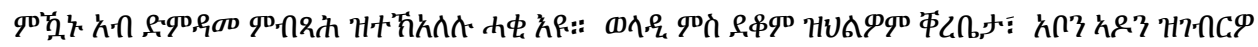

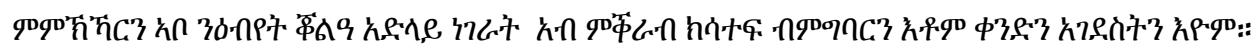

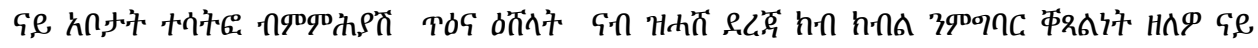

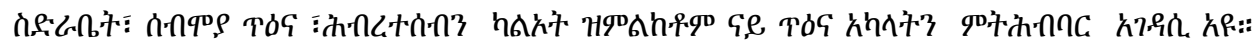




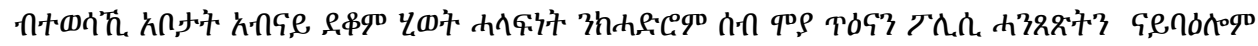

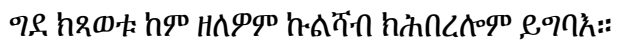

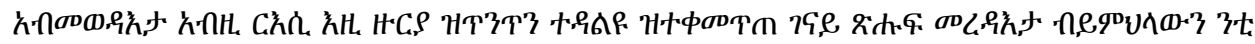

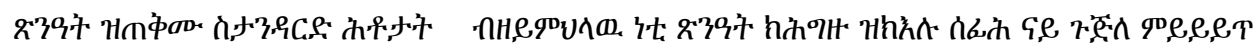

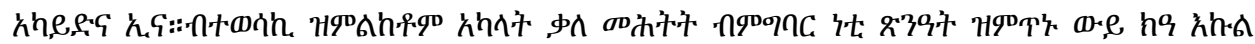

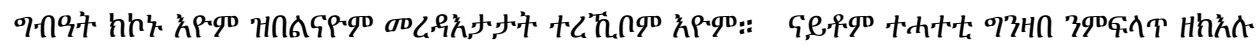

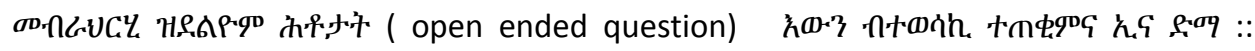

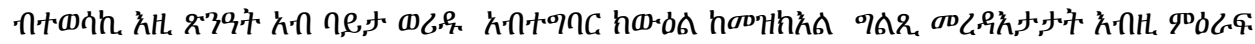

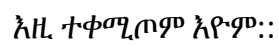


Resume (Summary in Spanish) 


\section{Resume (Summary in Spanish)}

En el Capítulo 1 desarrollamos la hipotesis sobre la influencia significativa de los padres en la alimentación infantil en el contexto de los países en desarrollo. El objetivo principal de esta tesis es evaluar los conocimientos, habilidades y actitudes de los padres respecto el cuidado y la alimentación del niño, analizando especialmente: 1) los desafíos y barreras familiares más significativos que influyen en las pautas de alimentación infantil; 2) el impacto de los conocimientos y actitudes del padre en el cuidado y la alimentación del niño; 3) las posibles intervenciones que puedan mejorar la participación; 4) de los padres en la alimentación del niño.

El Capítulo 2 plantea un estudio cualitativo y descriptivo sobre la participación y actitud de los padres en la alimentación infantil. Para ello, realizamos discusiones en grupos (focus groups) y entrevistas en profundidad entre las madres y profesionales de salud primaria que participaban en el programa de salud comunitario GMP (Growth monitoring programme). Este programa es una intervención en la que mide y registra el peso de los niños de forma sistemática y se utiliza esta información para orientar a los padres para tomar medidas que mejoren el crecimiento del niño. Los datos obtenidos fueron analizados utilizando técnicas de análisis cualitativo. Nuestros resultados indicaron que la mayoría de las madres y de los profesionales de salud estaban bien informados sobre la necesidad de un seguimiento regular del peso. Sin embargo, se observaron importantes desafíos y barreras para la correcta implementación de unas correctas prácticas de alimentación infantil debidas, esencialmente, a la falta de conocimiento, las creencias personales, la pobreza y el papel pasivo o negativo del padre.

En el Capitulo 3 analizamos, mediante un estudio transversal comparativo, la influencia de los conocimientos y actitudes de los padres en la diversidad de la alimentación infantil. Para ello, se trabajó con una muestra de 850 hogares, en áreas urbanas y rurales, con niños de edad entre 6 a 23 meses, en los que entrevistamos a las madres y padres sobre los conocimientos y actitudes sobre la la dieta de sus hijos. Nuestros resultados mostraron que casi la mitad (46\%) de los niños en las áreas rurales no contaban con una dieta diversa, y este desconocimiento fué aún peor (72\%) en las áreas urbanas. Los granos eran el grupo de alimentos más frecuente en ambos distritos, mientras la carne era el menos consumido. Las frutas y verduras tambien tenían una baja presencia en la dieta en ambos distritos. Casi todas las dimensiones del conocimiento y las prácticas del padre se corelacionaron significativamente con la diversidad de la dieta de los niños, sugiriendo una influencia significativa del padre en la nutrición de sus hijos. 
En el Capítulo 4, estudiamos, mediante un estudio cualitativo entre familias con niños entre 6 a 23 meses, los principales desafíos y bareras para la participación de los padres en las buenas prácticas de alimentación de sus hijos. Para ello, realizamos entrevistas individuales en profundidad y en grupos y, posteriormente un análisis temático de los datos recogidos para identificar temas emergentes. Nuestros resultados indicaron que aunque diversas percepciones y actitudes de los padres respecto a la alimentación padres habían mejorado respecto el pasado, la mayoría de los padres seguían percibiendo que el cuidado infantil y la alimentación de los niños eran responsabilidad de las madres. Las principales justificaciones de los padres al respecto estaban relacionadas con el hecho de estar demasiado ocupados con el trabajo, la falta de conocimientos, las creencias tradicionales y razones financieras. Todos estos datos nos permitió clasificar a los padres, atendiendo a sus percepciones, prácticas y actitudes respecto al cuidado y la alimentación de sus hijos, en tres grupos: padres tradicionales, en transición y modernos. Este modelo puede ser útil para los responsables de salud para diseñar intervenciones comunitarias específicas que mejoren las actitudes y conocimiento de los padres sobre la nutrición de sus hijos.

En el Capítulo 5 se presenta una serie de resultados y analisis cualitativos en relación a la educación de los padres sobre la alimentación infantil. Los datos se obtuvieron tambien a partir de entrevistas individuales y de grupos entre padres y profesionales de salud primaria en el norte de Etiopía (Tigray). Nuestros resultados sugerían que las principales razones de los padres para no estar involucrados en la educación de la salud infantil estaban relacionadas con el escaso reconocimiento que los profesionales de salud les ofrecían, además del poco tiempo que los padres disponen para sus familias y su escasa educación sobre salud infantil.

En el Capítulo 6, se analizan en conjunto los principales resultados de nuestros estudios, discutiéndolos con los datos publicados en la literatura y se proponen diversas intervenciones comunitarias. Asimismo, se discuten las metodologías utilizadas para estos estudios, como las entrevistas en profundidad y en grupos y el proceso de selección de los participantes. Se discute como una participación comunitaria más activa y dirigida específicamente hacia los padres para mejorar sus conocimientos y actitudes sobre nutrición infantil puede ser un factor clave para mejorar la desnutrición en estas comunidades. Se sugiere que la colaboración estrecha entre las familias y los profesionales de salud primaria es esencial para mejorar la participación de los padres en la mejora de los parámetros de salud infantil. 
Valorisation 


\section{Valorisation: Practical implication of the finding}

The findings of the research presented in this thesis could have important implications for child feeding, fathers' and mothers' involvement in raising children, and the child health care system. Specific implications of the findings of each study are discussed in the respective chapters. Here we summarized the overall implications of the major findings in this thesis.

\section{Implications for infant and young child feeding (IYCF) practice}

IYCF practice is one of the health activities that could contribute towards reaching the Millennium Development Goals of halving hunger and reducing child mortality by twothirds in 2015. IYCF practice gives primary focus to children below the age of two years and is usually targeted through mothers. Despite the fact that fathers are also primary caregivers, like mothers, and are also very important in improving child health, most child health services do not involve fathers. The fathers' role is especially relevant in developing countries, where household income generation and decision-making are mainly controlled by fathers. Our findings show the importance of involving the fathers in child care services, and confirmed that fathers' knowledge and practice towards childcare and feeding can have a direct impact on child feeding and thus child health. This indicates the strong influence of the father on child nutrition. Therefore, involving fathers in child health program is very likely to succeed quickly than programs that only targeted through mothers.

\section{Implications for improving fathers' involvement in child care practices}

Our study showed that improving fathers' knowledge and practice could be a prerequisite to meet children's appropriate feeding. However, wrong perceptions, traditional beliefs, being busy with other activities and financial reasons were commonly mentioned reasons why fathers are not participating in child feeding. Therefore, our finding added new insight to the current literature by developing a model to approach fathers in different modalities in relation to designing and planning of child care and feeding interventions. In order to engage fathers in child feeding, their perceptions, practices and challenges, should be known and the way fathers are approached should be customized to the ways fathers think and act. Additionally, bringing the education programs to their house and involving both parents (fathers and mother) could be a more practical and effective way to reach fathers.

\section{Implications for mothers}

We found that many fathers consider child care as being only the mothers' responsibility, which places a lot of pressure on the mothers' shoulder. This attitude is 
embedded in strong cultural and traditional beliefs in Ethiopia. Traditionally, the fathers are considered to be the only decision makers in the house, and the fathers should not be challenged by the mothers. Our findings suggest that health education should be delivered house to house involving both parents, but achieving this might be a significant challenge in the light of these deep-rooted gender specific cultural beliefs. These gender specific beliefs should have constant attention in order to bring both the father and the mother to the same level of understanding of proper child care and child feeding. We expect however, that the fathers' involvement will improve if there are corresponding improvements in the Ethiopian economy, work opportunities for mothers and increased exposure to foreign cultures, for example, through the media.

\section{Implications on child health care services}

Our findings suggest that involving the fathers in child health education is a worthwhile approach, but the attitude of health workers themselves seems a huge challenge. Especially, the health care professionals' low awareness, recognition and appreciation of the positive influence of fathers on child health outcomes are important obstacles. Therefore, health workers should be closely involved in developing new strategies to improve fathers' participation in health education programs. Additional training packages should be developed for health workers in order to succeed in improving the fathers' role in child care services.

\section{Implications on literature}

Considering the small number of studies on the fathers' role in young child feeding in developing countries, our findings contributed in filling a still existing gap in the scientific literature. Therefore, we believe our studies will give valuable input for the community by providing insight on the fathers' role in child feeding, which can help researchers, programmers, policy makers and health workers in their efforts to design health education programs. 
Acknowledgement 


\section{Acknowledgement}

I want to thank many people who have been very helpful in the completion of this thesis. Heartfelt thanks goes to all the fathers, mothers and health workers who participated in my studies. Their open sharing about their experiences has enhanced our understanding of the fathers' role in child feeding and contributed to filling a gap that has existed in the literature. I am especially grateful for my thesis advisors, Prof. dr. Geert-Jan Dinant, Dr. Roman Blanco and Dr. Mark Spigt, who have been very helpful through the entire research process.

I am especially grateful for Professor Dinant. His conceptual guidance, comments and practical suggestions have been crucial. In addition, I have valued all the discussions I had with him; all the discussions were refreshing, encouraging and fruitful. I also would like to thank Dr. Roman for believing in me to start the PhD program and also for his advice, support and follow up in the completion of the thesis. My heartfelt thanks go to Dr. Mark for his support and encouragement. His guidance and suggestions at each stage have kept me on track and have helped to expand my thinking, and he also helped all the time in the actual writing of the thesis. Besides that, I have learned how to be a good mentor. Dr. Mark has not only been my advisor, but he has also been a good friend. My special thanks goes to Dr. Mark's family, especially to his wife Maud and their beautiful kids Stan and Mette. They were so kind to care for me and my baby Nola, and they made my stays in Maastricht very enjoyable.

I am also grateful for the guidance provided by other co-authors in my studies: Dr. Afework Mulugeta, Dr. Albine Moser, Dr. Rik Crutzen and Dr. Kasia Czabanowska. Their suggestions have been very helpful in refining my research in both the proposal, analysis and writing stages. I also want to express my sincere appreciation to the College of Health Sciences of Mekelle University for the support in helping me complete the PhD program. It would also not have been possible without the support and assistance provided by my colleagues from the department of Public Health of Mekelle University. I am especially thankful for the professional advice and support I received from Dr. Araya Abrha. My appreciation also goes to Mr. Ashenfi Shumiye, Mrs. Kidan Abrha, Mr. Fiseha Haile and Mrs. Balem Dimtsu for their contribution and patience in the data collection.

In addition, I am grateful for the support I got from the Tigray regional Health Bureau. I am especially thankful for Mr. Mehari Gebre, for his positive support and suggestions. I would also like to thank Mr. Kifle Girmay, from the Atsibi district health bureau, for his graceful support in the data collection process. I am also grateful for the support I received from Mr. Birhanu, from the Adigrat health bureau. I would like to thank my colleague, Gidding Luc from Maastricht University, for the technical support he gave me 
during the data analysis. I also want to acknowledge the language editor of the thesis, Stefanie Suzanne Portelli, and Tiny Wouters for the layout of my thesis.

I am also grateful to my parents, sisters, brothers and friends who have always supported me.

Finally, I am most grateful to my wonderful Husband, Nephtalem, and our child, Nola. Their love and support have made the difference. In particular, Nephtalem's understanding and support have helped me through the program. Being a parent to my child is a treasured and meaningful responsibility that I cherish. Most of all, I give many thanks to the Almighty God for his blessing and being always there for me in times of joy and sadness, from the beginning to the end. 
Biography 


\section{Biography}

Selamawit Mengesha Bilal was born in 1985 in Southern Ethiopia in Sidama district. She

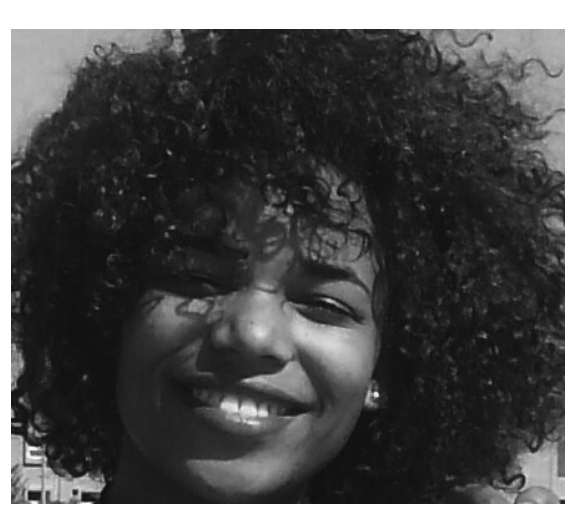
grow up in a middle class Ethiopian family with two brothers and two sisters. She went to school at early age and started her University college degree in 2004. She did her bachelor degree in Public Health from 2004/2005-2006/2007 at Hawassa University, Ethiopia.

Immediately after she finished her college degree, she started working at the university of Mekelle as an assistant lecturer since 2008. While she was working as an assitant lecturer at Mekelle university, she started a two years masters program in General Public Health at Gondar University, Ethiopia, and graduated in masters in General public health in 2010. Besides her teaching activities, she participated in different research projects.

Immediatelly after she finished her masters, she joined a joint PhD program between Alcala University, Spain and Maastricht University, the Netherlands in 2011. Her research area was the fathers' role in child nutrition. Selamawit's journey to higher education was not only a journey for success, it was also a journey for her to find out what she wants.

She also enjoys her free time by reading, listening to songs, watching movies and doing workouts. Besides her profession, being a wife and mom is what she cherishes most. 
